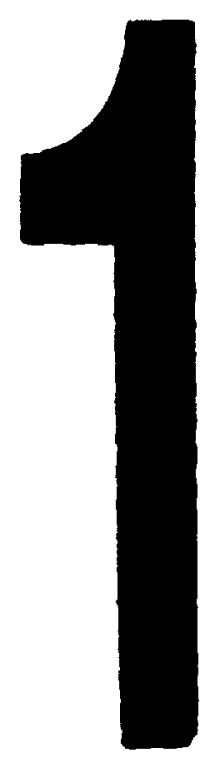

PM-1 3K" "X4" PHOTOGR. OHIC MICAOCOPY TARGET MES 1010a ANSI/ISO "2 EQUIVALENT

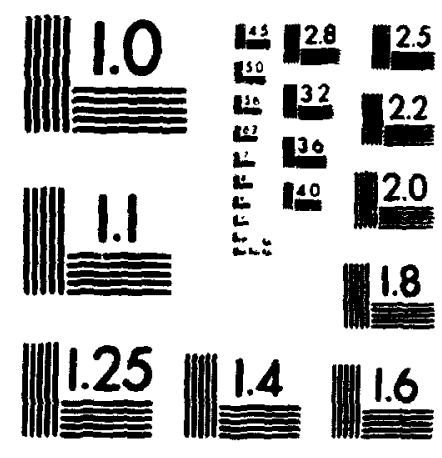




\title{
INITIAL INVESTIGATION ON THE POTENTIAL USE OF GAS CHROMATOMETER TO IDENTIFY PETROLEUM CONTAMı.VATED SOILS
}

\author{
by \\ Vanaja Sribalaskandarajah \\ B.Sc.(Hons), Civil Engineering, University of Peradeniya, Srilanka
}

\author{
A thesis submitted to the \\ Faculty of Graduate Studies and Research \\ in partial fulfilment of the requirements \\ for the degree of \\ Master of Engineering
}

Department of Civil and Environmental Engineering Carieton University

Ottawa, Ontario, Canada

May, 1996

\footnotetext{
"The Master of Engineering Program in Civil and Environmental Engineering is a joint program between Carleton University and the University of Ottawa. which is administered by the Ottawa-Carleton Institute for Civil Engineering
} 
National Library

of Canada

Acquisitions and

Bibliographic Services Branch

395 wetington Sired

Ottawa Oriario

K1A ONA
Bibliotheque nationale

du Canada

Direction des acquisitions ef

des services bibliographiques

395. ne Weington

Oilawa (Ontarió)

KIAONA

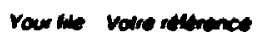

Our the Notre ruturences

The author has granted an irrevocable non-exclusive licence allowing the National Library of Canada to reproduce, loan, distribute or sell copies of his/her thesis by any means and in any form or format, making this thesis available to interested persons.
L'auteur a accordé une licence irrévocable et non exclusive permettant à la Bibliotheqque nationale du Canada de reproduire, prêter, distribuer ou vendre des copies de sa thèse de quelque manière et sous quelque forme que ce soit pour mettre des exemplaires de cette thèse à la disposition des personnes intéressées.

L'auteur conserve la propriété du droit d'auteur qui protège sa thèse. Ni la thèse ni des extraits substantiels de celle-ci ne doivent être imprimés ou autrement reproduits sans son autorisation.

ISBN $\quad 0-612-13852-6$ 
NanaTa - SRIBALASHANDARAJAH.

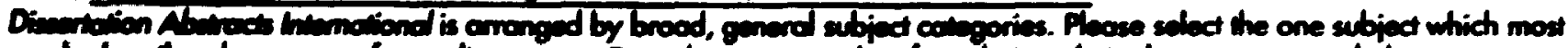

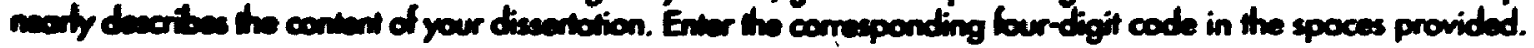

\section{Sulind Cenconim}

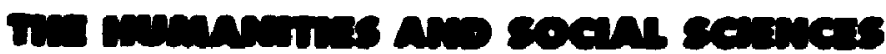

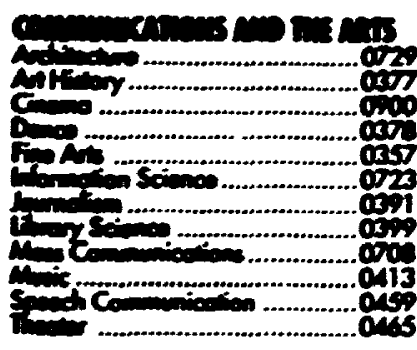

\section{Solving}

(1................................0515

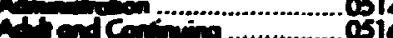

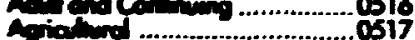

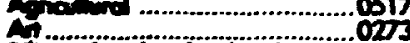

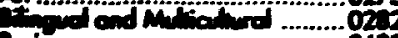

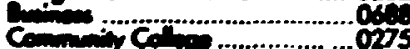
Copiadu and hecion .........072

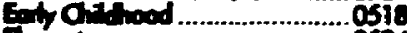
Evandiny ................................052

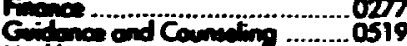
Hith ..................................6\% per.................................0745 020 1.

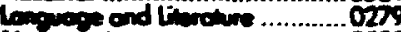

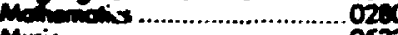
Mric..............................0522

Ansioc ........................................0523

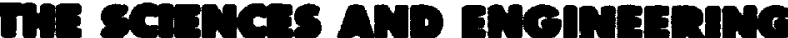

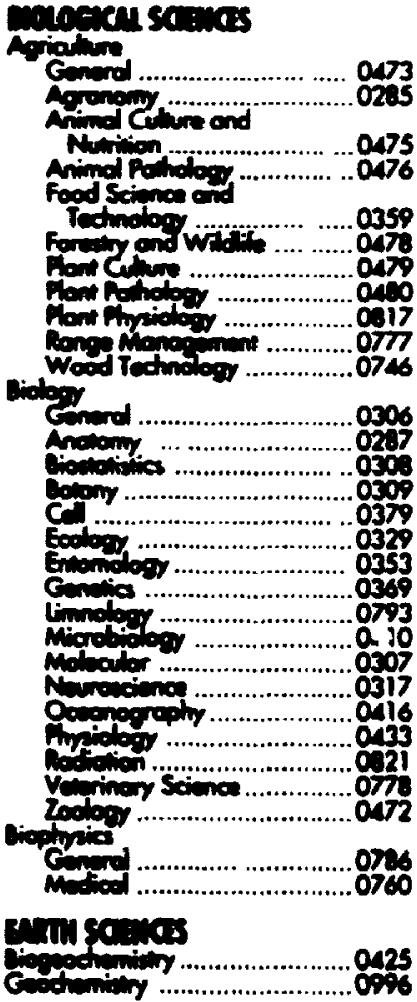

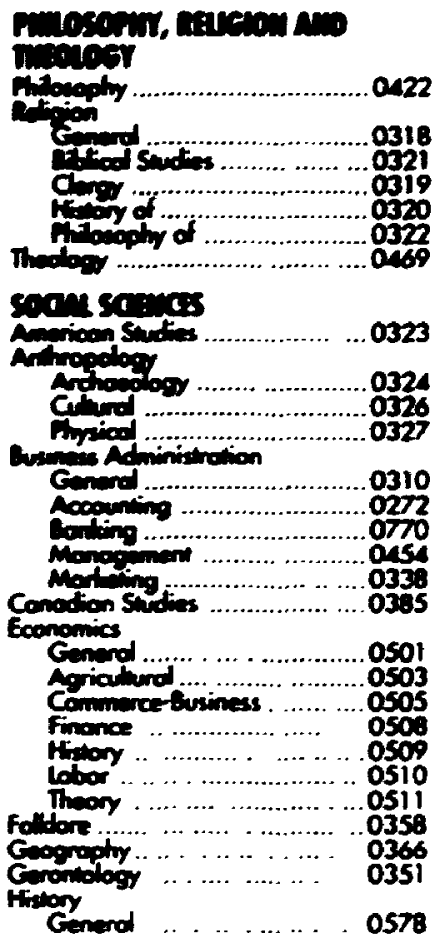

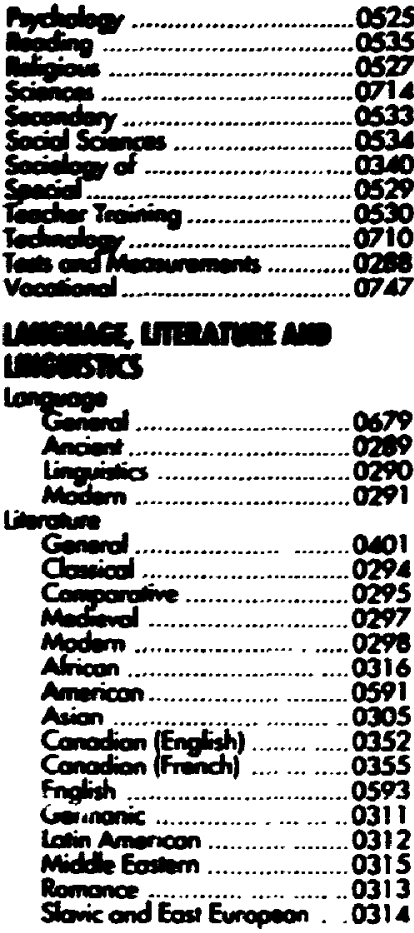

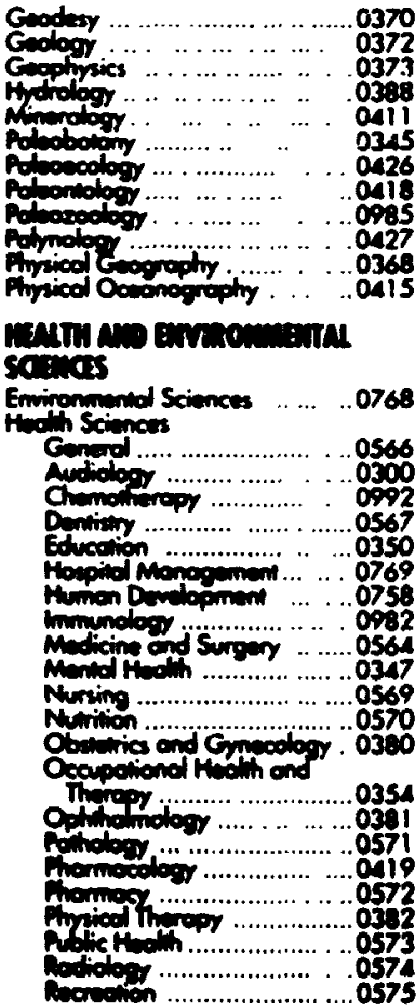

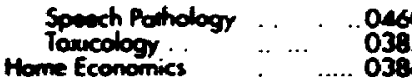

\section{Priserel satass}

Aure Sciences

Chemingy

Gomprol

Apricuburol

Arodicol....

horgonic

Orenor.

Organc.......

Prreiced

Poymat

Mathemotios

Prypics

Acovisia

Actomony and

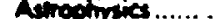

Amorphtaric Scionos......... 060

Abmix ........................ .074

Eecrenies ond Evaricity .... O60?

Hon Entor...

0799

.......0759

Moleculor ...........................0609

Nudver ............................0810

Opics ...........................0752

stid sta........................ Oofil

Stativios ....................................0463

Ansind Sabmes

Apind Muchorica

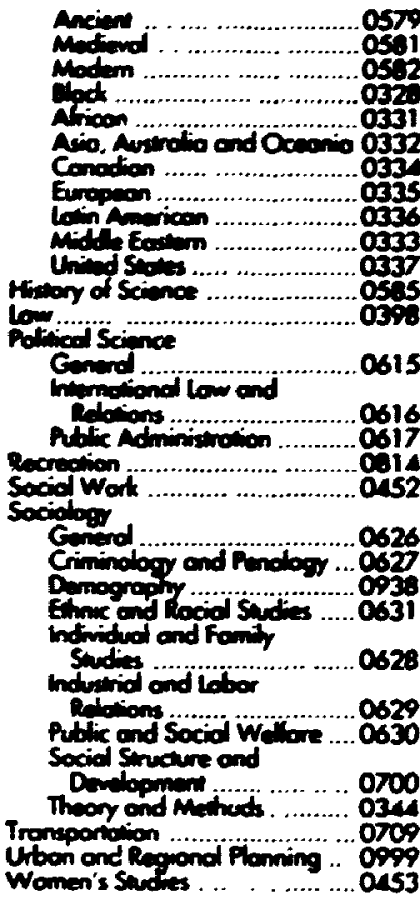

Elemprosy Fonides ond

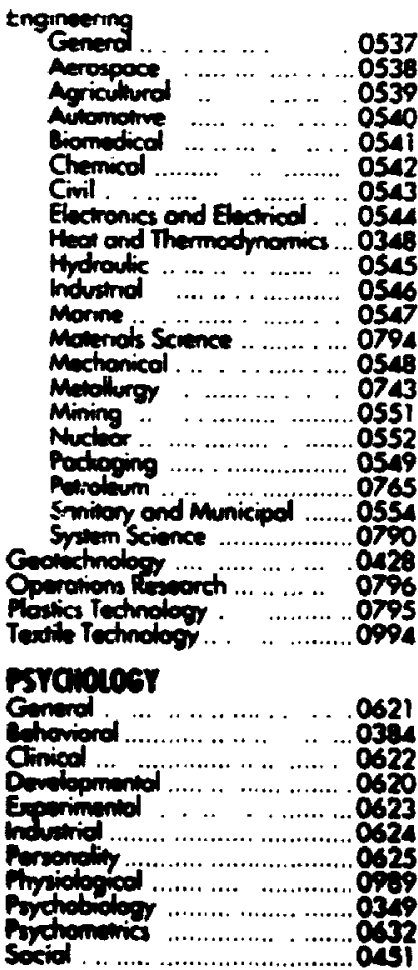

Enginering 
The undersigned hereby recommend to the Faculty of Graduate Studies and Research acceptance of the thesis entitled

\title{
INITIAL INVESTIGATION ON THE POTENTIAL USE OF GAS CHROMATOMETER TO IDENTIFY PETROLEUM CONTAMINATED SOILS
}

submitted by Vanaja Sribalaskandarajah

in partial fulfilment of the requirements for the Degree of Master of Engineering

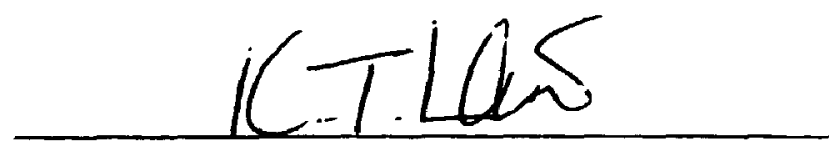

Professor K.T. Law, Thesis Supervisor

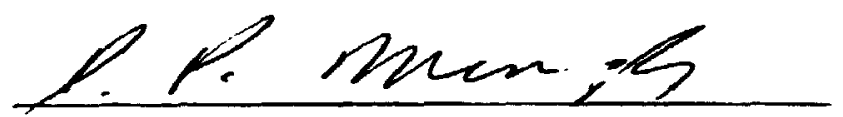

Mr. D.P. Menagh, Thesis Co-Supervisor

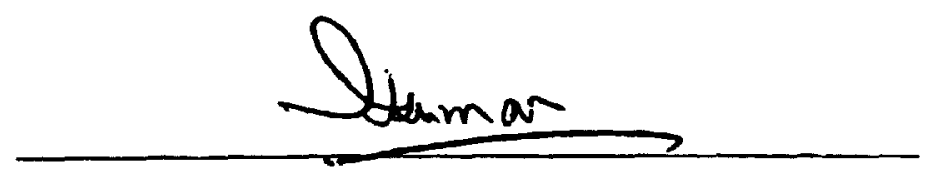

Professor J.L. Humar, Chair

Department of Civil and Environmental Engineering

\author{
Carleton University \\ May, 1996
}




\begin{abstract}
To interpret the chromatograms of the soil vapour samples extracted from the gasoline contaminated sites, lahoratory-made soil vapour samples were analyzed by gas chromatography. In preparing the soil samples in the laboratory known amounts of gasoline were added to known amount of soils in closed glass-vials. The chromatograms of the laboratory prepared samples were obtained by injecting a part of the vapour in the headspace of the samples onto the GC column. The correlation between the GC response and the type and amount of petroleum product present in the laboratory-made samples was found by relating the characteristics of the overall pattern of the chromatogram to the known amounts added.
\end{abstract}

To test the effec! of loss of volatile substances on the qualitative and the quantitative results. the same samples were tested after certain amount of vapour being removed from the sampling vials prior to analysis.

It was concluded qualitative identification is possible by soil vapour analysis for the experimental soil and the quantitative relation is affected ty loss of volatile substances. 


\section{ACKNOWLEDGEMENT}

I would like to thank my supervisor Prof. K.T. Law for the advice, guidance and the suggestions throughout the course of this studies, as well as in preparing this thesis. I would also like to thank my co-supervisor Mr. D.P. Menagh of the physics department for helping me with starting the laboratory work, the suggestions provided during this studies and for the constructive comments of my work. Thanks are also to Prof. E. Lai of the chemistry department for the glidance provided during the initial stage of this studies.

I wish to extend my thanks to $M$. Lam for writing the data acquisition software for the data collection system for the laboratory work.

My thanks are extended to my husband, parents and family for the encouragement they supported me throughout my studies. 


\section{TABLE OF CONTENTS}

ABSTRACT $\ldots \ldots \ldots \ldots \ldots \ldots \ldots \ldots \ldots \ldots \ldots \ldots \ldots$ iii

ACKNOWLEDGMENTS $\ldots \ldots \ldots \ldots \ldots \ldots \ldots \ldots \ldots$ iv

TABLE OF CONTENTS $\ldots \ldots \ldots \ldots \ldots \ldots \ldots \ldots \ldots$

LIST OF TABLES $\ldots \ldots \ldots \ldots \ldots \ldots \ldots \ldots \ldots \ldots \ldots \ldots \ldots \ldots \ldots \ldots$

LIST OF FIGURES $\ldots \ldots \ldots \ldots \ldots \ldots \ldots \ldots \ldots \ldots \ldots \ldots \ldots \ldots \ldots \ldots$

LIST OF GRAPHS $\ldots \ldots \ldots \ldots \ldots \ldots \ldots \ldots \ldots \ldots \ldots \ldots \ldots \ldots \ldots \ldots$

LIST OF APPENDIX $\ldots \ldots \ldots \ldots \ldots \ldots \ldots \ldots \ldots \ldots \ldots \ldots$ xviii

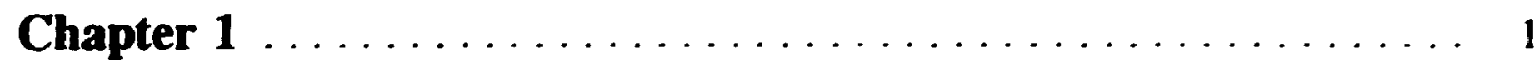

Introduction $\ldots \ldots \ldots \ldots \ldots \ldots \ldots \ldots \ldots \ldots \ldots \ldots \ldots \ldots \ldots$

1.0 Overview $\ldots \ldots \ldots \ldots \ldots \ldots \ldots \ldots \ldots \ldots \ldots \ldots \ldots \ldots \ldots$

1.1 Scope of The Work $\ldots \ldots \ldots \ldots \ldots \ldots \ldots \ldots \ldots \ldots$

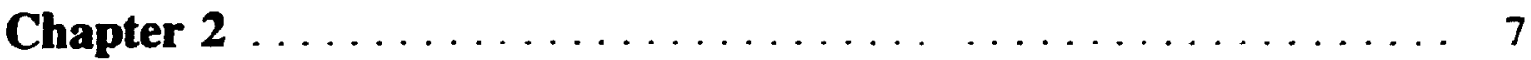

Literature Review $\ldots \ldots \ldots \ldots \ldots \ldots \ldots \ldots \ldots \ldots$

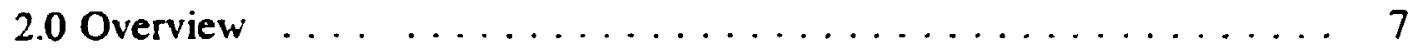

2.1 Sampling $\ldots \ldots \ldots \ldots \ldots \ldots \ldots \ldots \ldots \ldots \ldots \ldots \ldots \ldots \ldots \ldots \ldots \ldots$

2.1.1 Soil Vapour Analysis $\ldots \ldots \ldots \ldots \ldots \ldots \ldots \ldots \ldots \ldots 8$

2.1.2 Soil Sample Analysis . . . . . . . . . . . . 10

2.2 Field Methods $\ldots \ldots \ldots \ldots \ldots \ldots \ldots \ldots \ldots \ldots \ldots \ldots$

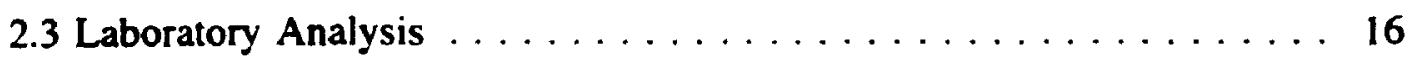

2.4 Sample Preparation $\ldots \ldots \ldots \ldots \ldots \ldots \ldots \ldots \ldots \ldots$ 
2.4.1 Static Headspace Analysis $\ldots \ldots \ldots \ldots \ldots \ldots \ldots \ldots 20$

2.4.2 Dynamic Headspace Analysis $\ldots \ldots \ldots \ldots \ldots \ldots \ldots 21$

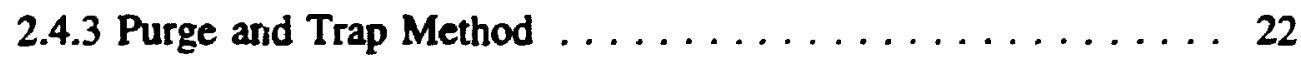

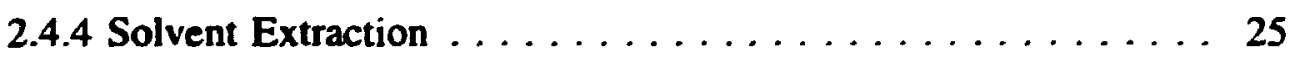

2.4.5 Soxhelet Extraction $\ldots \ldots \ldots \ldots \ldots \ldots \ldots \ldots$

2.4.6 Sonication $\ldots \ldots \ldots \ldots \ldots \ldots \ldots \ldots \ldots \ldots \ldots \ldots \ldots \ldots \ldots \ldots$

2.4.7 Supercritical Fluid Extraction $\ldots \ldots \ldots \ldots \ldots \ldots \ldots$

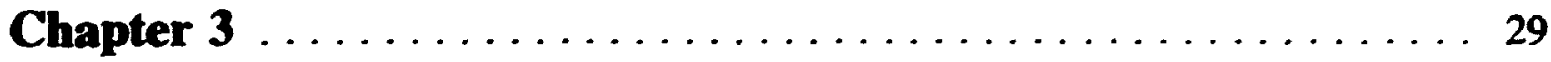

Chromatographical Techniques . . . . . . . . . . . 29

3.0 Overview $\ldots \ldots \ldots \ldots \ldots \ldots \ldots \ldots \ldots \ldots \ldots \ldots \ldots .29$

3.1 Instrumentation $\ldots \ldots \ldots \ldots \ldots \ldots \ldots \ldots \ldots \ldots \ldots \ldots \ldots \ldots$

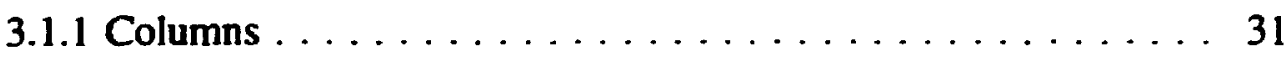

3.1.2 Detectors $\ldots \ldots \ldots \ldots \ldots \ldots \ldots \ldots \ldots \ldots \ldots \ldots \ldots$

3.1.2.1 Flame Ionizatıon Detector . . . . . . . . . . 34

3.1.2.2 Photoionization Detector . . . . . . . . . . 35

3.1.2.3 Electron Capture Detector . . . . . . . . . 36

3.1.2.4 Mass Spectrometer . . . . . . . . . . . . 37

3.2 Theory of Chromatography $\ldots \ldots \ldots \ldots \ldots \ldots \ldots \ldots \ldots \ldots$

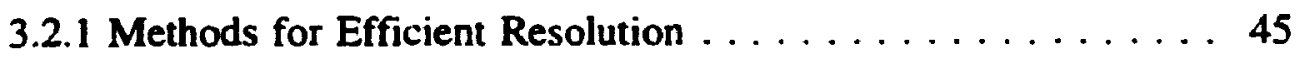

3.2.1.1 Temperature Programming . . . . . . . . . 46

3.2.1.2 Flow Programming $\ldots \ldots \ldots \ldots \ldots \ldots \ldots 47$ 
3.3.1 Qualitative Analysis $\ldots \ldots \ldots \ldots \ldots \ldots \ldots \ldots \ldots \ldots 48$

3.3.1.1 Retention Time . . . . . . . . . . . . . . 49

3.3.1.2 Uncertainties Involved in Qualitative Analysis ... . 51

3.3.1.3 Methods to Improve Uncertainties . . . . . . . . 54

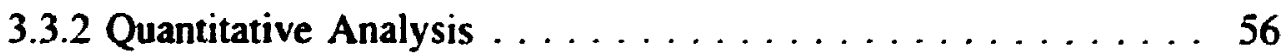

3.3.3 Standardization . . . . . . . . . . . . . . 59

3.3.3.1 Internal Normalization . . . . . . . . . . . 60

3.3.3.2 External Standardization . . . . . . . . . . 62

3.3.3.3 Internal Standardization . . . . . . . . . . . . . 64

3.3.3.4 Standard Addition Method . . . . . . . . . . 65

3.3.3.5 Calibration Methods for Headspace Analysis . . . . 67

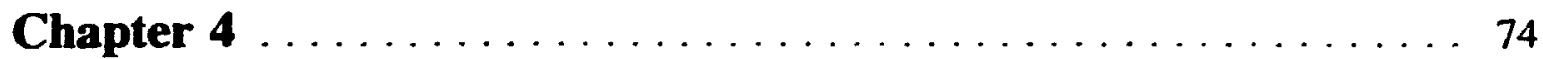

Spectrographical Techniques $\ldots \ldots \ldots \ldots \ldots \ldots \ldots \ldots \ldots \ldots$

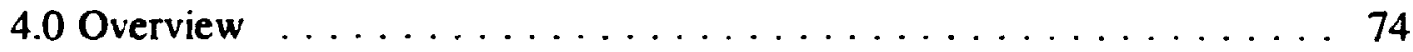

4.1 Theory of Spectrography $\ldots \ldots \ldots \ldots \ldots \ldots \ldots \ldots \ldots \ldots$

4.2 Types of Spectrometers Used in Hydrocarbon Analysis $\ldots \ldots \ldots 79$

Chapter $5 \ldots \ldots \ldots \ldots \ldots \ldots \ldots \ldots \ldots \ldots \ldots \ldots \ldots \ldots \ldots$

Degradation and Migration of Petroleum Products in Soil ... . 82

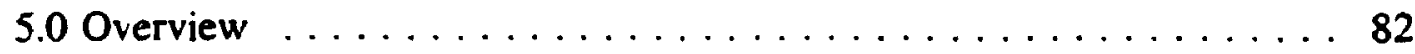


5.1 Migration/Transport of Petroleum Products $\ldots \ldots \ldots \ldots \ldots \ldots 84$

5.2 Transformation of Petroleum Products in Soils $\ldots \ldots \ldots \ldots \ldots$

5.2.1 Biological Transformation $\ldots \ldots \ldots \ldots \ldots \ldots \ldots \ldots .86$

5.2.2 Chemical Transformation ................ 89

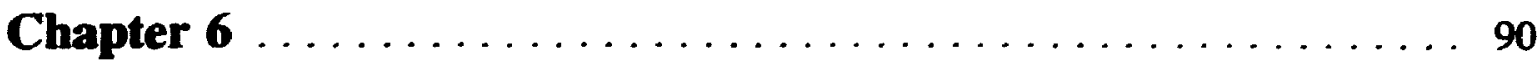

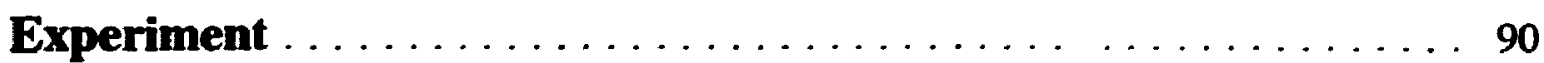

6.0 Overview $\ldots \ldots \ldots \ldots \ldots \ldots \ldots \ldots \ldots \ldots \ldots \ldots \ldots$

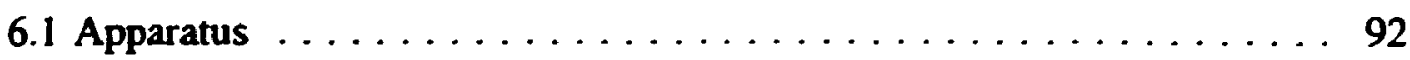

6.1.1 Gas Chromatometer . . . . . . . . . . . . . 92

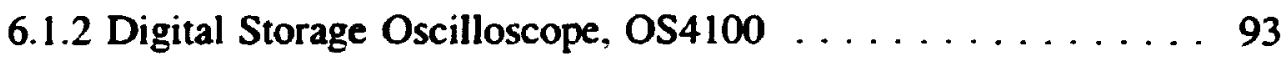

6.1.3 Computer with data acquisition software to collect 10 readings/s . . . . . . . . . . . . . . 93

6.1.4 Gas Supply $\ldots \ldots \ldots \ldots \ldots \ldots \ldots \ldots \ldots \ldots \ldots . \ldots 3$

6.1.5 Sampling Equipments $\ldots \ldots \ldots \ldots \ldots \ldots \ldots . \ldots 3$

6.1.6 Temperature Measuring Device . . . . . . . . . . . 94

6.1 .7 Samples . . . . . . . . . . . . . . . . . 94

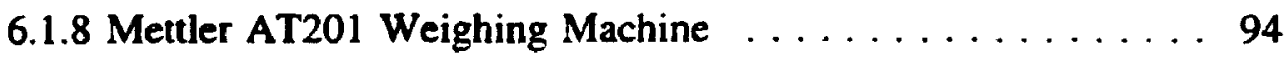

6.1 .9 Setup of Apparatus $\ldots \ldots \ldots \ldots \ldots \ldots \ldots \ldots \ldots$

6.2 Optimizing the Experimental Conditions $\ldots \ldots \ldots \ldots \ldots \ldots \ldots 9$

6.2.1 Optimizing Gas Flow rates $\ldots \ldots \ldots \ldots \ldots \ldots \ldots \ldots 98$ 
6.2.1.1 Procedure $\ldots \ldots \ldots \ldots \ldots \ldots \ldots \ldots \ldots \ldots 98$

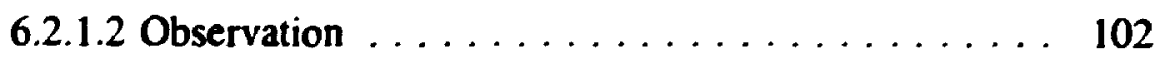

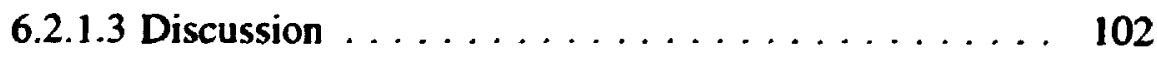

6.2.2 Optimizing Column Temperature . . . . . . . . . . 104

6.2.2.1 Procedure . . . . . . . . . . . . . 104

6.2.2.2 Observation $\ldots \ldots \ldots \ldots \ldots \ldots \ldots \ldots \ldots$

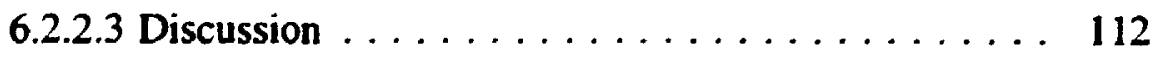

6.3 The validity of the Quantitative Relation for Lnresolved Peaks . . . 112

6.3.1 Procedure $\ldots \ldots \ldots \ldots \ldots \ldots \ldots \ldots \ldots \ldots \ldots \ldots 112$

6.3.2 Observation $\ldots \ldots \ldots \ldots \ldots \ldots \ldots \ldots \ldots \ldots \ldots$

6.3.3 Discussion $\ldots \ldots \ldots \ldots \ldots \ldots \ldots \ldots \ldots \ldots \ldots$

6.4 Soil Vapour Analysis of the Laboratory Prepared Petroleum

Contaminated Soil Samples $\ldots \ldots \ldots \ldots \ldots \ldots \ldots \ldots 115$

6.4.1 Sample Preparation $\ldots \ldots \ldots \ldots \ldots \ldots \ldots \ldots \ldots$

6.4.2 GC analysis of g zoline contaminated soil vapour sample $\ldots 118$

6.4.2.1 Experimental Conditions $\ldots \ldots \ldots \ldots \ldots \ldots 118$

6.4.2.2 Procedure $\ldots \ldots \ldots \ldots \ldots \ldots \ldots \ldots \ldots .118$

6.4.3 Observation $\ldots \ldots \ldots \ldots \ldots \ldots \ldots \ldots \ldots \ldots \ldots 120$

6.4.4 Data Interpretation for Qualitative Analysis $\ldots \ldots \ldots \ldots 132$

6.4.4.1 Pattern variation due to loss of volatile constituen . 133

6.4.4.2 Pattern Variation due to Sensitivity of the GC . . . 138 
6.4.4.3 Pattern Variation due to Adsorption of the Constituents on to the Soil Matrix ....... 140

6.4.5 Data interpretation for quantitative analysis $\ldots \ldots \ldots \ldots 142$

6.5 Practical difficulties encountered during the experiment $\ldots \ldots \ldots, 148$

6.5.1 Adsorption of the Constituents onto the Interior

Wall of the Syringes $\ldots \ldots \ldots \ldots \ldots \ldots \ldots \ldots \ldots$

6.5.2 Sensitivity $\ldots \ldots \ldots \ldots \ldots \ldots \ldots \ldots \ldots \ldots \ldots . \ldots 149$

6.5.3 Background Noise $\ldots \ldots \ldots \ldots \ldots \ldots \ldots \ldots \ldots$

6.6 Discussion $\ldots \ldots \ldots \ldots \ldots \ldots \ldots \ldots \ldots \ldots \ldots \ldots \ldots \ldots$

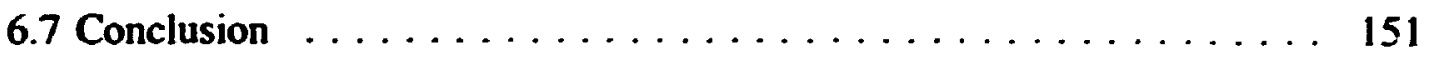

Chapter $7 \ldots \ldots \ldots \ldots \ldots \ldots \ldots \ldots \ldots \ldots \ldots \ldots \ldots \ldots \ldots$

Summary and Conclusions $\ldots \ldots \ldots \ldots \ldots \ldots \ldots \ldots \ldots$

7.0 Overview $\ldots \ldots \ldots \ldots \ldots \ldots \ldots \ldots \ldots \ldots \ldots \ldots \ldots \ldots \ldots$

7.1 Conclusions $\ldots \ldots \ldots \ldots \ldots \ldots \ldots \ldots \ldots \ldots \ldots \ldots \ldots \ldots \ldots \ldots \ldots \ldots$

7.1.1 Qualitative Identification $\ldots \ldots \ldots \ldots \ldots \ldots \ldots \ldots$

7.1.2 Quantitative Identification $\ldots \ldots \ldots \ldots \ldots \ldots \ldots 155$

7.2 Future experiments that may be conducted $\ldots \ldots \ldots \ldots \ldots \ldots$

References $\ldots \ldots \ldots \ldots \ldots \ldots \ldots \ldots \ldots \ldots \ldots \ldots \ldots \ldots$

Appendix $\ldots \ldots \ldots \ldots \ldots \ldots \ldots \ldots \ldots \ldots \ldots \ldots \ldots \ldots \ldots \ldots$ 


\section{LIST OF TABLES}

3.1 McReynolds Constants for Commonly Used Stationary Phases $\ldots \ldots \ldots 55$

3.2 Measurements of A Standards $\ldots \ldots \ldots \ldots \ldots \ldots \ldots \ldots \ldots \ldots$

6.0 Particle Size Distribution of the Experimental Soils $\ldots \ldots \ldots \ldots \ldots \ldots .94$

6.1 Flow Rates of $\mathbf{H}_{2}$ and $\mathbf{N}_{2}$ Tested $\ldots \ldots \ldots \ldots \ldots \ldots \ldots \ldots \ldots$

6.2 Conditions of the Gas Supply $\ldots \ldots \ldots \ldots \ldots \ldots \ldots \ldots \ldots \ldots$

6.3 Retention Time at Various Temperatures $\ldots \ldots \ldots \ldots \ldots \ldots \ldots \ldots \ldots 110$

6.4 Peak Heights at Various Temperatures $\ldots \ldots \ldots \ldots \ldots \ldots \ldots \ldots \ldots 110$

6.5 Retention Times at Various Sample Sizes $\ldots \ldots \ldots \ldots \ldots \ldots \ldots \ldots$

6.6 Peak Heights at Various Sample Sizes $\ldots \ldots \ldots \ldots \ldots \ldots \ldots \ldots 113$

6.7 The concentration of the samples prepared $\ldots \ldots \ldots \ldots \ldots \ldots \ldots \ldots$

6.8 Conditions of the Gas Supply $\ldots \ldots \ldots \ldots \ldots \ldots \ldots \ldots \ldots \ldots$

6.9 Parameters Measured for Qualitative and Quantitative Identification . . . . 130

6.10 Parameters Measured for Qualitative and Quantitative Identification . . . . 131

6.11 Multiplying Value for Different Sensitivities of the GC $\ldots \ldots \ldots \ldots 150$ 


\section{LIST OF FIGURES}

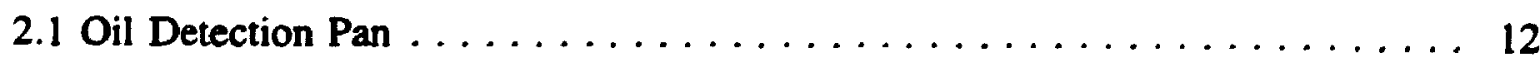

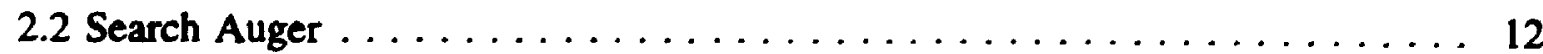

2.3 Soil Vapour Probe and Sampling Train $\ldots \ldots \ldots \ldots \ldots \ldots$

2.4 Purge-and-Trap System, Purge-Sorb Mode $\ldots \ldots \ldots \ldots \ldots$

2.5 Purge-and-Trap System, Purge-Desorb Mode . . . . . . . . . . . . . . . 24

3.1 Diagrammatic representation of an elution chromatographic separation of components $A$ and $B$ of a mixture $\ldots \ldots \ldots \ldots \ldots \ldots \ldots \ldots \ldots$

3.2 A Diagrammatic Representation of Partition of Solutes between Stationary Mobile thase $\ldots \ldots \ldots \ldots \ldots \ldots \ldots \ldots \ldots \ldots \ldots$

3.3 Distribution and separation of two substances $A$ and $B$ along chromatographical column $\ldots \ldots \ldots \ldots \ldots \ldots \ldots \ldots \ldots$

3.4 Chromatogram Illustrating Retention Nomenclature $\ldots \ldots \ldots \ldots$

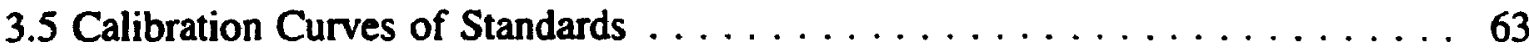

3.6 Discontinuous gas extraction apparatus $\ldots \ldots \ldots \ldots \ldots \ldots$

3.7 Calibration Curve For Discontinuous Extraction $\ldots \ldots \ldots \ldots \ldots$

4.1 A Typical Single-beam Infrared Spectrometer with Prism Monochromator . . 76 xii 
5.1 Gas chromatogram of the Extract Obtained from a Gas Oil Contaminated Soil $\ldots \ldots \ldots \ldots \ldots \ldots \ldots \ldots \ldots \ldots \ldots \ldots$

6.0 Setup of the Laboratory Equipment $\ldots \ldots \ldots \ldots \ldots \ldots \ldots \ldots$

6.1 "Sampling Vial A" for Pure Gasoline Vapour Samples . . . . . . . . 101

6.2 "Sampling Vial B" for Gasoline Contaminated Soil Samples $\ldots \ldots \ldots \ldots 117$

6.3 The Variation of $\log (\mathrm{GC}$ response) vs Number of withdrawals . . . . . . 147 


\section{LIST OF GRAPHS}

6.1 The gradation Curve of the Tested Soil $\ldots \ldots \ldots \ldots \ldots \ldots \ldots \ldots$

6.2 Chromatogram of Gasoline, Column temperature $20^{\circ} \mathrm{C} \ldots \ldots \ldots \ldots 6$

6.3 Chromatogram of Gasoline, Column Temperature $25^{\circ} \mathrm{C} \ldots \ldots \ldots \ldots$

6.4 Chromatogram of Gasoline, Column Temperature $30^{\circ} \mathrm{C} \ldots \ldots \ldots \ldots$

6.5 Chromatogram of Gasoline, Column Temperature $40^{\circ} \mathrm{C} \ldots \ldots \ldots \ldots 7$

6.6 Chromatogram of Gasoline, Column Temperature $60^{\circ} \mathrm{C} \ldots \ldots \ldots \ldots$

6.7 Chromatogram of Gasoline, Column Temperature $70^{\circ} \mathrm{C} \ldots \ldots \ldots 108$

6.8 Chromatogram of Gasoline, Column Temperature $80^{\circ} \mathrm{C} \ldots \ldots \ldots . .109$

6.9 Temperature vs Retention Time $\ldots \ldots \ldots \ldots \ldots \ldots \ldots \ldots \ldots \ldots 111$

6.10 Temperature vs Peak Height $\ldots \ldots \ldots \ldots \ldots \ldots \ldots \ldots \ldots \ldots, 111$

6.11 Peak Height vs Amount of Sample $\ldots \ldots \ldots \ldots \ldots \ldots \ldots \ldots \ldots 114$

6.12 Chromatogram of $L$ ickground Soil Vapour $\ldots \ldots \ldots \ldots \ldots \ldots \ldots \ldots 120$

6.13 Chromatogram of Pure Gasoline Vapour $\ldots \ldots \ldots \ldots \ldots \ldots \ldots \ldots 120$ 
Graphs 6.14 to 6.22 (a) and (b) show the chromatograms of polluted soil vapour at various concentrations

6.14 (a) Concentration $700 \mathrm{ppm}$, first withdrawal $\ldots \ldots \ldots \ldots \ldots \ldots$

6.14 (b) Concentration $700 \mathrm{ppm}$, second withdrawal $\ldots \ldots \ldots \ldots \ldots \ldots 121$

6.15 (a) Concentration $1500 \mathrm{ppm}$, first withdrawal $\ldots \ldots \ldots \ldots \ldots \ldots \ldots 122$

6.15 (b) Concentration $1500 \mathrm{ppm}$, second withdrawal $\ldots \ldots \ldots \ldots \ldots \ldots 122$

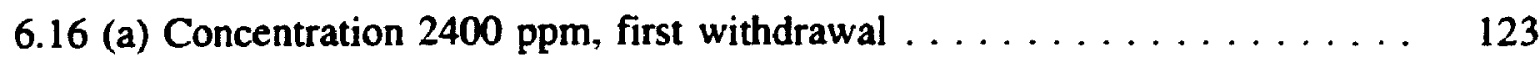

6.16 (b) Concentration $2400 \mathrm{ppm}$, second withdrawal $\ldots \ldots \ldots \ldots \ldots \ldots 123$

6.17 (a) Concentration $3100 \mathrm{ppm}$, first withdrawal $\ldots \ldots \ldots \ldots \ldots \ldots \ldots 124$

6.17 (b) Concentration $3100 \mathrm{ppm}$, second withdrawal $\ldots \ldots \ldots \ldots \ldots \ldots 124$

6.18 (a) Concentration $4400 \mathrm{ppm}$, first withdrawal $\ldots \ldots \ldots \ldots \ldots \ldots \ldots$

6.18 (b) Concentration $4400 \mathrm{ppm}$, second withdrawal $\ldots \ldots \ldots \ldots \ldots \ldots 125$

6.19 (a) Concentration $5400 \mathrm{ppm}$, first withdrawal $\ldots \ldots \ldots \ldots \ldots \ldots \ldots$

6.19 (b) Concentration 5400 ppm, second withdrawal $\ldots \ldots \ldots \ldots \ldots$

6.20 (a) Concentration $5650 \mathrm{ppm}$, first withdrawal $\ldots \ldots \ldots \ldots \ldots \ldots \ldots 127$

6.20 (b) Concentration $5650 \mathrm{ppm}$, second withdrawal $\ldots \ldots \ldots \ldots \ldots$ 
6.21 (a) Concentration $6600 \mathrm{ppm}$, first withdrawal

6.21 (b) Concentration $6600 \mathrm{ppm}$, second withdrawa

6.22 (a) Concentration $7600 \mathrm{ppm}$, first withdrawal $\ldots \ldots \ldots \ldots \ldots \ldots$

6.22 (b) Concentration $7600 \mathrm{ppm}$, second withdrawal

Chromatograms of pure gasoline vapour after various amounts of volatile substances are lost

6.23 (a) Sample Size $0.25 \mathrm{ml}$, Sensitivity $1 \mathrm{E}-10 \ldots \ldots \ldots \ldots \ldots$

6.23 (b) Sample Size $0.05 \mathrm{ml}$, Sensitivity $1 \mathrm{E}-11 \ldots \ldots \ldots \ldots \ldots \ldots$

6.23 (c) Sample Size $0.25 \mathrm{ml}$, Sensitivity $1 \mathrm{E}-11 \ldots \ldots \ldots \ldots \ldots \ldots$

Chromatograms of polluted soil vapour after various amounts of volatile substances are lost

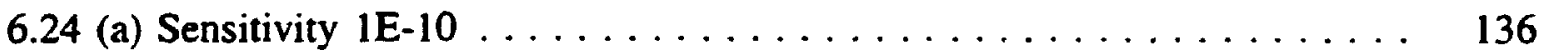

6.24 (b) Sensitivity $1 E-11 \ldots \ldots \ldots \ldots \ldots \ldots \ldots \ldots \ldots \ldots \ldots \ldots$

6.24 (c) Sensitivity $1 \mathrm{E}-12 \ldots \ldots \ldots \ldots \ldots \ldots \ldots \ldots \ldots \ldots \ldots \ldots \ldots$

Chromatogram Showing Saturated Peaks

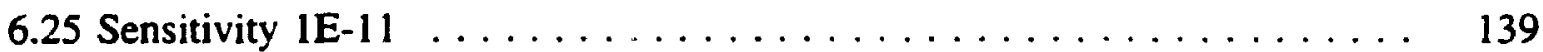

Chromatograms Showing the Adsorption onto the Soil Matrix

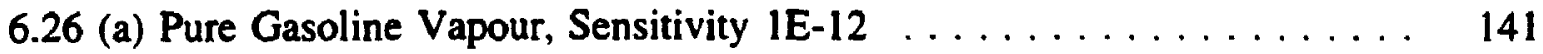




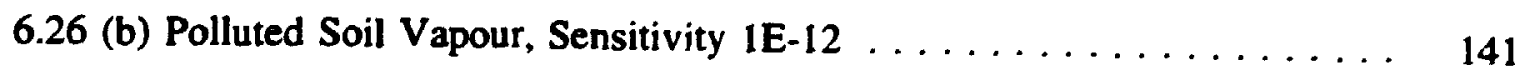

6.27 The Peak Height vs Concentration(ppm) $\ldots \ldots \ldots \ldots \ldots \ldots$

6.28 The Peak Height vs Concentration $(\mathrm{ppm}) \ldots \ldots \ldots \ldots \ldots$ 


\section{LIST OF APPENDIX}

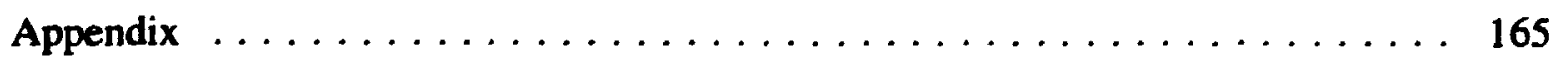




\section{Chapter 1}

\section{Introduction}

\subsection{Overview}

In the past several years, considerable attention has been given to the detection and cleanup of contaminated soil as people realize the effects of poor hazardous waste and substances handling practices. Several events have been reported where hazardous substances such as oil migrated to private properties and drinking water wells. Contamination of soil occurs from various sources, one of which is petroleum products leaked from underground storage tanks. The most widely used substances responsible for environmental contamination are refined petroleum products (Mapes et al.. 1993). A study conducted by the US Environmental Protection Agency's Underground Storage Tank Program showed approximately $29 \%$ of underground storage tanks may leak (Mapes et al., 1993). The extent of pollution will be greater if structural failure of a tank occurs. Other process that cause contamination of soil with oil includes improper disposal of oil.

Pollution of soil with oil can cause numerous adverse effects including social. economic. health and environmental problems. Social problems inclide the disruption caused when people need to be evacuated from their homes either because of a spill or because of a spill needs to be remediated. Remediation of contaminated soil is expensive. Volatile 
substances from spill may escape from subsurface environments to the atmosphere. Human health can be affected by inhalation of air polluted with petroleum products. Various levels of toxicity in human body can cause minor illness to cancer or death. The other major problem associated with leaked oil from underground storage systems is contamination of groundwater. Such problems necessitate clean up programs and consequently detection of contaminated soil becomes essential as being the first step in decision making.

The soils containing refined petroleum products are not classified as hazardous substances by the regulatory agencies. However technical standards for the operation of the underground storage tank systems include a requirement to detect and clean up the soils contaminated with petroleum products as a result of leaking underground storage tanks. The concentration levels to which gasoline, diesel fuel, benzene, and toluene are to be reduced are 10,100, 0.3, and $1 \mathrm{ppm}$ respectively (SWRCB, 1989). Contamination, frequently arises from gas stations close to commercial and residential areas.

The most abundant petroleum product available is gasoline. Gasoline consists of any combination of $C_{2}$ through $C_{13}$ petroleum hydrocarbons in addition to various additives. Motor gasoline contains upto 400 individual compounds in measurable amounts (arbitrarily $>100 \mathrm{ppm}$ ). The most environmentally significant components of gasoline are 
the monoaromatic compounds benzene, toluene, ethylbenzene, and xylene. The mobility of these four components of gasoline decrease in the order of Benzene > Toluene > Ethylbenzene $>$ Xylene (Reisinger et al., 1990). Due to the volatility, toxicity, and relatively high water solubility, Benzene is normally targeted as individual gasoline constituent of greatest concern (Fitzgerald, 1990).

Detection of contaminants in soil is essential in order to ensure the concentration levels are within the acceptable limits. A single method cannot be used for all kinds of contaminants and the choice of method mainly depends on the types of contaminants and soil. Several field and laboratory methods have been developed. In all methots, analysis is carried out to test the presence of the targeted compounds. However. interpretation of test results has been complicated by the complex nature of the soil-contaminant matrix. Prior knowledge of possible contaminants and preliminary investigations are essential to avoid misinterpretation of test results.

Subsequent actions such as decision making and choice of remediation technology are based on field and laboratory test results and therefore reliability of test results should be considered. Some field and laboratory techniques exist in literature but there is a lack for a fast and reliable field device for detection and monitoring. 
There are two main problems commonly encountered in identifying petroleum spills in soil. One is separating the analytical response of the targeted compounds (hydrocarbon compounds in this studies) from other contaminants which also may be present in soil matrix. To overcome or reduce this problem, several procedures have been developed to extract the interested compounds or to remove the un-wanted compounds from the soilmatrix prior to analysis. This is called sample preparation and discussed in Chapter 2 . The second problems is that the contaminant composition and concentration vary with time due to physical, biological, and chemical processes. Petroleum products consist of a number of constituents, each of which is susceptible to physical, biological and chemical processes to a varying degree. This causes spilled petroleum product to change in composition. The concentration level of spill also reduces as a result of evaporation. biodegradation and migration of compounds or constituents in the subsurface environment. The degree of transformation of spilled products depends on the length of time during which contaminants reside in soil and in many cases it is not known.

Various field and laboratory tests have been carried out on soil-vapour and soil samples in literature to test hydrorarbon contaminants. Field methods include portable gas chromatography, portable infrared analysis, and geophysical methods. The laboratory methods include chromatographical and spectrographical methods. Although these methods are already in practice, these methods are not yet considered to be reliable but 
considered to be the best possible methods.

The currently practiced methods are reliable when used to identify pure substances. The problem arises when these methods are used to identify substances with impurities. Presence of impurities will vary the results over a wide range and this causes lot of uncertainties in these methods when applied to identify petroleum products in soil. Moreover since the soil-pollutant matrix subject to natural processes this causes additional uncertainties. These problems in these methods could be fixed if the problem is thoroughly understood. This project is aimed at providing the necessar. information which will help understanding the problem thoroughly and to be a supporive document for the development of a fast and reliable method and an apparatus to identify petroleum contaminated soils.

Chapter 2 discusses the currently practiced methods. The theoretical aspects of chromatographical and spectrographical methods are discussed in Chapters 3 and 4 respectively. Transformation of spilled petroleum products is discussed in Chapter 5. Chapter 6 discusses the experiment carried out to test the possibility of the qualitative and quantitative identification of petroleum products in soil by using gas chromatometer. Chapter 7 discusses the summery and conclusions of this project. 


\subsection{Scope of The Work}

-To provide a review of the methods that have been practiced to identify the petroleum contaminated soils

-To provide a review on the theoretical techniques involved in the methods that have been practiced for the identitification of the petroleum contaminated soils

-To review the natural process that may influence the qualitative and the quantitative identification of the petroleum contamination in soil

-To investigate the potential use of a gas chromatometer to identify petroleum contaminated soils qualitatively and quantitatively 


\section{Chapter 2}

\section{Literature Review}

\subsection{Overview}

Precise qualitative and quantitative information on hydrocarbon contaminants in soils is essential to decide on the need for clean-up programs. Hydrocarbon contaminated soils have been investigated by a range of techniques from very simple field methods to highly sophisticated laboratory methods. Most of the field methods are employed in preliminary investigation and their results are used in screening the areas which need further laboratory investigation. Both laboratory and field tests involve sampling and subsequent analysis of contaminants qualitatively and quantitatively. Qualitative analysis is carried out to see the presence of contaminants under consideration. Quantitative analysis is carried out to test the concentration levels of contaminants identified.

Section 2.1 provides an overview of sampling and Sections 2.2 and 2.3 discuss field and laboratory tests respectively.

\subsection{Sampling}

The reliability of the test results is highly dependent on sampling methods and therefore, proper sampling is essential for both the field and the laboratory analysis. Taking 
representative samples in soil is always difficult. Errors due to this problem are mitigated by taking number of samples at a close spatial intervals in the ground.

Another major problem involved in sampling is that the preservation of the sample components, especially in the analysis of volatile organic substances. This problem is reduced by providing adequate protection to the sample and adopting suitable calibration methods which take possible losses into account. Presence of hydrocarbon contaminants in soil can be tested on soil-vapour or soil samples and are discussed individually in the following two Sections, 2.1.1 and 2.1.2.

\subsubsection{Soil Vapour Analysis}

This method is suitable to analyze volatile substances. According to Henry's law. organic contaminants present in the fuel oil will migrate to the soil vapour as a result of vapour pressure and concentration gradient (Nadeau et al., 1985). This facilitates the possibility of analyzing soil vapour for detecting hydrocarbon contaminants in soils. Soil vapour analysis is the most cost and time efficient method for determining presence of volatile organic substances (Rosemblem, 1988, Nadeau et al.. 1985). The cost of the soil vapour testing compared to the soil boring analysis for volatile organic substances in a site in Arizona was 1:7.5 (Rosemblem et al.. 1988).

Literature review 
In analyzing soil vapour to identify hydrocarbon contaminants, the interference from the volatile substances other than the targeted compounds that may also be present in the soil should be considered. The volatile orgaric compounds that may be present in soil include volatile aromatic compounds and phenols, aliphatic chlorinated hydrocarbons, aliphatic mixtures such as white sprit and petroleum distillates. In addition interference from slightly volatile organic compounds are also possible and such compounds include polycyclic aromatic hydrocarbons, organic chlorinated compounds (PCB's. pesticides. etc.), organic nitrogen and phosperous pesticides and mineral oils.

The disadvantage of soil vapour analysis is that less volatile substances such as diesel and aromatic hydrocarbons may not be identified by this method. Moreover this method does not work well with water saturated or clayey soils due to poor gas transportation (Selby. 1991).

Soil vapour samples are extracted by placing adsorbents in the excavation or withdrawal by specially designed apparatus such as a combination of soil gas probe and a hand pump. The commonly used adsorbents are activated charcoal and activated carbon. If the soil vapour is absorbed on the adsorbents, it is desorbed either thermally or by replacement with a solvent such as carbondisulphide (Kolb. 1976). The soil vapour samples withdrawn can be collected in a small $(150-200 \mathrm{cc})$ serum bottle. Light sensitive 
hydrocarbons can be stored in septum vials for several months without any serious degradation or loss of contaminants (Jones, 1987). Once samples are collected they are then analyzed in the laboratory by various methods depending on the purpose of the investigation and the accuracy needed.

\subsubsection{Soil Sample Analysis}

The soil samples are collected in small containers and subsequent analysis is carried out in the field or laboratory. One of the best containers for collecting soil samples is a glass canning jar fitted with a Teflon or aluminum foil liner placed between septum lid and the top of the jar. For organic analysis of the sample in the container, it is recommended that the container be rinsed in a spectrographic grade solvent and followed by being baked in a convention oven at $105^{\circ} \mathrm{C}$ (I.T. Corporation). If soil samples are collected in a large volume, further sub-sampling is required and during this action, loss of volatile substance will be considerable. As a result collection of small volume samples is recommended over large volume samples.

Loss of volatile contaminants is possible during sampling, transport and storage. In such situations, the sample may require quick freezing with dry ice. Moreover, if microorganisms are present in the sample, the biological activities may degrade the sample and this effect is reduced by keeping the samples in a dark and low temperature environment.

Literature review 
The amples can be protected against light by wrapping the container with a foil.

\subsection{Field Methods}

Most of the field methods are based on analysis of soil vapour samples. In Netherlands, apparatus such as oil detection pan, search auger, PH and EC-meters, and geophysical equipment have been successfully used to identify contaminated sites including former gas-work-sites and petrol stations (Slofstra, 1985). The oil detection pan and search auger were developed by Heidemij Advieshureau BV in the Netherlands.

The oil detection pan was designed to identify floating contaminants in soil and groundwater. The substances identified by this apparatus include oil-derivatives such as tar, lubricating oil and petrol. The apparatus comprises of two pans and a raised connection. This is shown in Figure 2.1. The soil under investigation was mixed with water and allowed to settle in one pan. Then the water above the soil was transferred to the other pan where observation was made. The type of contaminants were roughly estimated from the colouring caused by the differences in properties such as refractive index, fluorescence, and interface tension (Slofstra. 1985). The reliability of this method is highly dependent on the user's experience. This method was successfully applied to identify petroleum contamination in the Netherlands.

Literature review 


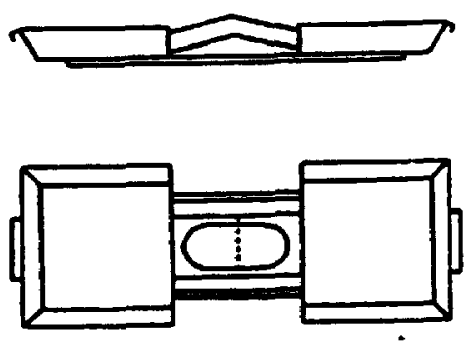

Figure $\mathbf{2 . 1}$

Oil Detection Pan, Developed by Heidemij Adviesbureau BV, Netherlands

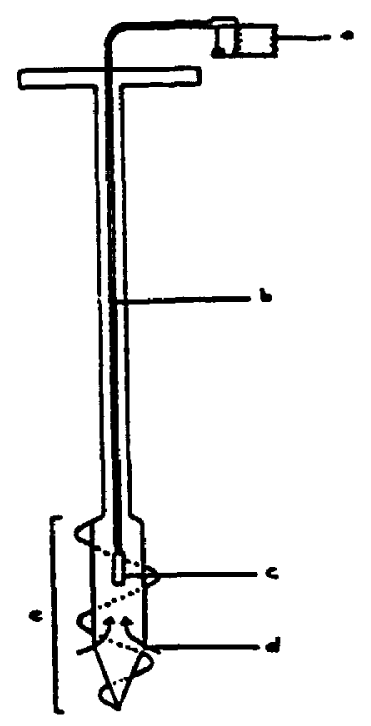

Figure 2.2

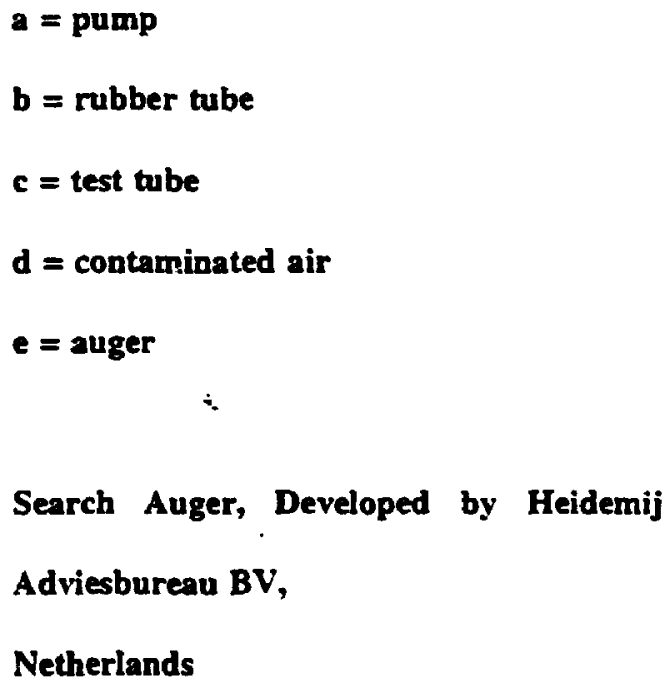


The search auger was used to identify volatile contaminants in soil. The apparatus is shown in Figure 2.2. Soil vapour was sucked through the rubber tube. Depending on the test tube, the colour change gives the information about the contaminant present.

In US, field analysis is carried out by portable instruments such as gas chromatography, photoionization detector, and infrared analyzer.

The apparatus shown in Figure 2.3 was used by the Environmental Response Team of the U.S. Environmental Protection Agency to identify volatile organic substances. A rough estimate on the amount of volatile organic substances present in the soil was made by connecting the probe of a portable photoionization detector to the sampling tube inserted into the ground. Then the probe was disconnected and soil vapour sample was collected in an air sampling bag with an air pump. The soil vapour withdrawn was then analyzed by portable photoionization gas chromatography. 


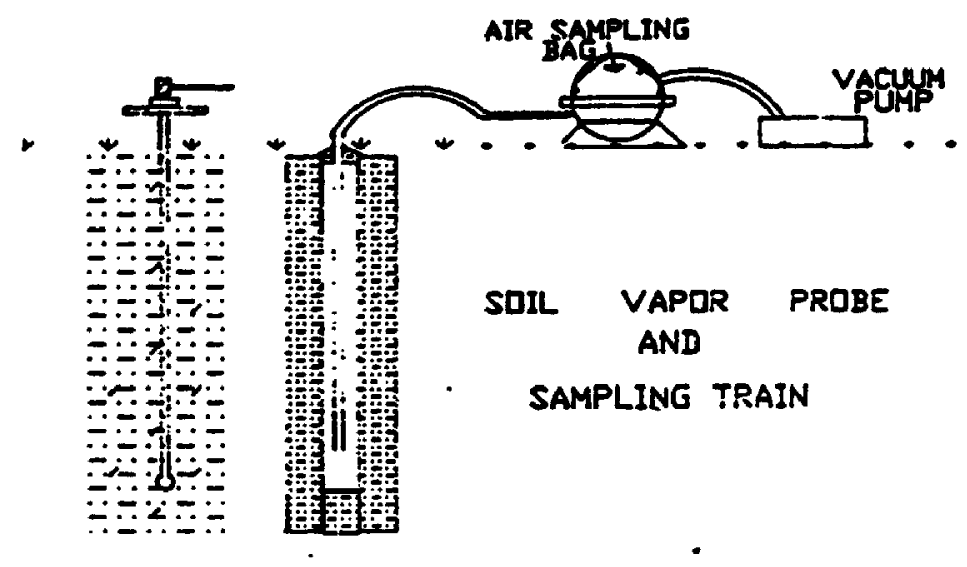

Figure $\mathbf{2 . 3}$

Nadeau, 1985 
Another apparatus that has been used in the field is the portable infrared analyzer. The apparatus can be used to obtain quick, reliable estimates of total petroleum hydrocarbon (TPH) concentrations for the soil samples in the field (Litzwnberg et al., 1992). This method is suitable for detecting diesel fuels, lubricating oils, fuel oils, asphalt, tars, crude oils, grease, kerosene and related substances (Litzwnberg et al., 1992). This method is suitable for both volatile and non-volatile substances. The theoretical aspects and the apparatus used in this method will be discussed in Chapter 4 .

Various geophysical methods have been attempted on an experimental basis to identify hydrocarbon contamination (Selby, 1991). These include, ground penetrating radar, induced polarization and electrica' esistivity survey. The identification of contaminants by ground penetrating radar is based on the characteristics of the returned radar signal. Radar is a system used to detect the presence of objects by sending out pulses of high frequency electromagnetic waves. The instrument is calibrated with known hydrocarbon substance prior to use in identifying hydrocarbon contaminants.

In the induced polarization method, the identification is based on the effect of induced polarization under application of a short-time current through a media. Under the application of a current, the distribution of positive and negative ions is altered. This change in distribution create a gradient effect. When this current is terminated, the 
gradient effect relaxes, resulting in a current flow and a measurable voltage termed as induced polarization. Theoretical and experimental evidence showed the presence of non polar organic molecules will reduce the induced polarization (Selby, 1991). This principle is used to identify hydrocarbon contaminants.

The electrical resistivity method is based on the reduced conductivity of soil material due to the presence of organic contents. This method is based on the fact that the presence of inorganic material in soil increase conductivity of the soil and therefore the presence of organic content will reduce the conductivity (Selby, 1991).

All geophysical methods are, at present. limited in application as separating the response of a targeted compound from the other compounds are generally difficult.

\subsection{Laboratory Analysis}

Laboratory methods are generally more precise than field methods. Soil or vapour samples are collected in such a manner that the hydrocarbon/volatile organic contaminants are not lost during the sampling. Contamination of collected samples with foreign substances is possible during sampling, transportation and storage. A recommended practice to check for such contamination during transportation and storage is to place a trip blank prepared from a reagent water with the samples during the transportation and 
storage (Parr et al., 1991). Analysis of this reagent will give information on sample contamination with foreign substances.

Components of interest are extracted (by various methods discussed in Section 2.4) from the soil or soil vapour samples and are analyzed by chromatographical or spectrugraphical methods. The most widely employed method is chromatographycal analysis where sample is analyzed on a gas chromatometer(GC) configured to FID or to any other detectors. However, high resolution gas chromatography-mass spectrometry (HRGC/MS) has shown the greatest success (Potter. 1990). The identification of the sample is based on the pattern recognition techniques which involve identifying a unique pattern for each component or for the targeted components in the sample. This unique pattern is a chromatogram or a spectrogram depending on the method employed for analysis. This is discussed in detail in Chapters 3 and 4 . In both chromatographical or spectrographical methods, the data interpretation of a sample involves comparison of experimentally derived patterns of samples to that of known standards. This has been done by simple visual observation or by computer based techniques.

In computer based pattern recognition techniques, patterns of standards under controlled experimental conditions are stored in the computer. When a sample is tested, the chromatograms or spectrograms are obtained under experimental conditions similar to 
those used to obtain the patterns of standards. Then once the sample pattern is obtained the computer searches for a matching pattern from the collection of standard patterns stored in the computer. If there is a similar pattern then the computer identifies the contaminant. If there is no similar pattern then the computer tells it is an "un-recognized pattern". An example of computer based search is a cluster analysis (Potter, 1990).

The basic concept of the cluster analysis is that a product can be represented as a point in a $\mathrm{x}$-dimensional space. Where $\mathrm{x}$ is a variable which is the number of parameters for which concentration data is available (Hope, 1983). In cluster analysis, a different set of variables for each set of samples is generated by computation such that the data may be represented in fewer dimensions while retaining most of the inherent variability within the data set. The cluster analysis can be done on a Zenith 386 work-station using the software package, "Spring-stat" (Potter, 1990). In this analysis, closeness of plots of different compounds are indicative of the degree of similarity.

In chromatographical methods, the individual components are separated in a GC column and identified by detectors. High-resolution capillary columns have greatly increased the separation power. Selective detectors (such as electron-capture, nitrogen-phosphorous and Hall's electrolytic conductivity detectors) have improved the identification power of the GC (Donnelly et al., 1993). In addition to selective detectors, mass spectrometers(MS)

\section{Literature review}


and Fourier transform infrared spectrometers have been widely used. Usually the GC-MS method is used for confirmatory purpose as it is expensive. The U.S. EPA conducts thousands of analysis each year by GC-MS to identify environmental contaminants (Donnelly et al., 1993). The data interpretation is carried out with the aid of usergenerated mass spectral libraries under specific conditions or by a commercial data base of mass spectra.

In both field and laboratory analysis, proper sample preparation is essential prior to analysis. In preparing samples for analysis. basically the components of interest are extracted from the soil matrix. In some cases a cleanup step may be required to remove unwanted sample interference. Also a concentration step in some cases is preferred to improve sensitivity. These are discussed through Section 2.4 to 2.4.7.

\subsection{Sample Preparation}

The extraction of an analyte (volatile organic) from a solid matrix is much more difficult than from a gas or liquid. There is no accepted method yet available in literature (Amaral et al., 1994). However several methods have been tested to develop a suitable method. These methods include static head space analysis, dynamic head space analysis, purge and trap, solvent extraction, soxhlet extraction, sapfonication extraction and supercritical fluid extraction. Each of these methods is discussed below. 


\subsubsection{Static Headspace Analysis}

This method is applicable for analysis of volatile hydrocarbons and organics from soil and water samples (Jones, 1987). Soil is heated within a capped vial after addition of water or methyl glycol (propylene glycol). Once equilibrium is achieved, the vapour in the headspace(HS) of the soil sample container is injected onto a GC column for analysis. The container is closed with a rubber septum to facilitate sample withdrawal by a syringe. The septum is usually made of specific material which will not adsorb organic contents from the vapour sample. Butyl rubber septa and silicon rubber septa are not recommended as these material cause a lot of adsorption problems. Adsorption problems are reduced by using a septa coated with either a polytetrafluoroethylene (PTFE. teflon) or aluminium foil (Seto, 1994).

The syringes are prewarmed to reduce sample condensation and contamination. In order to reduce disturbance of the equilibrium during sampling, the volume withdrawn for analysis is recommended to be less than $10 \%$ of the headspace (Seto, 1994). Whether the sample achieved equilibrium can be tested by injecting the vapour at different times.

This method can provide precise quantification and can efficiently measure volatile substances with relatively low water solubility. However the method is less sensitive for volatile substances with high water solubility. This method is applicable for solid. liquid 
or gas samples. The detection limit for Benzene and toluene by headspace analysis with GC-flame ionization detector is 10ppm (Kolb, 1976). This method requires additional calibration as the sample itself is not analyzed. instead the vapour from the sample is analyzed. This is discussed under calibration.

This extraction procedure is used in USEPA method 5020. to analyze volatile hydrocarbons and organics in soils and liquids (USEPA, 1982). In EPA 5020 method, the soil sample is weighed in a glass container, which is sealed and permitted to equilibrate at $90^{\circ} \mathrm{C}$. Once equilibrium is achieved, the headspace is withdrawn by a gastight syringe and analyzed by the gas chromatographic method.

\subsubsection{Dynamic Headspace Analysis}

In this method a carrier gas is passed over the sample under analysis for a specific time and trapped in a cryogenic or absorbent trap. The concentrated analyte is then introduced onto the GC column for analysis. This method has higher sensitivity due to trapping in an absorbent. However precise quantification ıs difficult as it involves intermediate steps for which the amount of analytes transferred is not known. Moreover the analytes transfer at each step may not be uniform enough to provide reproducibility of the test results. This method is applicable for solid and liquid sanples. 


\subsubsection{Purge and Trap Method}

Figures 2.4 and 2.5 shows the purge and trap apparatus in sorption and desorption mode. An appropriate solvent is added to the soil sample to dissolve the organics present in soil. The appropriate solvents are polyethylene glycol (PEG), or tetraglyne or any other solvents mentioned in the solvent extraction method discussed in Section 2.4.4. A part of the solution is mixed with water in the purge chamber. Following to this step, purge gas (helium) which has been filtered through a molecular sieve filter is bubbled through the solution in the purge chamber at ambient temperature. During this period, volatile components are transferred from the aqueous phase to the vapour phase. The vapour is then passed though a sorbent column where the volatile components are trapped. The sorbent column can be made of Tenex.

Components can be selectively trapped by choosing the proper sorbent column. After striping the components, the trap is heated and backflushed with helium to desorb components onto the GC column for analysis. The recommended temperature for desorption is $180^{\circ} \mathrm{C}$ (Parr, 1991).

As in dynamic headspace analysis, precise quantification and reproducibility of test results may be difficult due to several intennediate steps prior to analysis. 


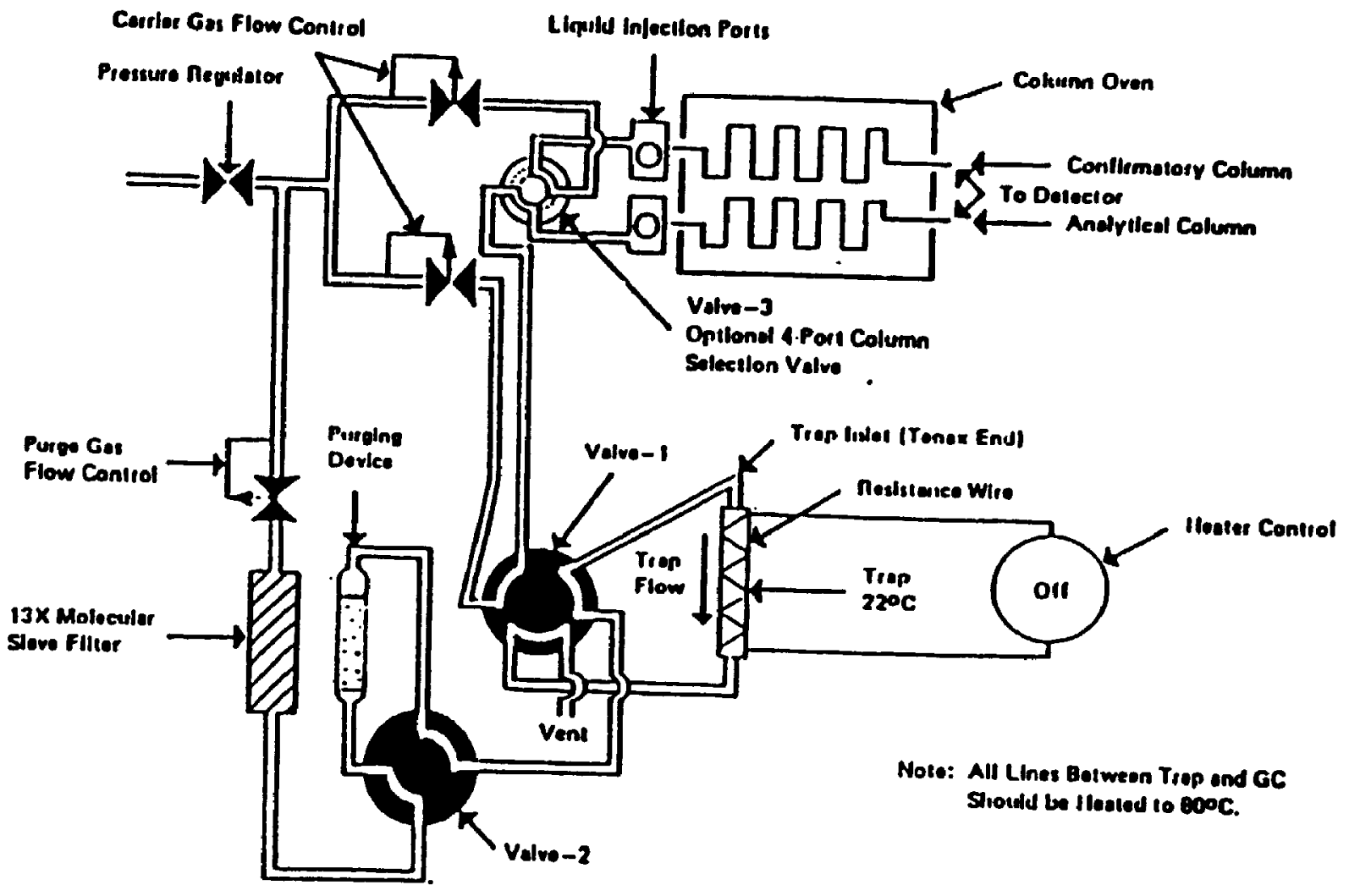

Figure 2.4

Purge-and-Trap System. Purge-Sorb Mode, Parr, 1991 


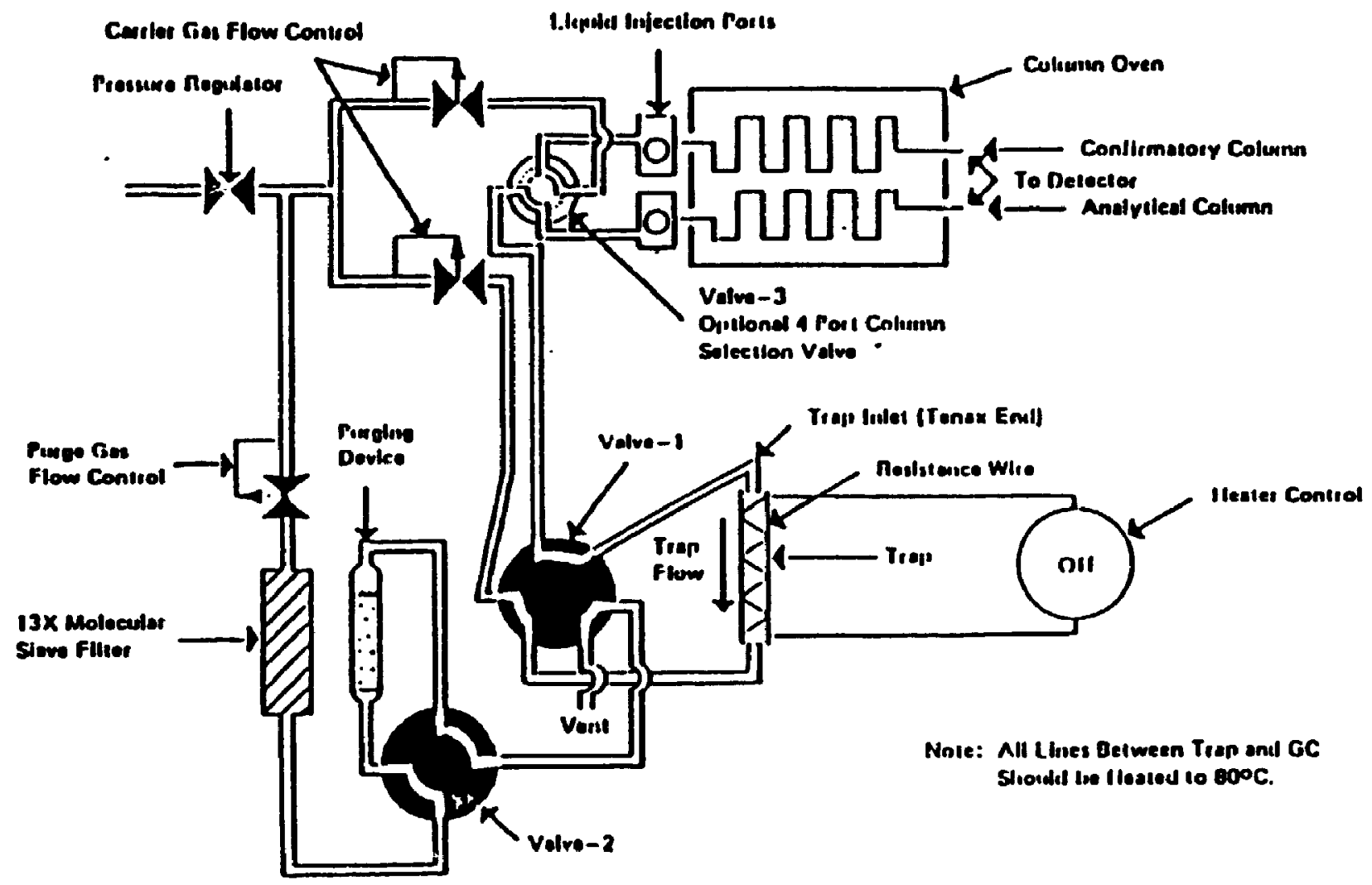

Figure 2.5

Purge-and-Trap System, Purge-Desorb Mode, Part, 1991 


\subsubsection{Solvent Extraction}

The components for analysis can be extracted from the soil matrix with organic solvents such as $\mathrm{n}$-hexane, n-pentane, n-pentane-propan-2-ol, and methanol. The solvent power in extracting analytes of interest can be selectively varied by changing the temperature and composition of the solvent. Subsequent analysis is carried out by direct injection of liquid sample or by headspace analysis. The solvent is removed from the extract by heating prior to analysis or by backflushing in the column. Otherwise solvent is selected in such a manner that it will elute before the sample components elute or after the elution of all sample components. Volatile substance in soil can also be extracted with carbon disulphide (McKown et al., 1981).

\subsubsection{Soxhelet Extraction}

This method is to extract nonvolatile and semi-volatile organics from soil matrix. This method ensures intimate contact of the sample matrix with extraction solvent. Soxhlet extraction procedure is used in EPA method 3540. In this method. the weighed soil sample is mixed with anhydrous sodium sulphate or magnesium chloride placed in an extraction thimbie between plugs of glass wool and is extracted for a minimum of 16 hour using the appropriate solvent in a soxhlet extractor (I.T. Corporation, 1985). The solvents that have been used are methylene chloride. mixtures of methylene chloride and methanol, carbon tetrachloride, freon 113, chloroform, tetrahydrofuran, pentane. hexane.

\section{Literature review}


carbon disulphide, and hydrogen sulphide. The extract is then dried over sodium sulphate and concentrated prior to analysis.

\subsubsection{Sonication}

This could be an alternative to soxhlet extraction. This is also used to extract nonvolatile and semi-volatile organics from soil. Sonication extraction is used in EPA 3550 . In this method, the soil sample is ground and mixed with an appropriate extraction solvent. This mix is then dispersed into the solvent using sonication. Solvents which have been used for the extraction of hydrocarbons from soil include methy!ene chloride, methylene chloride/methanol, carbon tetrachloride, chloroform, freon 113, tetra hydrofuran, pentane, hexane, and carbon disulphide (USEPA, 1982).

\subsubsection{Superc: itical Fluid Extraction}

This method is similar to solvent extraction method with the exception that a supercritical fluid(SCF) is used as a solvent. A SCF is a fluid that has a terr; "ature above its critical temperature. The critical temperature of a fluid is the temperature above which the density of the fluid and the vapour is same. When a substance is maintained above its critical temperature it is impossible to liquify its vapour by increasing its pressure (Lynch, 1995). Therefore a single phase is maintained regardless of the applied pressure. 
A SCF has properties between liquids and gases and therefore it is more powerful in extracting the analytes from the solid matrix. The density of a SCF is close to a liquid, as a result SCF has higher solubilizing power. The diffusivity is greater than that of soluits in liquids and this helps rapid transfer of material from a solid surface to the extract. Moreover, the viscosity of SCF is lower than the liquid and surface tension is zero. This helps to penetrate the micro-pores in the matrix and improve extraction.

The solvent power of a SCF can be adjusted to a wide range by varying the pressure. Therefore the selectivity of the solvent can be adjusted to target the analytes of interest (Lynch, 1995).

The SCF extraction can be static or dynamic as of headspace analysis. In static extraction, the container containing the sample is pressurized with the SCF to allow the sample to soak in the SCF. Once the system has achieved equilibrium the extract is removed and analyzed. This method is suitable when the analyte has high affinity for the solvent and low affinity for the matrix. In dynamic extraction, the SCF is continuously passed over the sample and exits through a back pressure device into the trap. The analytes in the trap are desorbed arid analyzed. The dynamic SCF extraction is suitable when the solute has a high affinity for the sample matrix. 
In both static and dynamic methods, once the extract is taken, the solvent is removed prior to analysis. There are two methods described in literature by Eisenbach. These are isobaric and isothermal methods. In isobaric method, the SCF with the dissolved material is heated. The density decreases and the dissolved material falls out and is collected in a separation vessel. In the isothermal method, the extract (SCF with dissolved mass) is expanded to reduce the pressure below the critical pressure and consequently the material falls out and is collected in a separation vessel.

Carbon dioxide has been the supercritical fluid of choice as the critical point is easily assessable and is good organic solvent (Schantz et al., 1986). It is also non-toxic, nonflammable and readily available at a low cost. 


\section{Chapter 3}

\section{Chromatographical Techniques}

\subsection{Overview}

As discussed earlier, chromatographical methods have been widely used to identify hydrocarbon contaminants in soil. This is probably due to the fact that in chromatographical methods, the separation and identifying power can be adjusted over a wide range by proper selection of experimental conditions and parts of the instruments such as detectors and columns. Alss there is an ample amount of information regarding the application of chromatographical techniques available from medical, chemical, biological and environmental fields. In chromatographical methods. sample components are separated in a column and consequently identified with the aid of detectors. Also in these methods sample constituents can be selectively identified (in other words the problems due to the presence of impurities can be reduced) by choosing proper experimental conditions, the type of column and the detecto: and by appropriate sample preparation.

Chromatography includes a group of methods which separate. isolate, and identify sample components. Nevertheless, the identification is not straight forward and the instrument has to be calibrated for each components that is to be identified. Many types of 
chromatographical methods are available including, gas chromatography(GC), liquid chromatography(LC), high performance liquid chromatography(HPLC), supercritical fluid chromatography(SFC), thin layer chromatography(TLC), and ion chromatography. In all such types of chromatographical methods, the separation of a sample is achieved by the distribution or partitioning of the sample between two different phases, the mobile phase and the stationary phase. The classification of the above mentioned methods is based on the type of the mobile and the stationary phases (solid, liquid or gas) or the method of fixing the stationary phase onto a solid support.

Among these methods, GC has been widely used for identifying contaminants in soil. GC is preferred for the organic compounds which can be vaporized without decomposition (Kolla, 1994). In the GC method, the mobile phase is an inert carrier gas and the stationary phase is a high molecular weight liquid which deposited either on a packed column or on the wall of a capillary column.

The efficiency of chromatographical methods depends on the proper selection of experimental and instrumental conditions. Also the efficiency depends on the choice of the calibration method. In order to fulfil the above two conditions it is important to understand the basic techniques involved. This chapter provides an overview of the instrumentation, theoretical aspects, and calibration methods which will allow the efficient 
use of these methods for the purpose.

\subsection{Instrumentation}

The apparatus used in this method basically consists of a column, a detector and a recorder. The column provides the separation capability of the instrument, in which the sample is separated into its constituents in separate bands. The detector recognizes sample-constituent's chemical or physical characteristics and converts them to a voltage. The recorder provides the visual display of a plot of converted voltage vs time called a chromatogram.

\subsubsection{Columns}

The column can be a packed column or a capillary column. A packed column is one in which the stationary phase (a liquid) is deposited on solid particles and packed in a tubular column. A capillary column is one in which the stationary phase is deposited onto the interior wall of the column. In both types of column, the sample is introduced on the head of the column and carried through the column by the mobile nhase. Some of the columns that have been used in the analysis of hydrocarbons in the literature are given in Appendix. 


\subsubsection{Detectors}

Commonly used detectors in hydrocarbon analysis of soils are, flame ionization detector(FID), electron capture detector(ECD), mass spectrometer(MS), and photoionization detector(PID). The detector's function in the chromatographical process is to identify the unique characteristics (can be physical or chemical depending on the techniq zs employed in the design of detector) of the separated components of the sample and to corivert it into a voltage. The detector's function is quantitatively defined by minimum detectable limit(MDL), response factor and the linear dynamic range. The MDL is the least amount of sample that has a discernible signal. The response factor is the ratio of the signal size to the sample size. The linear dynamic range is the ratio of the maximum value to the minimum value of the range over which the detector has a linear response. Detectors can be universal, selective or specific. A universal detector means it responds to all components in a sample. Therefore a detector may be universal for one iype of sample while it is not for another in which the detector is incapable of identifying all components (O'Brien, 1985). FID and thermal conductivity detectors(TCD) respond to nearly all organic compounds (Poole, 1991) and therefore these detectors are considered to be universal for organic compounds. The detectors which respond only to specific compounds are called specific detectors. The specific detectors include the flame photometric, thermionic ionization and atomic emission detectors. Some detectors have the power of discriminating the response of two different compounds and these are called 
selective detectors. The difference in detector response is quantitatively defined by selectivity and it is the ratio of the detector sensitivities to two different compounds, compound classes, heteroatoms, etc. The selective detectors can be element-selective or structure selective. Structure selective detectors include electron-capture and photoionization detectors (Poole, 1991).

Further detectors can be concentration or mass sensitive and the response factor is given below for both type.

For mass sensitive detectors (assuming a triangular peak):

$$
\text { Response factor }=\frac{\left[\frac{s \times w}{2}\right]}{m}=\frac{A}{m}
$$

For concentration sensitive detectors (assuming a triang»lar peak):

$$
\text { Response factor }=\frac{\left[\frac{s \times w}{2}\right]}{m} \times F=\frac{A}{m} \times F
$$

where $s=$ Peak height 


$$
\begin{aligned}
& w=\text { Peak width } \\
& A=\text { Peak area } \\
& F=\text { Flow rate } \\
& m=\text { Mass of compound injected }
\end{aligned}
$$

The values $s, w$ and $A$, are the properties of the GC component peak and are measured from the chromatogram.

\subsubsection{Flame Ionization Detector}

This has nearly universal response with approximately the same high sensitivity to all organic compounds. The compounds that will not be identified by a FID include fixed gases such as $\mathrm{He}, \mathrm{Xe}, \mathrm{H}_{2}$ and $\mathrm{N}_{2}$, certain nitrogen oxides, $\mathrm{N}_{2} \mathrm{O}, \mathrm{NO}$, compounds containing a single carbon atom bonded to oxygen or sulphur $\left(\mathrm{CO}_{2}, \mathrm{CS}_{2}, \mathrm{COS}\right)$, inorganic gasses $\left(\mathrm{NH}_{3}, \mathrm{SO}_{2}, \mathrm{H}_{2} \mathrm{~S}\right)$, water and formic acids (Poole, 1991). In petroleum and petrochemical laboratories, it is the rule that all compounds can be measured at very low level with the FID (O'Brien, 1985).

The detector response is based on the current created as a result of ions formed by combustion of the GC effluent in a hydrogen flame. When an organic compound burns in hydrogen flame negative ions form and the amount will be proportional to the number 
of organic molecules present in the organic compound. These negative ions are collected by a collector electrode by applying an appropriate voltage and the resulting current is measured. The hydrogen flame also produces very few ions (about $10^{-14} \mathrm{~A}$ background current) when burming which is negligible compared to the ions produced by a GC-peak compound. In the FID detection the chromatogram is a plot of the resulting current vs time.

The FID is a mass flow sensitive detector in that the area of a given peak is proportional to the mass of single carbon fragments (McMinn et al., 1992). The FID responds uniformly to most of the hydrocarbon compounds and its relative response factor (defined later) for all hydrocarbon compound is close to $1.0( \pm 3 \%)$ with the exception of 0.9 for benzene and 0.95 for Toluene (Sutton, 1985). The FID will accommodate modest changes in flow, pressure and temperature without affecting its operation. The FID's minimum detection quantity is $10^{-11} \mathrm{gm}$ and the linear dynamic range is $10^{7}$.

\subsubsection{Photoiorization Detector}

The detector response is based on the ion current formed as a result of photoionization of a species. Photoionization occurs when a molecular specie absorbs a photon of light energy and dissociates into a parent ion molecule and an electron ( $O^{\prime}$ Brien, 1985) as shown in Equation (3.3).

Chromatographical Techniques 


$$
R+h v-\cdots R^{*}+e^{-}
$$

Alkanes and Alkenes are less sensitive to photoionization than benzene. The response relative to benzene increases when electron-releasing groups are substituted to benzene rings and decreases when electron-capturing groups are substituted to benzene rings. PID has high selectivity and sensitivity to alkenes and aromatic compounds (McMinn, 1992). The PID is 5 to 10 times more sensitive than the FID for alkanes and about 50 times more sensitive for aromatic compounds (O'Brien, 1985).

\subsubsection{Electron Capture Detector}

The detector consists a radioactive beta emitter which emits high-energy electrons and electrodes to measure the current. When the GC carrier gas (nitrogen) enters the detector the high energy electrons create low-energy electrons and positive ions in the nitrogen carrier gas. When an electronegative compound exist in the GC effluent (carrier gas) it reacts with low-energy electrons and as a result the number of low-energy electrons is reduced. This reduction in low-energy electrons is measured as a reduction in the current at the anode of the ECD. The ECD response is based on the reduction in current and it is quantitatively defined by Equation (3.4). 


$$
\frac{I S-I}{I}=K \times C
$$

where $\quad I_{s}$ is the background current

I is the current after low-energy electrons react with contaminants

$\mathrm{K}$ is the proportionality constant, and

$\mathrm{C}$ is the concentration of the sample

This detect, is selective for electronegative compounds, that is the compounds which have the ability to react with electrons. The minimum detection limit of the detector is $10^{-12} \mathrm{gm}$ and linear dynamic range is $10^{2}$ for $\mathrm{DC}$ mode.

\subsubsection{Mass Spectrometer}

This is the most efficient detector for analyzing environmental samples qualitatively as well as quantitatively. However, due to the cost involved in this system, this method is not affordable by many of the research laboratories. As a result, this detector, at many places has been used only for confirmatory tests. Usually GC-MS systems are equipped with computer hardware and software which allows the veres to perform complex data interpretation easily.

The mass spectrometer consists of an ionizing chamber and an analyzer with an ion 
collector (both in a vacuum), and a computerized data management system. In the ionizing chamber, electrons are emitted from an ionization source consisting of a heated tungsten or thenium filament. These electrons will be accelerated in a mtential field of 5-100V and attain energy in the 50-100ev range ( $O^{\prime} B$ rien, 1985). However for standardizing purposes most of the instruments are designed in such a way that electrons attain 70ev. This facilitates the possibility of comparing mass spectra of different samples. While electrons are attracted towards electrodes, the electrons react with GCpeak compounds and as a result positive ions are created. The positive ions formed are grouped according to the mass-to-charge $(\mathrm{m} / \mathrm{z})$ ratios by the analyzer. A plot of their relative abundance vs mass constituents gives the mass spectrum (Karasek et al., 1988). Like chromatograms in GC-detector system, in GC-MS, the mass spectrum is used to identify compound classes qualitatively and quantitatively.

\subsection{Theory of Chromatography}

In chromatographic process, a separation is achieved by distributing the sample between two phases, a mobile and a stationary phase in a column. The distribution basically depends on the molecular interaction between the individual solute molecules, and the molecules of stationary and the mobile phase. Three types of molecular interaction commonly exist between molecules, namely: ionic, polar and dispersive. Depending on the degree of molecular attraction between the solutes and the stationary or mobile phase, 
solutes retain in stationary and mobile phase for different time periods.

Molecules which have a greater affinity to stationary phase remain for more time in the stationary phase than in the mobile phase. Similarly molecules which have a greater affinity to the mobile phase remain for more time in the mobile phase than in the stationary phase in the column. As the mobile phase travels down the column, it carries the solute molecules distributed into this phase. As a result, solute molecules which have a greater affinity to the mobile phase will elute earlier than the molecules which have a greater affinity to the stationary phase. Consequently, the individual components of solute molecules are separated in different bands. A diagrammatic representation of this procedure is shown in Figure 3.1.

The distribution of solutes in stationary and mobile phase is quantitatively defined by partition coefficient $\mathrm{K}$ given by Equation (3.5).

$$
K=\frac{C_{s}}{C_{m}}
$$

Where $\quad C_{5}=$ The analytical concentration of a solute in the stationary phase $C_{m}=$ The analytical concentration in the mobile phase 
At low solute concentrations, $\boldsymbol{K}$ is found to be at least approximately constant so that a linear relationship exists between $C_{s}$ and $C_{m}$. When $K$ remains constant, the chromatography is termed as linear chromatography. A diagrammatic representation of the partition of the solute components between both phases and consequent separation is shown in Figures 3.2 and 3.3. In the example given in Figure 3.2, it is assumed that there are only two solutes (A \& B) present and their partition coefficients are 1 and $1 / 3$ respectively. 


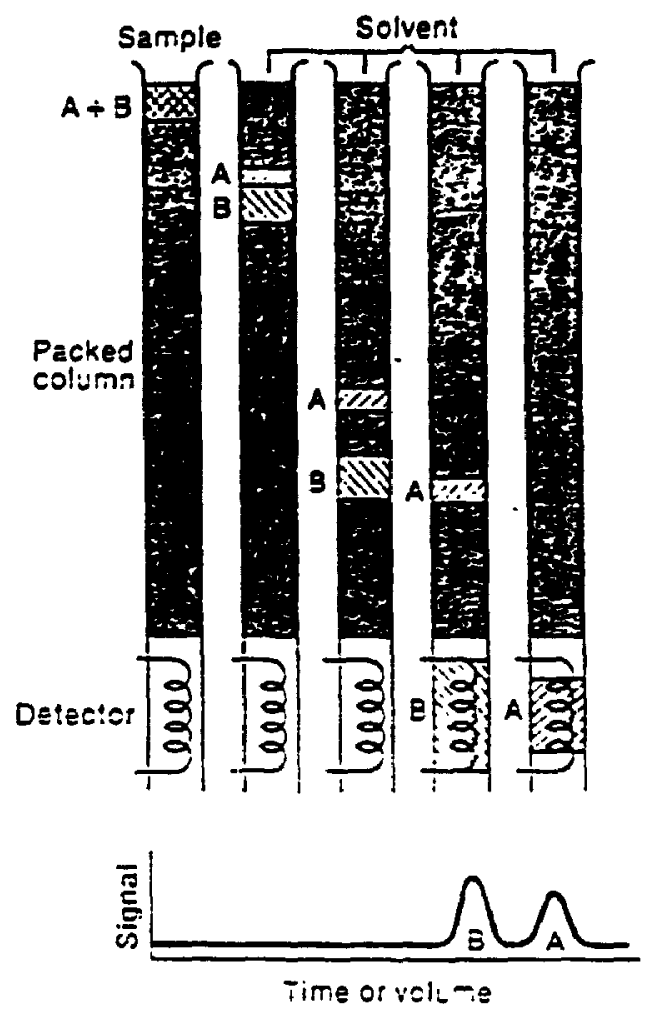

Figure 3.1

Diagrammatic representation of an elution chromatographic separation of components A and B of a mixture. Skoog. 1982 
For effective separation, the components to be separated must be soluble in the mobile phase and must also be capable of interacting with the stationary phase either by dissolving in it, or by reacting chemically with it. Therefore the selection of mobile and the stationary phase play a major role in separating the compounds selectively from the sample matrix.

In Figure 3.2, the column in the left represents the stationary phase and the column in the right represents the mobile phase as it travel down the column. Divisions of the column, 1 to 6 , indicate the part of the column on which each time the mobile phase becomes in contact with stationary phase and the partition takes place. In reality. the thickness of these divisions is very small. Different stages (a) to (f) of the process shown in Figure 3.2 explains the equilibrium of the solute partition when every time mobile phase becomes in contact with a new section of a stationary phase. For simplicity, the length of the column is assumed to be made up of five equilibrium divisions. In reality there will be a large number of equilıbrium sections. These equilibrium sections are called theoretical plates and the larger the number of theoretical plates the higher the separation efficiency of the column. Once the separated sample reaches the end of the column (5th division in this example), it will elute from the column. 


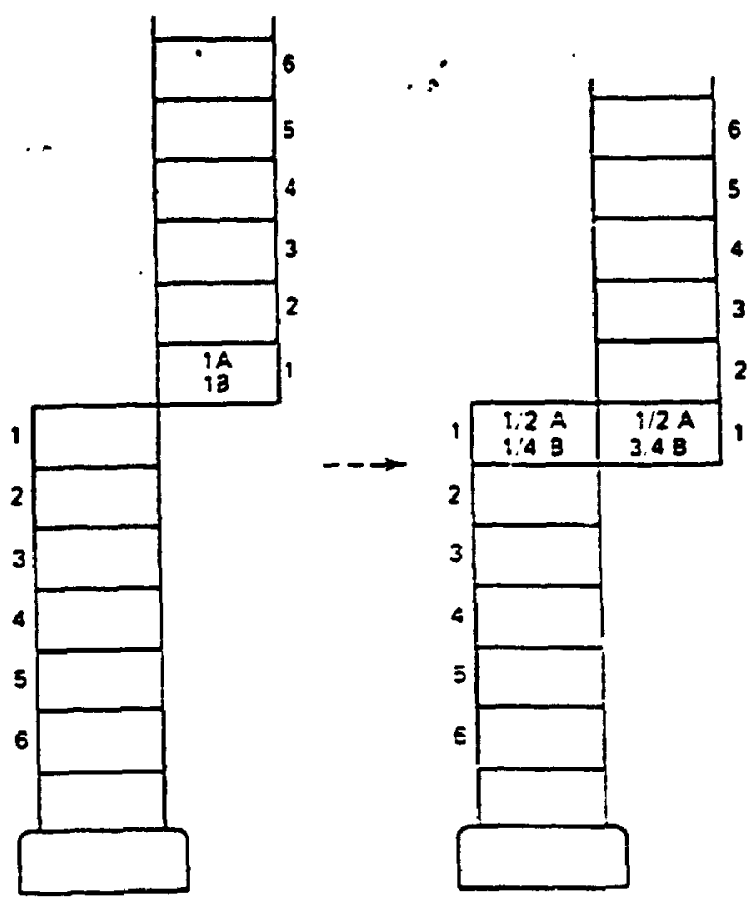

(b)

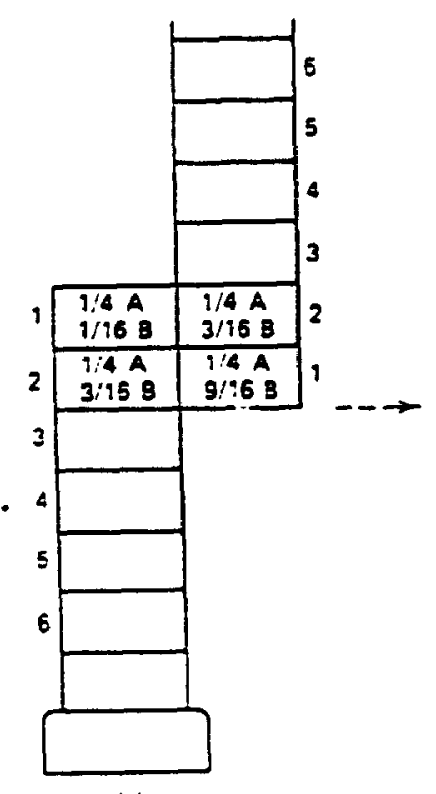

(c)

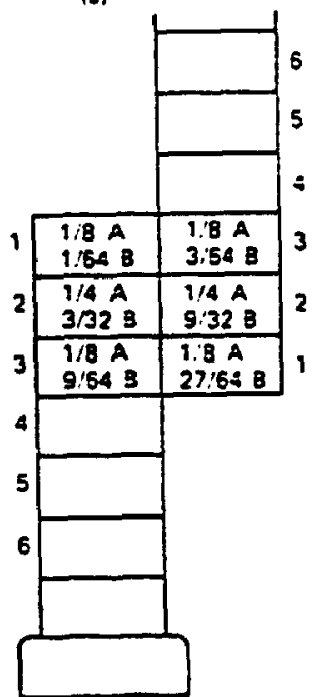

(द)

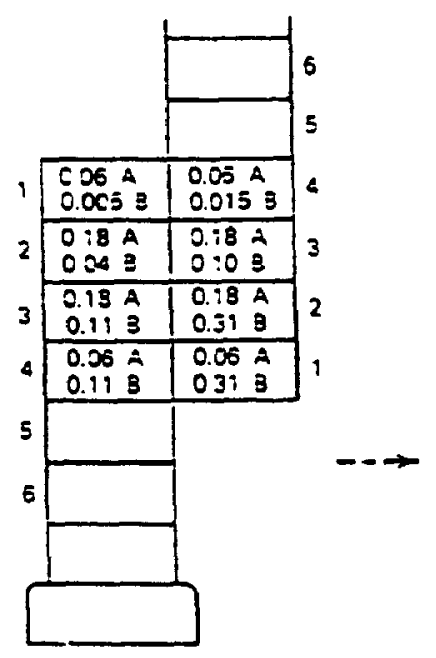

(e)

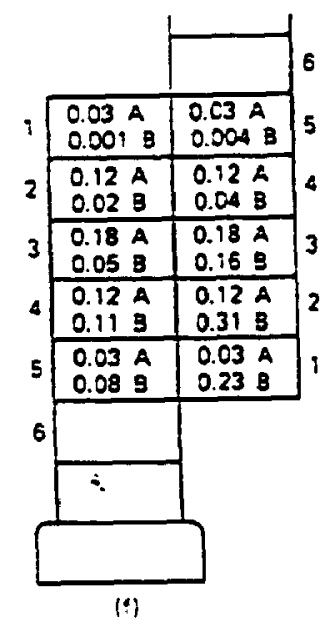

Figure 3.2

A Diagrammatic Representation of Partition of Solutes between

Stationary and Mobile Phase, Christian, 1986

\section{Chromatographical Techniques}




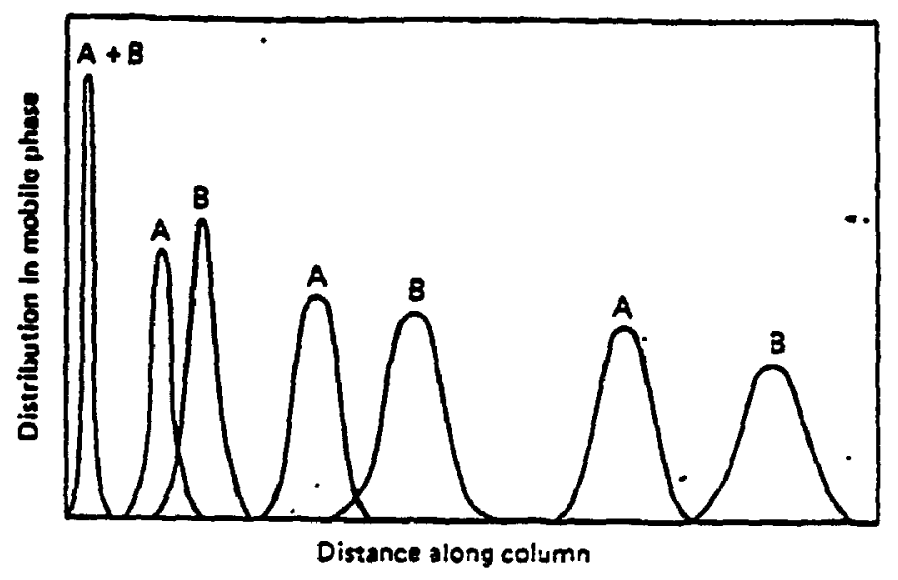

Figure 3.3

Distribution and separation of two substances $A$ and $B$ along a chromatographical column Christian, 1986 
The following facts must be realized from Figures 3.1, 3.2, and 3.3:

If there are two more components having similar partition coefficient, it is possible there can be two or more components eluting together in a single soluteband

-The resolution increases with increased length of column

-The faster the mobile phase travels down the column, the lesser will be the analysis time but the separation will be less as there is not enough time to complete partition at each equilibrium sections

\subsubsection{Methods for Efficient Resolution}

In chromatographical separations, if the sample has components with wide range of retention times (ie, components with wide range of boiling points), it will increase the analysis time. In order to reduce the analysis time in gas chromatography, the temperature or the flow can be programmed in a manner which will rednce the elution time of the components which elute considerably later. This will reduce the over all analysis time and allow more samples to be run. There are two methods that have been used in the literature and are discussed below. 


\subsubsection{Temperature Programming}

In this method the temperature is set such that the column temperature is increased with time. When the chromatographical column is maintained at a low temperature, the lowboiling components will elute at a reasonable time but the high boiling components will take a considerably longer time causing overall analysis time to increase. Keeping the column at a high temperature isothermally will not solve the problem where low-boiling point temperature solutes will elute so quickly that the solute-peaks are at a very close intervals and difficult to observe. To overcome this problem, in temperature programming, the initial temperature is set such that low-boiling components elute separately enough to observe component-peaks. Then the maximum temperature is set to elute the high-boiling component in a reasonable time. The temperature is programmed in a way that the maximum temperature required is achieved in a reasonable time. The theory behind this is the retention time (time taken for a component to elute from the column) of a peak is proportional to exponent of the reciprocal of the absolute temperature. This is given in Equation (3.6).

$$
R_{t} \propto e^{1 / T}
$$




\subsubsection{Flow Programming}

In this process, the flow is increased continuously during the development of the chromatogram such that to accelerate the elution of the more retained solute peaks. Unlike in the temperature programming, the velocity of the separated solute bands are only linearly proportional to the flow rate therefore in order to elute solutes with very high retention time, a very high flow rate is important and consequently very high inlet pressure is needed. For many detectors the sensitivity changes with flow rate. As a result, this method has limited applications.

\subsection{Calibration Procedures}

As discussed in previous section, in chromatographical procedures, instrument should be calibrated qualitatively and quantitatively for each class of compounds which are to be identified. The output of the chromatographical analysis is a chromatogram, a visual display of which is produced by a computer, a strip chart recorder, or by an oscilloscope. Basically two parameters of a chromatogram of a sample are taken for qualitativa and quantitative calibration. These are the retention time and the size of the peak. Calibration in chromatography basically involves relating these two parameters to the quality and the quantity of the sample injected.

Chromatographical Techniques 


\subsubsection{Qualitative Analysis}

This is the process by which retention-times of known compounds are identified and this information is used for future analysis of unknown compounds. There are two ways to identify components in environmental samples qualitatively and these are:

- Component by component analysis

- Fingerprint analysis

In component by component analysis the individual components of the sample are identified and the result is used to interpret the possible source of contaminant. This method of analysis will be more precise as individual components are identified. However, this method necessitates the need for separation of all components and is not an easy task.

In fingerprint analysis each of the component in the sample is not identified individually but the overall pattern obtained is compared with chromatograms of possible sources of contaminants tested under similar experimental conditions.

In both methods, the retention-time of the sample component is the factor which characterizes the chromatographycal patterns of the samples. For reliable interpretation of test results, a clear understanding of this parameter and how it is subjected to 
experimental conditions is important. This is discussed below.

\subsubsection{Retention Time}

The retention time of a component in the sample is the time between the injection and the maximum of that particular component-peak when it passes through the detector. This retention time is a constant under fixed chromatographic conditions and the charac.sistic of the constituents. The retention time is measured for each peak and each of such tirr: corresponds to a specific component. This parameter is also defined by retention volume and is the product of retention time and flow rate. The retention time data is diagrammatically shown in Figure 34.

Chromatographical Te:hniques 


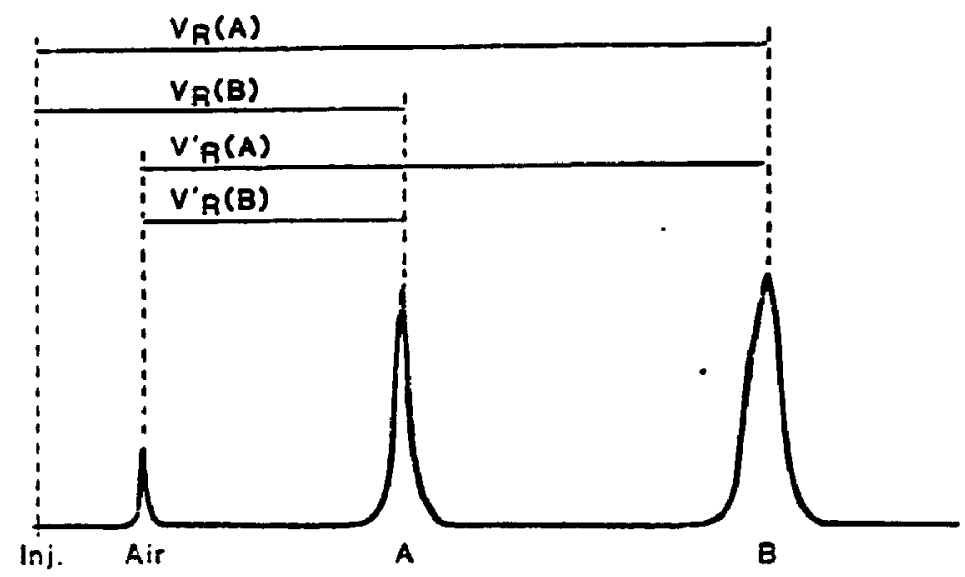

Figure 3.4

Chromatogram Illustrating Retention Nomenclature

Debbrecht. 1985

where

$V_{R}$ is the retention volume $\left(t_{R} \times\right.$ flow rate $)$

$V_{R}{ }^{\prime}$ is the adjusted retention volume $\left(t_{R}{ }^{\prime} \times\right.$ flow rate $)$

$t_{R}$ is the retention time

$t_{R}{ }^{\prime}$ is the adjusted retention time

$r_{2 b}$ is the relative retention time/retention volume 
Debbrecht, 1985 mentioned three ir - $_{\text {- }}$ ortant facts that should be understood before doing any qualitative interpretation of test results with retention time data. These are given below.

-If the retention time of a solute "A" is equal to an unknown solute then it does not prove that the unknown solute is solute " $A$ ". This should be understood from the discussion provided in Section 3.2. That is the retention of a sample component depends on various molecular interactions between the solute and the mobile and the stationary phase. If two or more chemical constitutes have similar retention time, then qualitative analysis from retention time fails.

-If the retention of an unknown solute is not equal to that of solute " $A$ "., then it is certain that the unknov'n solute is not " $A$ ".

-If the sample does not have a discernible peak at the retention time of solute "A", then the samrle does not have solute " $A$ " in it.

\subsubsection{Uncertainties Involved in Qualitative Analysis}

The retention time may vary even for the same compound due to minor changes in operational conditions and this will lead to false interpretation of data. Factors which 
cause such a variation in retention time include:

- temperature

- flow rate

- sample size injected

aging of the column

- sample introduction time

The change in temperature of approximately $30^{\circ} \mathrm{C}$ changes the retention time by a factor of two (Debbrecht, 1985). To maintain a $1 \%$ repeatability in retention time measurement, the recommended $\mathrm{t}$.mperature within which the column has to be maintained is $0.3^{\circ} \mathrm{C}$ (Debbrecht, 1985). Practically this may not be possible as all temperature measuring instruments do not have such precision. Moreover, if the column-temperature is above a specific component's boiling point in a sample, then a tailing peak (which has a sudden rise and a slow drop) will appear causing the time of the maximum of the peak to shift to the left resulting in reduction in retention time.

A $1 \%$ change in the carrier-gas flow rate affects the retention time by approximately $1 \%$. If too much sample is introduced onto the column for its diameter, a leading peak (which has a slow rise and a sudden drop) will result causing the time to the maximum of the 
peak to shift to the right resulting in an increase in retention time. Therefore these minor changes in operational conditions may cause false interpretation when retention time alone is used to identify a component in a sample.

In analyzing samples sometimes retention times of siandards are tabulated and these are compared against the retention times obtained under similar experimental conditions and instruments used (type of detector and column). In such cases. a similar column but not the one used to find the retention times of the standards tabulated may be used. Under such situations, even for the same type of column, variations in packing density, activity of the suppori and age of the stationary phase of the column may cause the retention time to vary slightly for the same compound. To overcome this problem. another parameter which is less subject to variation from column to column and slight changes in temperature and flow was introduced. This is called relative retention time, and it is the ratio between the adjusted retention time of a component to the adjusted retention time (Figure 3.4) of a reference material.

Another factor which causes uncertainty in retention time is the sample injection time. A fraction of a second increase in injection time can double the width of the peak and reduce the height by $50 \%$ (Debbrecht, 1985). This can cause the width of the specific peak to widen and as a result the consequent retention times of other peaks will increase. 
Also in gas-solid chromatography, retention time and peak broadening usually increase with concentration and thus influence the difference of retention time between the two peaks (Chang, 1968)

\subsubsection{Methods to Improve Uncertainties}

As discussed earlier in this chapter, if two components have similar retention times it will give a false interpretation. However these two components which have a similar retention time in one column may have a different retention time in an other column. This is because the second column can have different stationary phase in which the molecular interaction of those two components may be different and as a result these two components will be retained to a different extent. Consequently the two components may have different retention times in the second column. Therefore, the reliability of the result increases with amount of retention time-data available for a single component using various columns. However the columns have to be selected in such a manner that the process by which components are retained is somewhat different. 
McRevnoids Constants for Commonly Used Stationary Phases

\begin{tabular}{|c|c|c|c|c|c|}
\hline \multirow[b]{2}{*}{ Phase } & \multicolumn{5}{|c|}{ McReynolds Constants } \\
\hline & $x^{\prime}$ & $y^{\prime}$ & $z^{\prime}$ & $u^{\prime}$ & $s^{\prime}$ \\
\hline Apiezon L & 32 & 22 & 15 & 32 & 42 \\
\hline Carbowax 20M & 322 & 536 & 368 & 572 & 510 \\
\hline DC 200 & 16 & 57 & 45 & 66 & 43 \\
\hline Dexsil 400 & 72 & 108 & 118 & 166 & 123 \\
\hline Dinonyl Phthalate & 83 & 183 & 147 & 231 & 159 \\
\hline FFAP & 340 & 580 & 397 & 602 & 627 \\
\hline OV-1 & 16 & 55 & 4 & 65 & 42 \\
\hline OV-17 & 119 & 158 & 162 & 243 & 202 \\
\hline OV -225 & 228 & 369 & 338 & 492 & 386 \\
\hline OV-1701 & 67 & 170 & 153 & 228 & 171 \\
\hline SE-30(GC grade) & 15 & 53 & 4 & 64 & 41 \\
\hline SE-54 & 33 & 72 & 66 & 99 & 67 \\
\hline Silar $5 \mathrm{CP}$ & 319 & 495 & 446 & 637 & 531 \\
\hline$=510 \mathrm{CP}$ & 520 & 757 & 660 & 942 & 800 \\
\hline SP-1000 & 332 & 555 & 393 & 583 & 546 \\
\hline SP-2100 & 17 & 57 & 45 & 67 & 43 \\
\hline SP-2250 & 119 & 158 & 162 & 243 & 202 \\
\hline SP-2340 & 520 & 757 & 659 & 942 & 800 \\
\hline Squaiane & 152 & 341 & 238 & 329 & $3+4$ \\
\hline THEED & 463 & 942 & 626 & 801 & 893 \\
\hline
\end{tabular}

Table 3.1

Supina, 1985 
The columns are classified to meet this criterion by McReynolds constants. Columns having different McReynolds constants ( $x^{\prime}$ to $s^{\prime}$ from Table 3.1) are suitable to use as secondary columns to improve reliability of the test results. A detail discussion on this subject is provided by Supina, 1985, and the McReynolds constants for some columns given by Supina, 1985 is shown in Table 3.1 .

Other methods include identification of components by use of two or more detectors. In such cases the eluent from the GC column is split into parts and fed to two or more different types of detectors and two or more chromatograms are obtained for each sample to improve reliability.

\subsubsection{Quantitative Analysis}

This is the process by which concentration levels of the components in the injected sample are identified. Quantitative results are obtained from the size of the componentpeak. This size of the peak is measured in terms of one of the two parameters:

\footnotetext{
- height of the peak

- area under the peak
}

Theoretically the width of the separated bands of all components shown in figure 3.1 should be the same and equal to the width of the sample injected. This is the width of 
the component peak in a chromatogram that appeared in Equations (3.1) and (3.2). If this width practically remains equal for all component peaks, the area of the peak is proportional to the height of the peak and therefore the height alone can be measured and related to the amount of sample present. However. practically this condition does not remain true and due to several reasons, peak broadening does occur. When a large amount of sample is introduced the liquid or the absorptive phase becomes saturated with the material, causing broadening of the peak (Debbrecht, 1985). The extent of peak broadening will not be uniform for ali components. Lnder such situations the peak height will not be proportional to the peak area and the area itself should be measured. The peak height measurement is taken for the quantitative identification when the chromatogram consists of small peaks for which area measurement is difficult.

The height of the peak is taken as the perpendicular distance from the maximum point to the baseline. The baseline is drawn by connecting the baseline segments before and after the peak.

The area method is useful when there is a derectable amount of contaminant in the sample injected. Several methods are available in the literature by which peak-areas are measured. These include:

- cut and weigh 
- planimeter

- disc integrator

- electronic integrators and computers

As the name of the method indicates, cut and weigh involves cutting the peaks of the chromatogram of the sample and weighing it. Then the area is found by weighing a known area of a similar paper used to print the chromatogram of the sample. The advantage of this method is that area of distorted peaks can be measured easily. However if the paper is inhomogeneous it gives non-reliable results.

The planimeter method involves measuring the area under peak with a planimeter. This method also accommodates distorted peaks.

In disc integrator method, the irstrument is attached to a recorder pen. When the chromatograph is drawn, the integrator gives a number which is directly proportional to the peak area.

In electronic integrator system, the detector response is fed to an electronic integrator and is converted into a frequency such that the sum of the pulses are proportional to the area under the curve. This method is fast and accurate but it is expensive. Electronic 
integrators and computers are the commonly used instruments for collecting output data of a chromatogram. These are capable of measuring and reporting peak heights and peak areas for complex peaks.

\subsubsection{Standardization}

This is the process by which the detector response is related to the amount of samplecomponents present in the injected sample. There exists a linear relationship between the size of the peak and the amount of the particular component injected. All calibration procedures involve finding this linearity for quantitative analysis and the retention time for qualitative analysis. Although linearity exists for all components in general, it does not remain the same for different components and has to be determined individually for all components analyzed in the sample matrix. This linearity is defined by the response factor(R) and is given by the Equations (3.1) or (3.2).

Since this response factor is not unique for all solutes present in a sample introduced. a relative response factor $\left(R_{R}\right)$ is introduced with respect to a reference compound.

$$
R_{R}=\frac{\text { Response Factor of a Analyte }}{\text { Response Factor of a Reference Compound }}(3.7)
$$


There are several methods in literature by which the calibration methods are standardised. These include internal normalization, external standardization, internal standardization and sample addition methods. These are discussed individually below.

\subsubsection{Internal Normalization}

In this method, individual weights of the sample components in the injected sample are calculated from the chromatogram and given as a weight ratio. The disadvantage of this method is that regardless of the components of interest, all components should be separated. A standard is prepared by adding known amounts of components present in sample. Then both sample and the standard are tested chromatographically under similar operational and instrumental conditions. Table 3.2 shows a set of data required for internal normalization method. The method of calculation is she wn below.

\section{Typical Measurements taken for a Standard}

\begin{tabular}{cccc}
\hline $\begin{array}{c}\text { Coniponents } \\
\text { present }\end{array}$ & $\begin{array}{c}\text { Weights } \\
\text { added/(gm) }\end{array}$ & $\begin{array}{c}\text { Area/( } \mathrm{cm}^{2)} \\
\text { under the peak }\end{array}$ & $\begin{array}{c}\text { Weight/Area } \\
\left(\mathrm{gm} / \mathrm{cm}^{2}\right)\end{array}$ \\
\hline$C_{1}$ & $\mathrm{~m}_{1}$ & $\mathrm{a}_{1}$ & $\mathrm{r}_{1}$ \\
$C_{2}$ & $\mathrm{~m}_{2}$ & $\mathrm{a}_{2}$ & $\mathrm{r}_{2}$ \\
$\mathrm{C}_{1}$ & $\mathrm{~m}_{1}$ & $\mathrm{a}_{1}$ & $\mathrm{a}_{1}$ \\
$C_{\mathrm{n}}$ & $\mathrm{m}_{\mathrm{n}}$ & $\mathrm{a}_{\mathrm{n}}$ & $\mathrm{r}_{\mathrm{n}}$ \\
\hline
\end{tabular}

Table 3.2

Chromatographical Techniques 
If the area obtained for the component " $n$ " in sample from chromatogram is $a_{n \text { sample, }}$ and the amount present is $m_{n \text { sample }}$, the amount is found by:

$$
m_{n} \text { sample }=r_{n} \times a_{n} \text { sample } g m
$$

The percentage of sample component " $n$ ", (pm) $)_{\text {sample }}$, given by Equation (3.9).

$$
(\mathrm{Dm})_{n \text { sample }}=\frac{m_{n \text { sampie }}}{\sum m_{n \text { sample }}} \times 100
$$

Where $\mathrm{n}$ is the number of solutes present in the sample. Similarly, the percentage of mass is found for all solutes present in the sample. Normally the value $\Sigma(\mathrm{pm})_{\mathrm{n} \text { sample }}$ should be added up to hundred. If it is not, it should be normalized. This method requires that the detector responds somewhat equally to all components. Therefore electron capture and flame photometric detectors are not suitable (Debbrecht, 1985). Normally the response factor remains constant as far as the operational conditions remain constant (Debbrecht, 1985). FD is relatively insensitive to flow and temperature changes, and therefore it is ideal for internal normalization. 


\subsubsection{External Standardization}

As in the normalization method, a standard is prepared by adding known amounts of solutes present in the sample in the external standardization method. Then both the standard and the sample are tested chromatographically under similar conditions. For the standard with a known concentration the calibration curve, detector response vs concentration, is drawn for all interested olutes. An example is shown in Figure 3.5. The unknown amount of the solute present in the sample is directly found from the particular solute's calibration curve. It is also possible that a standard can be any compound provided the relative response factor is found for calibration (Navak, 1988). 


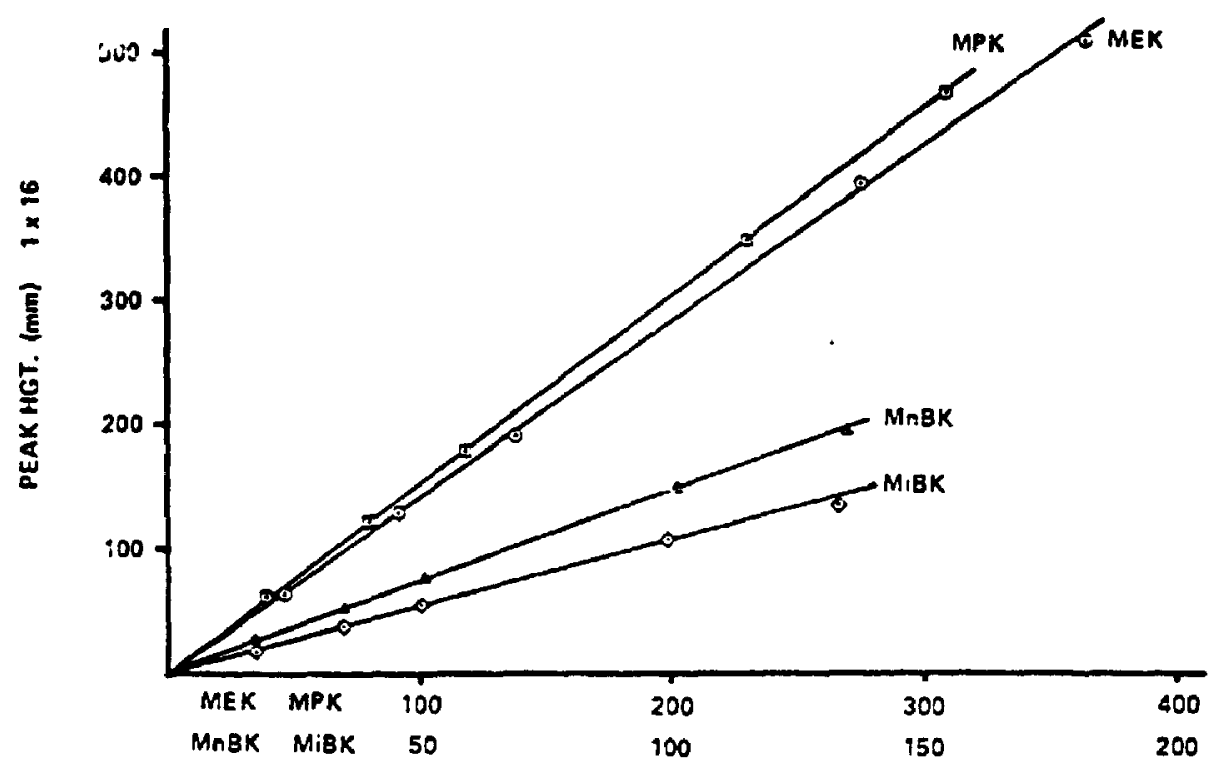

MEK: 2-butanone, MPK: 2-pentanone, MnBK: 2-hexanone, MiBK: 2-methy'1, 4-pentanone

Fig're 3.5

Calibration Curves of Standards, Debbresht, 1985 


\subsubsection{Internal Standardization}

In this method, a pure fo , of each of the solutes of interest is mixed with the internal standard. An internal standard is one which does not have any constituents which are present in the sample. The number of such mixtures prepared will be equal to number of the interested solutes present in the sample. Each such mixture is tested and the peak size is measured for the internal standard and the solute. From the peak size measurement and from the known amounts of internal standard and the solute the " $K$ " value is computed by the Equation (3.10).

$$
K=\frac{\text { Weight Ratio }}{\text { Area Ratio }}
$$

This " $\mathrm{K}$ " value is ccmputed for all the components by testing all such mixtures. Then a known amount of internal standard is added to the actual sample to be analyzed and the peak size is measured for each of the interested solutes and for the internal standard. The individual ratio of area of the internal standard to the interested solute is computed and corresponding weigit ratio is found by multiplying this ratio by K. Since the amount of internal standard added is known, the unknown amount of solute $i n$ the sample is found. This methed does not require the standards and the sample to be tested under similar conditions as in external standard method. The internal standard should be such that:

It is well separated from the other components:

Chromatographical Techniques 
It should not react with sample;

It should be similar in functional group type to the components of interest. If such a component is not readily available a hydrocarbon substance should be substituted (Debbrecht, 1985, Poole et al., 1985).

The most commonly used internal standards include analogs, homologs, isomers, enartiomers, and isotopically labelled analogs of the analyte to be determined (Poole et al., 1985). Among these. widely available substances are analogs and homologs.

\subsubsection{Standard Addition Method}

In this method. a portion of the unknown sample is tested chromatographically. Then a known amount of each of the interested solutes is added to individual portions similar to the unknown portion of sample analyzed before. Then each such portion with known amount of interested solute is tested chromatographically under exactly similar operational conditions as those applied before. Since there exists a linearity between the amount of sample and the detector response, the unknow.. weight is calculated as follows:

Assume one of the interested solute is " $\mathrm{A}$ "

Assume the amount of solute "A" present in the sample portion analyzed $\quad=\mathrm{W}_{\mathrm{a} 0}$

The area under the solute peak " $\mathrm{A}$ "

$=\mathrm{A}_{0}$

The amount of solute "A" is added to a portion of sample similar to

the original sample analyzed

$=\mathrm{w}_{\mathrm{a} 1}$

Cl romatographical Techniques 
The area under the solute-peak " $\mathrm{A}$ "

From linearity;

$\begin{array}{lll}\mathrm{W}_{\mathrm{a} 0} & \propto & \mathrm{A}_{0} \\ \mathrm{~W}_{\mathrm{a} 0}+\mathrm{W}_{\mathrm{a} 1} & \propto & \mathrm{A}_{1}\end{array}$

From the above two relationship,

$$
W_{a 0}=\frac{W_{a 1}}{\left[1-\frac{A_{1}}{A_{0}}\right]}
$$

Similarly amounts of all unknown components are determined. The disadvantage of this method is that several chromatographical runs are required. Moreover, there may be errors due to the matrix effect since the matrix is changed when each time the analyte is added to the original sample. 


\subsubsection{Calibration Methods for Headspace Analysis}

In the chromatographical analysis of the samples, only a small part of the sanple is analyzed by the GC to characterize the sample. When a single-phase-sample (liquid or gas) is tested, the concentration of the constituents in the part of the sample analyzed will be the same as those in the sample. The headspace analysis is applied for multi-phasesample (iiquid-gas or solid-gas) and a part of the gaseous phase is analyzed to characterize the multi-phase-sample. In this case, the concentration of the constituents in the part of the gaseous phase of the sample analyzed will not be the same as those in the multi-phase-sample. This necessitates additional calibration when the headspace analysis is carried out. This can be done experimentally or from theoretical deductions concerning solute distribution into different phases. Some of the theoretical methods given by Drozd et al.. 1079 are given below.

Consider a simple two phase liquid-gas system. According to the mass balance equation.

$$
W_{1}=C_{1 G}\left(K_{1} V_{L}+V_{G}\right)
$$

where

$$
\begin{aligned}
& \mathrm{W}_{1}=\text { Total mass of solute } \mathrm{i} \text { in the closed vial } \\
& \mathrm{C}_{1 \mathrm{G}}=\mathrm{W}_{1 \mathrm{G}} / \mathrm{VG} \\
& \mathrm{W}_{1 \mathrm{G}}=\quad \text { Mass of solute "i" present in the vapour phase } \\
& \mathrm{K}_{1}=\text { The distribution constant } \\
& \mathrm{V}_{\mathrm{L}}=\text { Volume of the liquid phase in the vial } \\
& \mathrm{V}_{\mathrm{G}}=\quad \text { Volume of the gas-phase in the vial }
\end{aligned}
$$


$W_{1 G}$ can be found by chromatographical analysis and if $K_{1}, V_{L}$, and $V_{G}$ are known the $W_{\text {, }}$ can be found. $V_{L}, V_{G}$, can be found by measuring the volumes but in many cases. $K_{t}$ is not known for real samples. Drozd et al., 1979, suggested some methods to eliminate $\mathrm{K}_{\text {, }}$ or the factor $\left(\mathrm{K}_{1} \mathrm{~V}_{\mathrm{L}}+\mathrm{V}_{\mathrm{G}}\right)$ as a whole. These are discussed below:

\section{(a) Elimination of $\mathrm{K}$}

In this approach $K_{1}$ from Equation (3.12) is eliminated by raising the temperature to a value at which the liquid-gas system become one phase-gas system. Under this condition Equation (3.12) becomes:

$$
\mathrm{w}_{1}=\mathrm{C}_{\mathrm{IG}} \times \mathrm{v}_{\mathrm{G}}
$$

By analyzing $C_{1 G}$ with a $G C$ and measuring the volume $V_{G}$ the amount $W_{1}$ can be determined. However it is not always possible to convert the liquid-gas system to gas only system.

\section{(b) Elimination of Factor $\left(K_{1} V_{\perp}+V_{c}\right)$ using - Reference Model}

In this system a standard is prepared with a known amount of solutes of interest with the composition being the same to that of the sample matrix. Then the standard and the sample is tested chromatographically under similar experimental conditions separately. In addition the equilibrium condition for headspace analysis is achieved for both sample and standard in equal volume vials with samc amount of sample and standard. Under 
such conditions the factor $\left(K_{l} V_{L}+V_{G}\right)$ is same for the standard and the sample. Equation (3.12) became for the standard and the sample:

$$
\begin{array}{lll}
\mathbf{W}_{1}^{*}= & \mathrm{C}_{\mathrm{i}} \cdot\left(\mathrm{K}_{\mathrm{l}} \mathrm{V}_{\mathrm{L}}+\mathrm{V}_{\mathrm{G}}\right) \ldots \ldots \ldots \ldots & \text { Standard } \\
\mathbf{W}_{1}=\mathrm{C}_{\mathrm{G}}\left(\mathrm{K}_{\mathrm{l}} \mathrm{V}_{\mathrm{L}}+\mathrm{V}_{\mathrm{G}}\right) \ldots \ldots \ldots . & \text { Sample }
\end{array}
$$

From the above equations by eliminating the factor $\left(K_{,} V_{L}+V_{G}\right)$ :

$$
\mathbf{W}_{1}=\mathrm{W}_{1}^{*}\left[\mathrm{C}_{\mathrm{iG}} / \mathrm{C}_{1 \mathrm{G}} \mathrm{i}\right]
$$

Since $W_{1}^{*}$ is known and by measuring $C_{1 G}$ and $C_{1 G} \cdot$ by any of the chromatographical methods $W_{\text {, can }}$ be found. This method has serious limitations since preparing the standard simulating the sample matrix is often not easy.

(C) Eliminating $\left(K_{1} V_{\perp}+V_{0}\right)$ by Standard addition method

In this method, the sample is allowed to equilibrate in a vial and the gaseous phase is withdrawn and analyzed. After that a known amount of solute is added to the system and allowed to equilibrate again. Once the equilibrium achieved. again the gaseous phase is analyzed.

For the origina' sample from mass balance:

$$
W_{1}=C_{1 G 0}\left(K_{1} V_{L}+V_{r}\right)
$$

After withdrawing and addition of solute i. mass balance: 


$$
\mathrm{W}_{\mathrm{i}}-\mathrm{w}_{\mathrm{l}}+\mathrm{W}_{\mathrm{s}}=\mathrm{C}_{\mathrm{IG} 1}\left(\mathrm{~K}_{\mathrm{i}} \mathrm{V}_{\mathrm{L}}+\mathrm{V}_{\mathrm{G}}\right)
$$

Where $w_{i}$ is the amount of sample component $i$ present in the gaseous phase withdrawn for the analysis and $W_{s}$ is the amount of component $i$ added.

From the above two equations, eliminating $\left(\mathrm{K}_{1} \mathrm{~V}_{\mathrm{L}}+\mathrm{V}_{\mathrm{G}}\right)$,

$$
W_{i}=\frac{W_{s}-w_{i}}{\left[\frac{C_{i G 1}}{C_{1 G 0}}-1\right]}
$$

(d) Elimination of ( $\left.\mathrm{KV}_{\mathrm{L}_{1}}+\mathrm{V}_{\mathrm{a}}\right)$ by subsequent withdrawal and analysis of gaseous phase after equilibrium

For the original sample the mass balance becomes:

$$
\mathrm{W}_{1}=\mathrm{C}_{\mathrm{IG}}\left(\mathrm{K}_{1} \mathrm{~V}_{\mathrm{L}}+\mathrm{V}_{\mathrm{G}}\right)
$$

For the consequent analysis after withdrawing sample, from mass balance,

$$
\mathrm{W}_{1}-\mathrm{W}_{1 \mathrm{GO}}=\mathrm{C}_{\mathrm{GII}}\left(\mathrm{K}_{1} \mathrm{~V}_{\mathrm{L}}+\mathrm{V}_{\mathrm{G}}\right)
$$

From a similar computation as in Method c, 


$$
W_{1}=\frac{W_{160}}{\left[1-\frac{C_{2 G 1}}{C_{260}}\right]}
$$

Where $\mathrm{W}_{\mathrm{iGo}}$ is the amount of component $\mathrm{i}$ in the gaseous phase of the original system and $\mathrm{C}_{1 \mathrm{Go}_{0}}$ and $\mathrm{C}_{\mathrm{IGI}}$ are the concentration of gaseous phase of the sample before and after withdrawal of gaseous phase for analysis. Since these three values can be find by chromatographical analysis, the original amount of solute " $i$ " present in the sample is calculated from the equation above.

In methods discussed in b, c, d. it is assumed the value of the distribution factor $K_{1}$ will not be altered due to minor changes in concentration levels of solutes.

\section{(e) Discontinuous Gas Extraction}

This method has been developed for quantification of volatile compounds in solid matrix (Kolb, 1976). The arrangement of the apparatus is shown in Figure 3.6. While the solid sample is heated in glass tube, the carrier gas is bypassed through path " $b "$ ". Once the sample is thermostated, the carrier gas is flushed through the tube containing solid sample (path "a"). During this, the vapour containing volatile contaminants will be introduced into the GC column. The same procedure is repeated several times. The extraction procedure follows exactly an exponential relation (Kolb. 1976) and therefore the original 
concentration can be found by extrapolating the curve $\log (\mathrm{A})$ vs $\mathrm{N}$ shown in Figure 3.7, where $\mathbf{N}$ is the number of extractions. The same graph is drawn for each components and the concentration is determined similarly.

where

$$
\begin{aligned}
& A=\text { the area under the component peak } \\
& N=\text { number of withdrawals }
\end{aligned}
$$




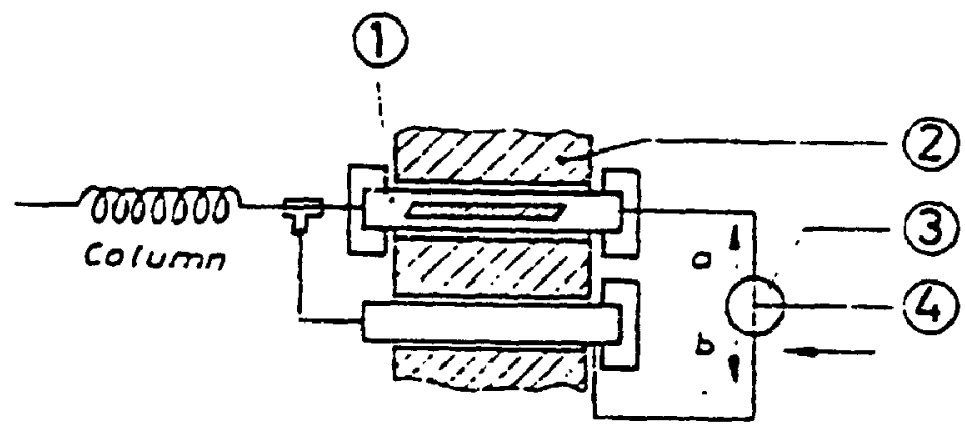

Figure 3.6

Discontinuous gas extraction apparatus, Kolb, 1976

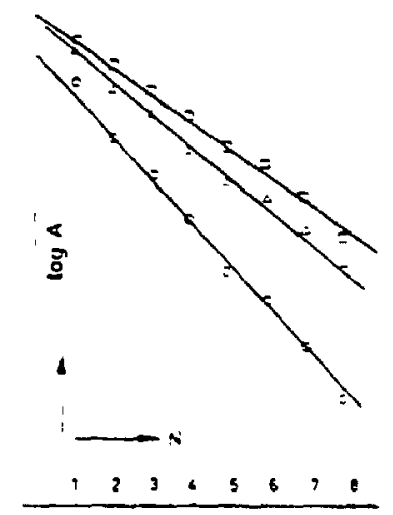

$\square$ Ethyl acetate

$\Delta$ Ethanol

- Toluene

Where $\mathrm{A}$ is the peak area and $\mathrm{N}$ is the number of extraction

Figure 3.7

Calibration Curve For Discontinuous Extract:on, Kolb, 1976 


\section{Chapter 4}

\section{Spectrographical Techniques}

\subsection{Overview}

Spectrographical techniques also have been used to identify soil contamination with hydrocarbons but to a lesser extent compared to chromatographical techniques. In this method compound characteristics are identified by measuring adsorption, reflection or emission of various wave-length electromagnetic radiation by the compound. As in chromatographical methods, the qualitative analysis is carried out by comparing the spectrograms of the known standards and the samples. The quantitative analysis is carried out by measuring the amount of adsorption, reflection or emission of radiation by the sample. In spectrographical methods constituents in a sample can be selectively identified. Some of the problems due to the presence of impurities can be reduced by choosing proper range wave-length radiation and by appropriate sample preparation.

To understand spectral phenomena, it is vital to be familiar with some of the terms used in spectrography. A spectroscope is a device which separates radiation into constituent frequencies and presents them for visual inspection. A spectrometer is a device which allows measurement of frequencies in addition to separate radiation into constituent frequencies. A spectrophotometei measures energy of each wave-length in addition to 
separating and measuring the individual frequency of individual wave-length.

A spectrophotometer basically consists of a source of radiation, a tubular cell in which sample under spectral analysis is contained, a monochromator which separates radiation according to its wave-length, and a detector to measure absorbance, reflection or emission of particular wavelength radiation by the sample filled in the cell. A typical single-beam infrared spectrometer with prism monochromator is shown in Figure 4.1.

In spectral analysis, radiation from a source is transmitted through the sample cell and consequently separated according to its wave-length by the prism. Prior to entering the monochromator (prism). the radiation is made parallel by a suitable mirror. When radiation exits the prism, it is separated according to its wave-lengths. The separated wave-length is focused to an exit slit " $S_{q}$ ", one specific wave-length radiation at a time by a rotating mirror "L" (Figure 4.1). The radiation throus.1 the exit slit is directed to the detector where the magnitude of the radiation is measured. Once the specific radiation is measured the radiation for another wave-length is measured by rotating the mirror. The detector's function in spectral analysis is to change the illumination level of radiation into electrical signal so that sample's transmission can be measured. Similar to chromatogram, a spectrogram is a plot of me usured parameter vs wave-length. These spectrograms are characteristics of compounds and are used in identifying unknown compounds provided Spectrographical Techniques 


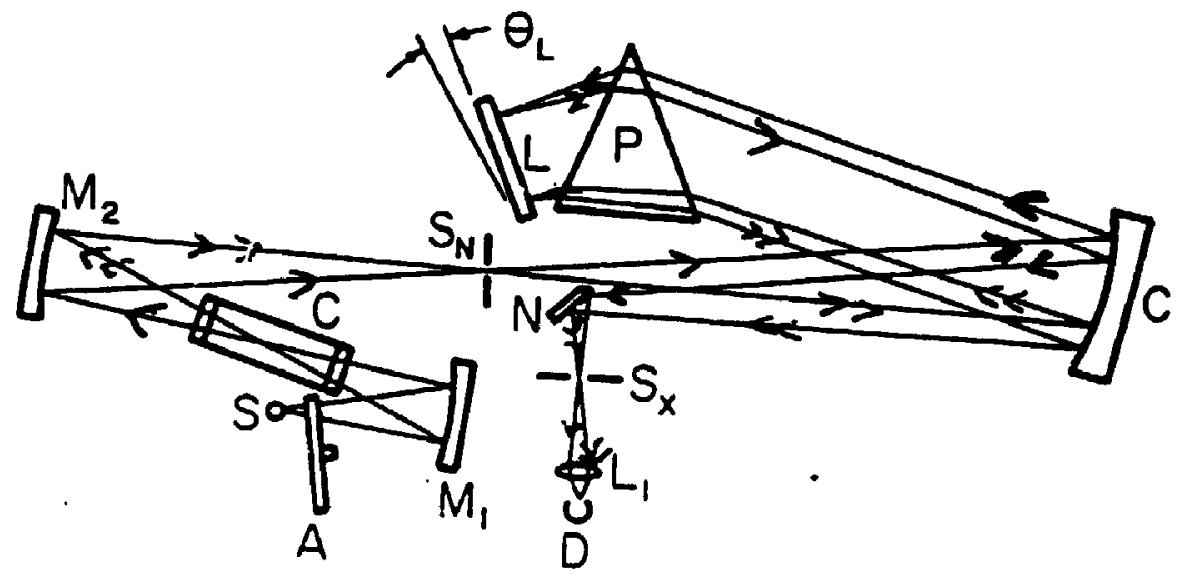

Figure 4.1

A Typical Single-beam Infrared Spectrometer with Prisin Monochromator Stewart, 1970 
the instrument is calibrated prior to use sith know.. standards. Radiant energy is emitted in the form of electromagnetic waves. The electromagnetic spectium has a set of electromagnetic waves having various wave-lengths emitted by' a source. The wavelength is measured in microns, or micrometers $(\mu \mathrm{m})$ and the frequency is measured as wave number $v$.

where

$$
v=\frac{f}{\sigma} \mathrm{cm}^{-}:
$$

where $c$ is the velocity of electromagnetic radiation in frci space and equal to $2.99776 \times 10^{10} \mathrm{~cm} / \mathrm{sec}$

The radiation emitted by a source is classified into various regions including $\mathrm{X}$-ray. ultraviolet. visible. infrared. and microwave reginn. Each of such re:ion $c$ insists ol a particular range of wave-length. Spectral instruments are classified according to the range of wave-lengtì radiation used in the analysis (eg. ultraviolet spectrome.er. fluoriscence spectrometer and infrared spectrometer). 

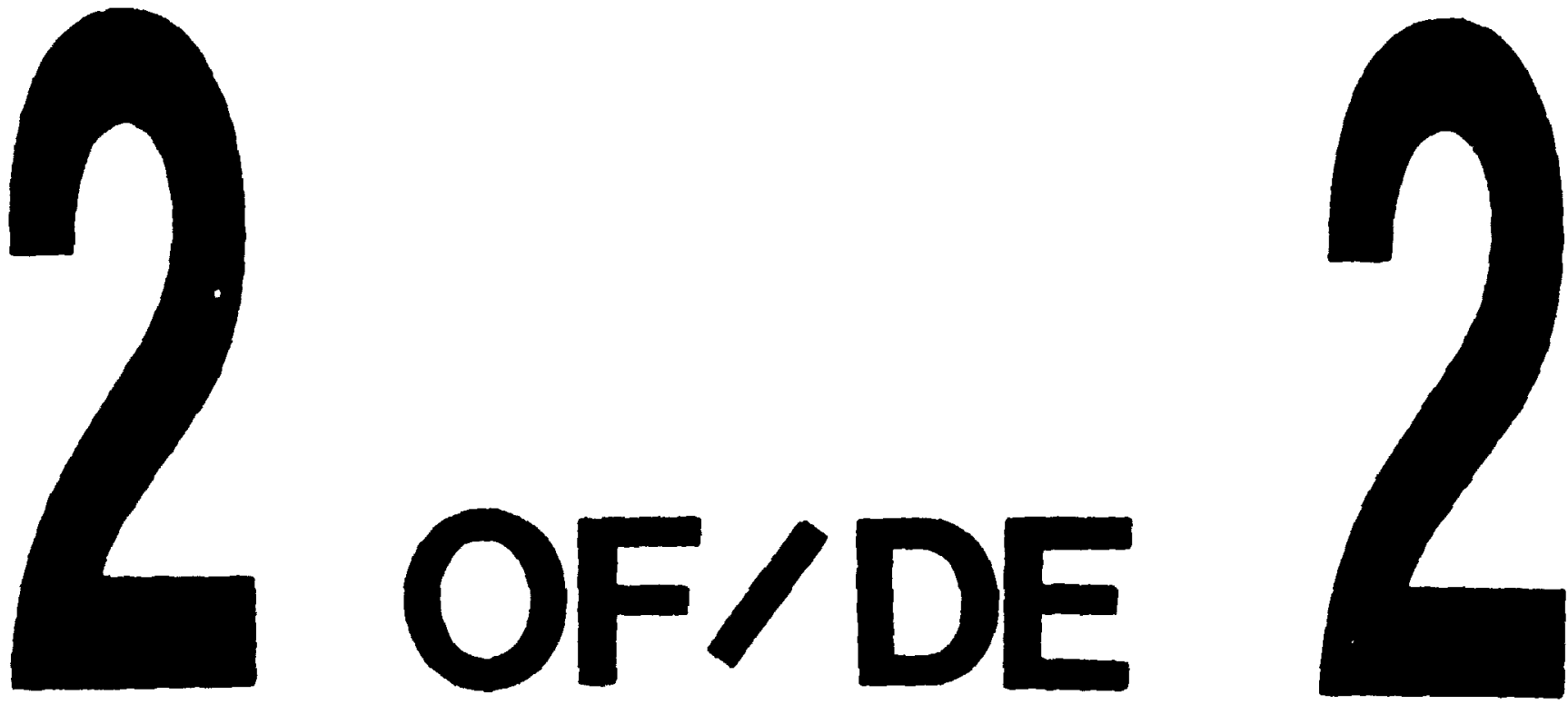

PM-1 3\%" "4" PHOTOGRAPHIC MICROCOPY TARGET NAS 1010a AMSI/ISO \#2 EOUIVALENT

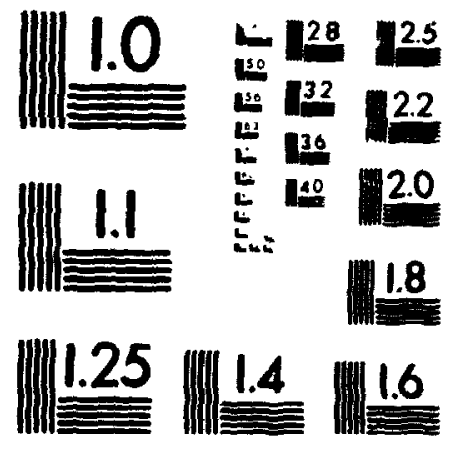




\subsection{Theory of Spectrography}

\section{Absorption law or Beer's Law}

If $I_{o}$ is the intensity of radiation entering the sample and $I$ is the intensity transmitted by the sample, then

$$
\frac{I}{I_{0}}=T
$$

If the thickness of the sample cell is " $b$ " and the absorbing component has a concentration c. then the fundamental equation goveming the absorption of radiation is:

$$
\begin{aligned}
& T=I / I_{o}=10^{-3 b c} \\
& \text { from this } \\
& \log _{10}\left\{I_{\sigma} / I\right\}=a b c
\end{aligned}
$$

If $\log _{10}\left\{I_{0} /\right\} \cdot s$ defined as $A$

$$
A=a \times b \times c
$$

Where $\mathbf{A}$ is called absorption, and " $\mathrm{a}$ " is a constant and the characteristic for a specific sample at a specific wave-length. Beer's law is considered to be additive and therefore

$$
A={ }_{1=1}^{n} a_{1} b c_{1}
$$




\subsection{Types of Spectrometers Used in Hydrocarbon Analysis}

\section{(a) Infrared Spectrophotometry}

This is suitable for analysis of aliphatic hydrocarbons in soil or sediment water. After extracting hydrocarbons from a sample, the extract is subjected to infrared radiation. The resulted spectrum is compared to standards by infrared analysis.

The portable infrared analyzer measures the infrared radiation. Infrared radiation is the electromagnetic radiation with wave lengths ranging from 0.78 micrometers to 1000 micrometers. The relative positions of atoms in a molecules changes as a result of vibration. When a molecule subjected to infrared radiation, certain wavelengths of IR radiation will be absorbed creating adsorption bands. These adsorption bands are characteristics of molecules or substance, and are used to identify compounds in an analytical application.

The wavelength of IR radiation adsorbed by the $\mathrm{C}-\mathrm{H}$ bond is 3.48 micrometers. The portable infrared analyzer used in the field screening application of hydrocarbon detection utilizes a narrow barud of IR spectrum of wavelength around 3.48 micrometers. The qualitative analysis is based on comparing the adsorption bands of the sample to the known patterns of hydrocarbon standards. The quantification is carried out by calibrating the instrument with absorption of known concentration of total petroleum hydrocarbon. 
From Beer's law, conceitration "C" is directly proportional to adsorption " $A$ ".

$$
\begin{aligned}
& C \propto A \text { from this } \\
& C=K \times A
\end{aligned}
$$

Where $K$ is a constant associated with cell path length, the adsorption coefficient of compounds involved and other variables. $\mathrm{K}$ is found experimentally and is the gradient of "C" vs "A" graph.

Before analyzing soil samples by infrared analyzer. the hydrocarbon is extracted from soil with a reagent which does not have bonds that adsorb IR radiation in the same region which $\mathrm{C}-\mathrm{H}$ bonds absorb. The $\mathrm{O}-\mathrm{H}$ bond adsorbs the same waveiengths as $\mathrm{C}-\mathrm{H}$ bonds and therefore water molecules are removed before analysis. A suitable reagent is trichlorotrifluroethane (Freon). Addition of silica gel to the extracted solution will remove polar compounds such as water, soaps, alcohols, pesticides and fertilizers. The extracted and cleaned up solution is then subjected to IR radiation.

\section{(b) Ultraviolet Spectrophotometry}

This method is used for analysis of aromatic hydrocarbons. Aromatic hydrocarbons absorb radiation having the wave-length range of 225 to 325 micrometers. In this method the sample is extracted with an appropriate solvent and subject to ultraviolet radiation. 
The hydrocarbon content is calculated by measuring the adsorption of light at a wavelength within the range 225 to 325 micrometers (usually 254 micro meter).

\section{(c) Fluorescence Spectroscopy}

This method is used to analyze aromatic hydrocarbon contents in sediments/water. In this method the extract of the sample is analyzed by fluorescence spectroscopy. 


\section{Chapter 5}

\section{Degradation and Migration of Petroleum}

\section{Products in Soil}

\subsection{Overview}

The aim of this chapter is to discuss the effects of degradation and migration of petroleum products in soil on the analytical test results. As discussed in Chapter 1. petroleum products degrade in soil. The processes which cause degradation of petroleum products in soil include adsorption. migration. decomposition. dissolution. and chemical and biological activities. The hydrocarbons which are leaked or spilled in soil migrate downward in the unsaturated zone due to gravity and capillary forces (Dragun et al.. 1991). Migration eventually ceases when the spill reaches the capillary fringe or when the soil reaches its residual saturation. The volume of soil polluted as a result of a spill depends on various factors including the amount of spill and the properties of the spill and the soil.

Hydrocarbons consist of numerous constituents which have different properties. While migrai ion is taking place, some of the constituents may be adsorbed on soil particles and organic matter. Subsequently their migration is retarded. Another portion of constituents which are volatile escapes to soil vapour. Also constituents which are susceptible to 
degradation processes are transformed into different products which might not be originally present in the spilled product.

Identification of petroleum leaks or spills in soil is carried out by analyzing soil or vapour samples collected from the suspected places. Generally the volume of the sample taken is much smaller than the volume of soil polluted. Consequently it is not possible to take a sample containing all the constituents present in the original product. The constituents of the spill trapped in the sample taken depends on the place and the time at which the sample is taken. Within the constituents which are trapped into the sample matrix taken, transformed constituents may also be present. As discussed earlier, the identification of spills or leaks is based on comparison of chromatograms of possible petroleum products (standards) to that of samples. In obtaining standards, suspected petroleum product are mixed with the type of soil under investigation and the extract is rested chromatographically. In that manner most of the constituents may be identified as the simulated sample (standard) but less subjected to degradation processes compared to the actual sample in the field. In some studies, attempts were made to simulate the field conditions by allowing the sample to undergo synthetic degradation. However, it is difficult to simulate the exact field situation.

From the above discussion it should be understood that even if there is a variation in the 
chromatograph of the sample it could still be a relevant identification of the expected spill. However for reliable interpretation of test re ults which accompanying such variations, the possible variations in patterns should be definable. This chapter provides some of the criteria on which the migration and transformation depend.

\subsection{Migration/Transport of Petroleum Products}

The migration of petroleum products when they are leaked from storage tanks is influenced by several factors. The transport of petroleum constituents in the unsaturated region is caused by vapour migration and by percolating rain water.

Volatile substances of the refined petroleum product stored in the underground storage tanks, when exposed to standard atmospheric pressure and temperature. escape to the vapour phase (Schwendeman, 1987). These constituents will be carried by the vapour in the unsaturated zone. The transport of vapours in the unsaturated zone is governed by the diffusion and convection process. Diffusion is the process by which vapour molecules migrate as a result of concentration gradient. The diffusion process is described by Fick's first law. Corvection is the process by which molecules migrate in the vapour phase as a result of pressure gradient.

Some amount of leaked petroleum product will reach the water table either by gravity or 
by percolating rain water. The miscible constituents will be transported with the groundwater by the processes of advection and dispersion. Advection is the process by which dissolved organic substances are transported by the bulk motion of flowing groundwater. The dispersion is the process by which constituents -pread while groundwater flow occurs as a result of molecular diffusion caused by concentration gradient. While advection and dispersion are taking place, some of the constituents will be retarded by the process called sorption. Sorption is the process by which constituents are adsorbed on the solid particles encountered in the constituent's migration path.

Transport of immiscible substances which reach groundwater will depend on the density of the substances. The density of gasolines and petroleum distillates is commonly less than the density of water. As a result immiscible components of gasolines and petroleum distillates which reach groundwater will float in the groundwater and in the capillary zone of the groundwater system. Their migration is regulated by viscosity and surface wetting properties (Schwendeman, 1987).

\subsection{Transformation of Petroleum Products in Soils}

Petroleum products are transformed into various products as a result of biological anci chemical process. The biological transformation is caused by the microorganisms present in soil. The principal chemical reactions are hydrolysis and oxidation (Schwendeman, 
1978).

\subsubsection{Biological Transformation}

Microbial degradation of petroleum products in soil is a common phenomenon. Studies conducted on synthetic degradation of crude oils by microorganisms showed paraffinic hydrocarbons are easily degraded while aromatic hydrocarbons are preferentially resistant against biodegradation (Puttmann, 1988). The factors influencing biological degradation include the quality and the composition of the hydrocarbon, availability of oxygen. nitrogen, and phosphate, and PH-value, temperature and moisture content of the soil. Presence of high molecular weight or chlorinated organics may inhibit biological transformation or reduce its speed.

The transformation products resulting from biodegradation may have characteristics different from the original product and this will produce a slightly different chromatogram from the one obtained from the standard tests. For instance polar transformation products of aromatic hydrocarbons are more water soluble compared to the original product. Therefore these components will be removed from the spill by percolating rain water. Also in some cases this transformed products have no response to a particular analytical method. In infrared analysis, the polar transformation products of aromatic hydrocarbons produced by microorganisms will not be identified (Puttmann, 1988). 
Figure 5.1 shows a gas chromatogram of an extract (dichloromethane) obcained from a soil contaminated by gas oil (diesel or fuel oil) (Puttmann, 1988). In this chromatogram n-alkanes (potential nutrition for microorganisms) are removed and other constituents found to be greater in concentrations. The compounds found in degraded products in this example are called isoprenoid hydrocarbons and are less subject to microbial degradation. In addition biodegraded gas oils have a hump on baseline in the lower boiling point region. 


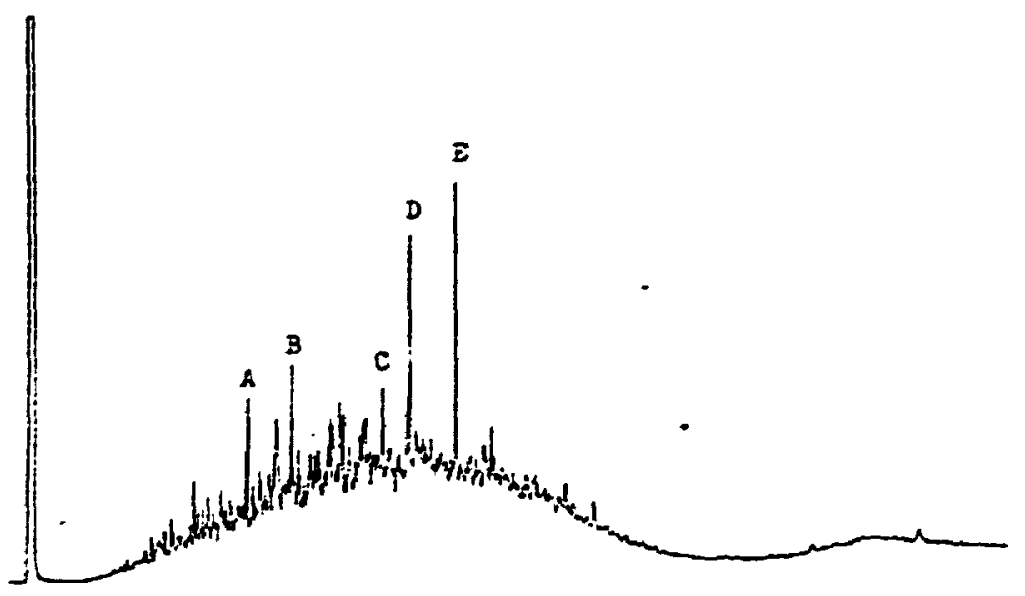

A-Farnesane, B- $\mathrm{C}_{16}$-Isoprenoid, C-Norpristane, D-Pristane, E-Phytane

Figure 5.1

Gas chromatogram of the Extract Obtained from a Gas Oil Contaminated Soil

Puttmann, 1988 


\subsubsection{Chemical Transformation}

Commonly cccurring chemical reactions in soil include oxidation, reduction, hydrolysis, substitution and elimination. Among these, the principal chemical reactions are oxidation and hydrolysis (Schwendeman, 1987). The chemical reactions that transform some of the organic chemicals found in diesel fuel ari oxidation and reduction (Dragun et al., 1991).

In oxidation process, electrons are removed from a chemical compound. For oxidation to occur, the potential of the soil system must be greater than that of the organic chemical under consideration (Dragun et al., 1991).

In reduction process, organic chemicals gain electrons. Reduction generally takes place if the potential of the soil system is less than that of the chemical under consideration. 


\section{Chapter 6}

\section{Experiment}

\subsection{Overview}

This chapter summarizes the laboratory analysis carried out on the soil samples to test the possibility of qualitative and quantitative identification of petroleum contaminated scils by analyzing the soil vapour samples extracted from the potential contaminated places. To simulate the field conditions, petroleum contaminated soil samples were prepared in closed glass vials and the vapour in the sample vial was analyzed by gas chromatography(GC). The interpretation of the test results was based on the overall pattems of the chromatograms made of unresolved peaks rather than analyzing the components individually (a detail discussion on the data interpretation of the chromatographical analysis is provided in Section 3.3.1).

As discussed in Chapter 3. the efficiency of the chromatographical analysis is highly dependent on the selection of the parts of the instrument (detector and column) and the experimental conditions. Section 6.1 lists the apparatus used for the experiment including the main components of the GC (detector and the column) selected. The GC was selected for the chromatographical analysis of samples for various reasons discussed in chapter 3 . The detector employed was a flame ionization detector (FID) for reasons discussed in 
Section 3.1.2.1. The FID needs three gas streams, a carrier gas, hydrogen and air, to support combustion of the GC effluent. The GC column and the carrier gas selected were the Ultra Alloy-1 capillary column and $\mathrm{N}_{2}$ respectively.

Having selected the type of the detector, column, and gases, the experimental conditions to be found for efficient analysis were the flow rates of gases and the column temperature. Section 6.2 was assigned for optimizing the experimental conditions for efficient identification.

The usual practice of quantitative identification from the chromatogram is based on the linear relation between the quantity of a specific constituent present in the injected amount of sample to the separated-peak-size of the corresponding constituent-peak. However the separation of the individual constituent-peaks was not attempted in this study as the data interpretation for the qualitative and quantitative identification was based on the overall pattern of the chrom?tograms. Section 6.3 is assigned to test the validity of this quantitative relation for the unresolved peaks.

Section 6.4 includes the laboratory analysis and the results. Since the test results of the chromatographical analysis is highly method dependent, careful attention was given to strictly define the procedures adopted for the analysis including the sampling vials used. 
Included in Sections 6.5, 6.6, 6.7, and 6.8 are the practical difficulties encountered, discussion, conclusion, and the future experiments that may be conducted.

\subsection{Apparatus}

The specifications for the test equipment, description of the soil tested and the contaminant, and the setup of equipments are described in the following.

\subsubsection{Gas Chromatometer}

equipped with

\section{-Flow System}

- Column Oven (temperature range ambient to $400^{\circ} \mathrm{C}$. and cooling rate of $400^{\circ} \mathrm{C}$ to $40^{\circ} \mathrm{C}$ in 6 minutes)

- Flame ionization detector

Delectability $9 \times 10^{-13} \mathrm{gm}$ (a measure of the smallest detectable quantity)

Sensitivity 0.01 coulombs/gm (a measure of the detector's ionization and ion collection efficiency using air to support combustion)

Linear range $3 \times 10^{7}$

Temperature limit $400^{\circ} \mathrm{C}$

- Injection port

Temperature range ambient to $400^{\circ} \mathrm{C}$

- Temperature monitoring device

Thermocouple pyrometer capable of reading temperatures of injector, column oven and detector

Electrometer (converts the small current changes at the output of the ionization detector 
to representative voltage changes which are capable of driving a recorder pen, integrator or computer)

Sensitivity $1 \times 10^{-12} \mathrm{Amp} / \mathrm{mv}$

Noise less than $10 \mu v$ at maximum, sensitivity

-Ultra-ALLOY-1 capillary column

Phase:

UA-1 (100\% dimethylsilicone)

Column length:

$15 \mathrm{~m}$

Internal Diameter:

$0.8 \mathrm{~mm}$

Film thickness:

2 micron

Maxim'ım temperature

(at isothermal operation) $\quad 330^{\circ} \mathrm{C}$

\subsubsection{Digital Storage Oscilloscope, OS4100}

For on-line visual dispiay of chromatograms (GC output)

\subsubsection{Computer with data acquisition software to collect 10 readings/s}

\subsubsection{Gas Supply}

Carrier gas: $\quad \mathrm{N}_{2}$ with necessary pressure measuring devices and regulators

For detector: $\quad \mathrm{H}_{2}$ and Air with necessary pressure measuring devices and regulators

Soap-bubble flowmeter: To measure gas flow rates

\subsubsection{Sampling Equipments}

- Clear screw top vial $1.5 \mathrm{ml} \mathrm{w}^{: \text {th }}$ varian auto-sampler seals $8 \mathrm{~mm}$ 010 micro litre Hamilton Syrin ?, (precision 0.2 micro litre to prepare contaminated samples)

- 1/2 cc U-100 Insulin Syringe with $0.36 \mathrm{~mm} \times 13 \mathrm{~mm}$ needle 
6.1.6 Temperature Measuring Device

DigiDial temperature measuring equipment range $-40^{\circ} \mathrm{C}$ to $150^{\circ} \mathrm{C}$ to measure room temperature

\subsubsection{Samples}

Gasoline

-Soil, silica 24 (The particle size distribution and the gradation curve of the experimental soil which is clean sand are given in Table 6.0 and Graph 6.1 respectively)

\subsubsection{Mettler AT201 Weighing Machine}

Sensitivity $0.01 \mathrm{mg}$

Particle Size Distribution of the Experimental Soil

\begin{tabular}{ccccc}
$\begin{array}{c}\text { Mesh } \\
\text { Number }\end{array}$ & $\begin{array}{c}\text { Mesh } \\
\text { Size } \\
(\mathbf{m m})\end{array}$ & $\begin{array}{c}\text { Weight } \\
\text { Retaining } \\
(\mathbf{g m})\end{array}$ & $\begin{array}{c}\text { Percentage of } \\
\text { Weight } \\
\text { Retaining }\end{array}$ & $\begin{array}{c}\text { Percentage of } \\
\text { Weight } \\
\text { Passing }\end{array}$ \\
\hline 16 & 1.190 & 1541.70 & 68.41 & 31.6 \\
20 & 0.850 & 445.20 & 19.76 & 11.8 \\
30 & 0.600 & 125.40 & 5.56 & 6.3 \\
40 & 0.425 & 92.40 & 4.10 & 2.2 \\
60 & 0.250 & 38.80 & 1.72 & 0.4 \\
70 & 0.212 & 3.20 & 0.14 & 0.3 \\
120 & 0.125 & 5.00 & 0.22 & 0.08 \\
\hline 200 & 0.075 & 1.40 & 0.06 & 0.01 \\
\hline pan & - & 0.40 & 0.02 & 0 \\
\hline
\end{tabular}

Table 6.0 


\section{The Gradation Curve of the Tested Soil}

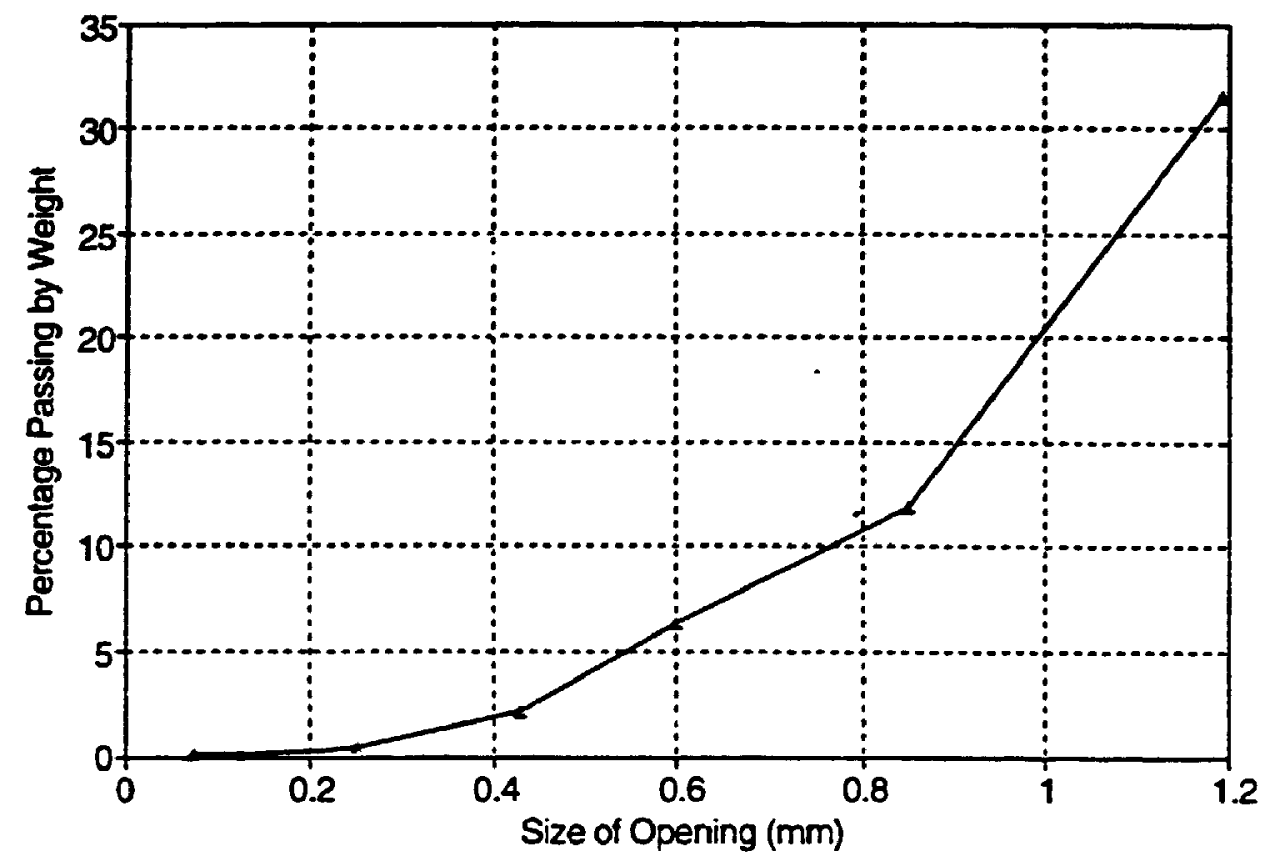

Graph 6.1 


\subsubsection{Setup of Apparatus}

Figure 6.0 (a) shows the setup of the GC used to test the soil vapour of the contaminated samples. The vapour sample is injected onto the injection port of the GC and the continuous supply of the carrier gas pushes the sample down the column. Figure 6.0 (b) shows the elongated sections of the column showing different positions of the sample while the sample travels down the column. The interior wall of the column is coated with a chemical substances called stationary phase. As a result of the chemical and the physical processes the sample undergoes between the carrier gas and the stationary phase inside the column. the sample constituents are separated in to different bands. When these separated constituent bands exit from the column the detector connected to the column identifies the characteristics of the individual constituents and provides electrical signals. The oscilloscope connected to the GC output displayed these electrical signals for visual display and the computer with data acquisition software recorded the readings at a rate of 10 readings/s. 

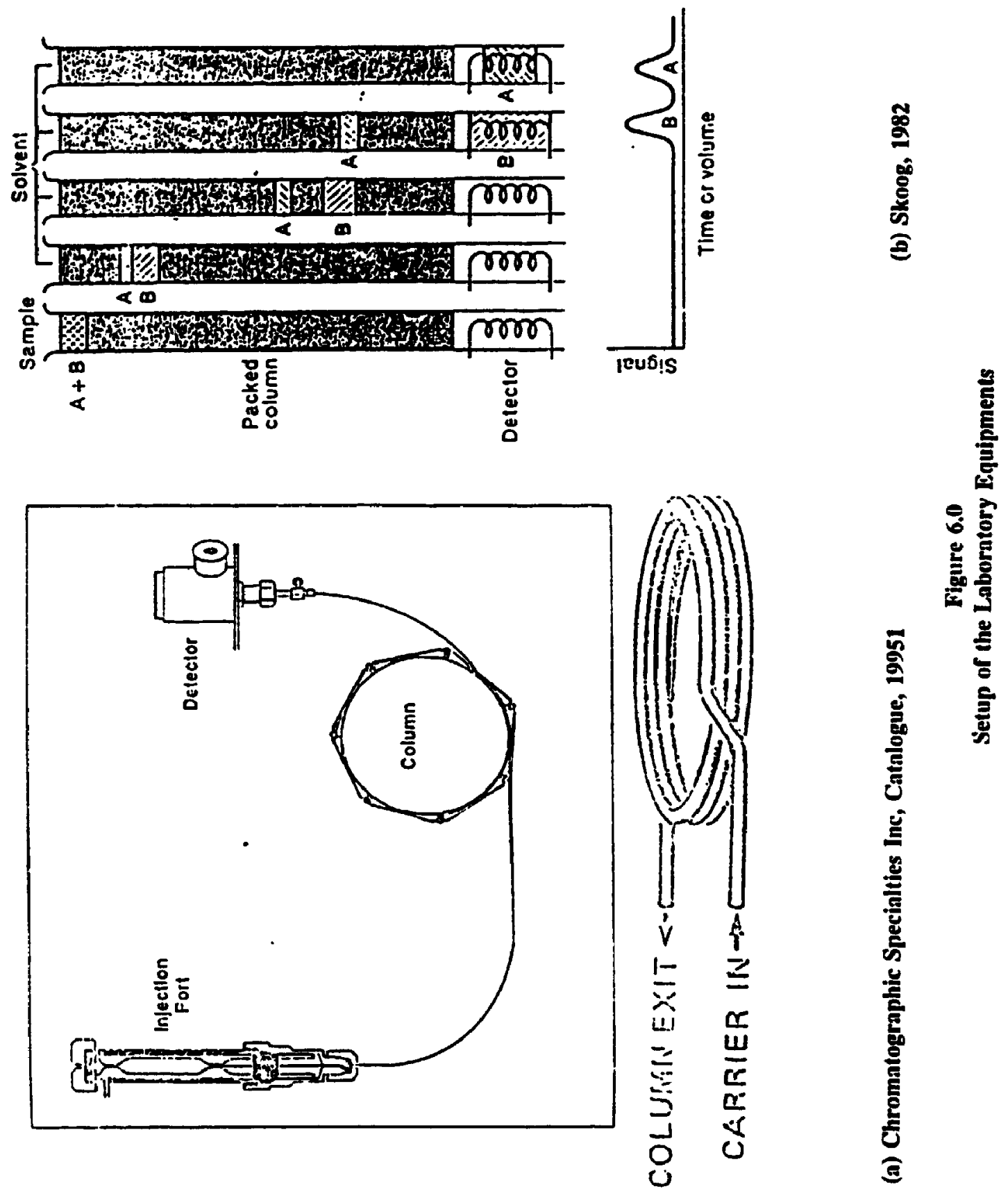


\subsection{Optimizing the Experimental Conditions}

The identifying power of the FID and the separating power of the GC column depend on the gas flow rates and the temperature of the column. The sensitivity of the FID is affected by the hydrogen flow rate and air flow rate. The separating power of the GC is affected by the carrier gas $\left(\mathrm{N}_{2}\right)$ flow rate. Section 6.2 .1 is assigned to find the optimum gas flow rates of $\mathrm{H}_{2}$, air and $\mathrm{N}_{2}$.

In addition to the gas flow rates, the temperature of the column influences the shape of the chromatograms obtained for a given type and the amount of sample analyzed. Improved resolution and sensitivity could be obtained by choosing an optimum temperature. Improved resolution and sensitivity are desirable for the qualitative and quantitative identification of the sample respectively. Section 6.2 .2 describes the determination of the optimum column temperature to satisfy both of the above conditions.

\subsubsection{Optimizing Gas Flow rates}

\subsubsection{Procedure}

According to the recommendations given in the FID-Instruction-Manual, $\mathrm{H}_{2}$ flow rates of $30 \mathrm{ml} / \mathrm{min}$ and $60 \mathrm{ml} / \mathrm{min}$ were selected for testing. With each of the $\mathrm{H}_{2}$ flow rates selected for testing, three different carrier gas $\left(\mathrm{N}_{2}\right)$ flow rates were tested. The sensitivity of the FID also depends on the air flow rate and the sensitivity increases up to an air flow 
rate of $300 \mathrm{ml} / \mathrm{min}$ and there after the sensitivity remains constant (Instruction Manual). Therefore an air flow rate of $300 \mathrm{ml} / \mathrm{min}$ was selected and kept constant during the experiment. Table 6.1 shows the combination of $\mathrm{H}_{2}$ and $\mathrm{N}_{z}$ flow rates tested. The pressures of the gas supply and the temperature conditions ware as below.

Pressure of the gas supply

Nitrogen

Hydrogen

Air

Temperature conditions

Temperature of the column

Room temperature
$37 \mathrm{kPa}$

$165 \mathrm{kPa}$

$140 \mathrm{kPa}$

$\begin{array}{ll}\text { Temperature of the column } & 50^{\circ} \mathrm{C} \\ \text { Room temperature } & 20.4^{\circ} \mathrm{C}\end{array}$

Flow Rates of $\mathrm{H}_{2}$ and $\mathrm{N}_{2}$ Tested

\begin{tabular}{cccc}
\hline $\begin{array}{c}\mathrm{H}_{2} \text { flow rate } \\
(\mathrm{ml} / \mathrm{min})\end{array}$ & $\begin{array}{c}\text { Carrier gas flow rate } \mathrm{N}_{2} \\
(\mathrm{ml} / \mathrm{min})\end{array}$ \\
\hline 30 & 30 & 37.5 & 50 \\
60 & 30 & 37.5 & 50 \\
\hline
\end{tabular}

Table 6.1

Under the above conditions, at each of the combination of flow rates set, a $0.25 \mathrm{ml}$ volume of gasoline vapour was injected onto the $G C$ column and the chromatograms were observed. To standardize the test conditions, the gasoline vapour analyzed at each of the combination of flow rates set was taken from the "sampling vial A" (Figure 6.1). The Teflon-lined rubber septum cap of the glass vial facilitated the withdrawal of gasoline 
vapour by the U-100 insulin syringe without opening the vial. This prevents the possibility of losing any of the volatile substances during the transfer of vapour from the sampling vial to the GC column. 


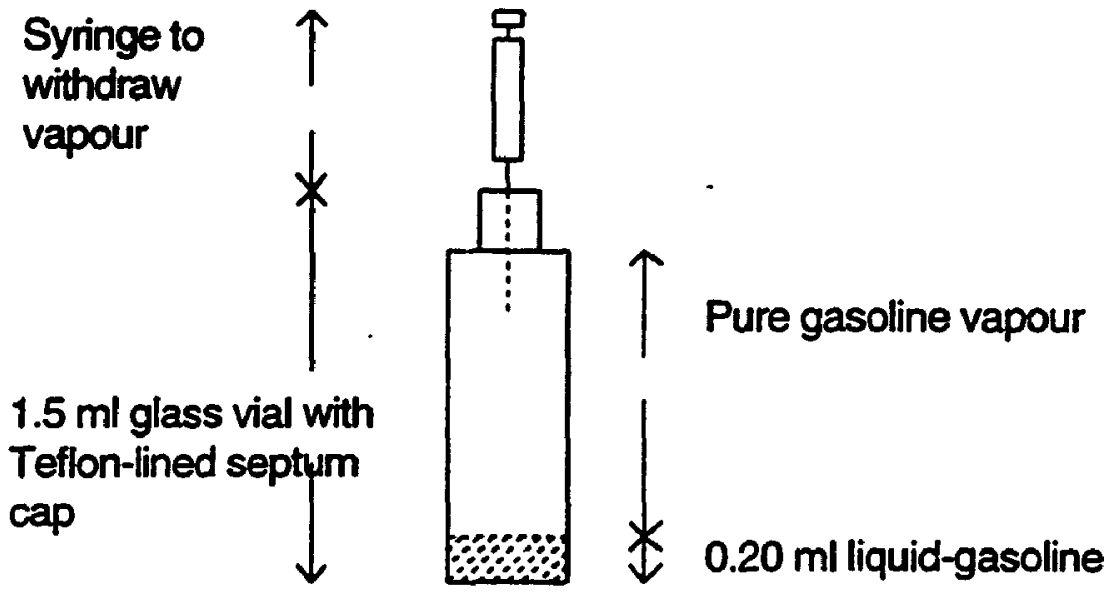

Figure 6.1

"Sampling Vial A" for Pure Gasoline Vapour Samples 


\subsubsection{Observation}

Better sensitivity was observed at a $\mathrm{H}_{2}$ flow rate of $30 \mathrm{ml} / \mathrm{min}$ and this flow rate was selected for the rest of the analysis. Among the flow rates tested for the carrier gas $\mathrm{N}_{2}$, better resolution accompanied with desirable analysis time was observed at $50 \mathrm{ml} / \mathrm{min}$. With slower flow rates tested, 30 and $37.5 \mathrm{ml} / \mathrm{min}$, three undesirable phenomena were noticed and those are given below.

- Increase in analysis time

- Occurrence of peak broadening

- Decrease in resolution

\subsubsection{Discussion}

Among the above three undesirable phenomena at the slower flow rates of the carrier gas, an increase in analysis time is obvious as the analysis time is inversely proportional to the flow rate.

Peak broadening occurred at lower flow rates of the carrier gas because of longitudinal diffusion. Especially when the mobile phase is a gas, longitudinal diffusion occurs from the concentrated part of the separated band to the both ends (Figure 3.1). As a result the separated bands become wider resulting in peak broadening. This effect is greater at slower flow rates as more time is available for diffusion to occur. Moreover, for a given 
flow rate tested, peak broadening occurred at later peaks when the flow rate is low. This may be due to the fact that for a specific samf : injected, the components eluting later have more resident time than the constituents eluting earlier.

On the other hand peak broadening also occurs at very high flow rates, but due to a different reason. This is because of the non-equilibrium mass transfer due to the lack of resident time to complete the equilibrium during the time when the mobile phase is in contact with the stationary phase. As a result in order to achieve equilibrium when each time the mobile phase is in contact with the stationary phase, equilibrium will take place in a longer section than usual (Figure 3.2). Subsequently peak broadening occurs at rapid flow rates as well.

The interpretation of the test results in this study is based on the overall pattern of the chromatograms and is not based on the individual peaks of the constituents. Therefore among the optional parameters measured for the quantitative analysis (Section 3.3.2) the one that could be used in this study is the peak height. The peak area measurement cannot be used in this study as there was no attempt to separate the individual constituentpeaks. Peak broadening causes reduction in peak height to keep the area under the peak constant. Therefore if peak broadening occurs, from Eyuations (3.1) and (3.2), it could be realized thrt peak height cannot be assumed to be proportional to the area under the 
peak. Therefore it is important to select a flow rate where the peak broadening will be minimum. Considering these facts a flow rate of $50 \mathrm{ml} / \mathrm{min}$ was selected for the carrier gas.

Poor resolution results from the overlapping of the separated bands (Figure 3.1) due to peak broadening at slower flow rates.

\subsubsection{Optimizing Column Temperature}

\subsubsection{Procedure}

With the experimental conditions shown below, a range of temperature 20 to $80^{\circ} \mathrm{C}$ was tested. At each of the temperatures set, a $0.25 \mathrm{ml}$ of gasoline vapour was analyzed by the GC. In all the tests, the analyzed vapour was taken from the "sampling vial $A$ " (Figure 6.1). The transfer of gasoline vapour from the sampling vial to the GC column was by the $\mathrm{U}-100$ insulin syringe. The chromatograms were obtained in each run and the heights and the retention times of the peaks were noted. 
Experimental Conditions

Conditions of the Gas Supply

\begin{tabular}{ccc}
\hline Type of Gas & $\begin{array}{c}\text { Flow Rate } \\
(\mathrm{ml} / \mathrm{min})\end{array}$ & $\begin{array}{c}\text { Outlet Pressure } \\
(\mathbf{k P a})\end{array}$ \\
\hline Nitrogen & 50 & 37 \\
Hydrogen & 30 & 165 \\
Air & 300 & 140 \\
\hline
\end{tabular}

Table 6.2

Room temperature:

Temperature of the Injection Port:

$21.5^{\circ} \mathrm{C}$
$200^{\circ} \mathrm{C}$
$280^{\circ} \mathrm{C}$
$1 \mathrm{E}-11$
1
$0.25 \mathrm{ml}$

Temperature of the Detector:

The sensitivity of the GC set:

The attenuation of the GC set:

Sample size:

$0.25 \mathrm{ml}$

\subsubsection{Observation}

The Graphs 6.2 to 6.8 are the chromatograms obtained at different temperatures tested.

Tables 6.3 and 6.4 show the retention time and the peak height information of the chromatogram at different temperatures. Graphs 6.9 and 6.10 shows the variation of the retention times and peak height with respect to the temperature respectively. 


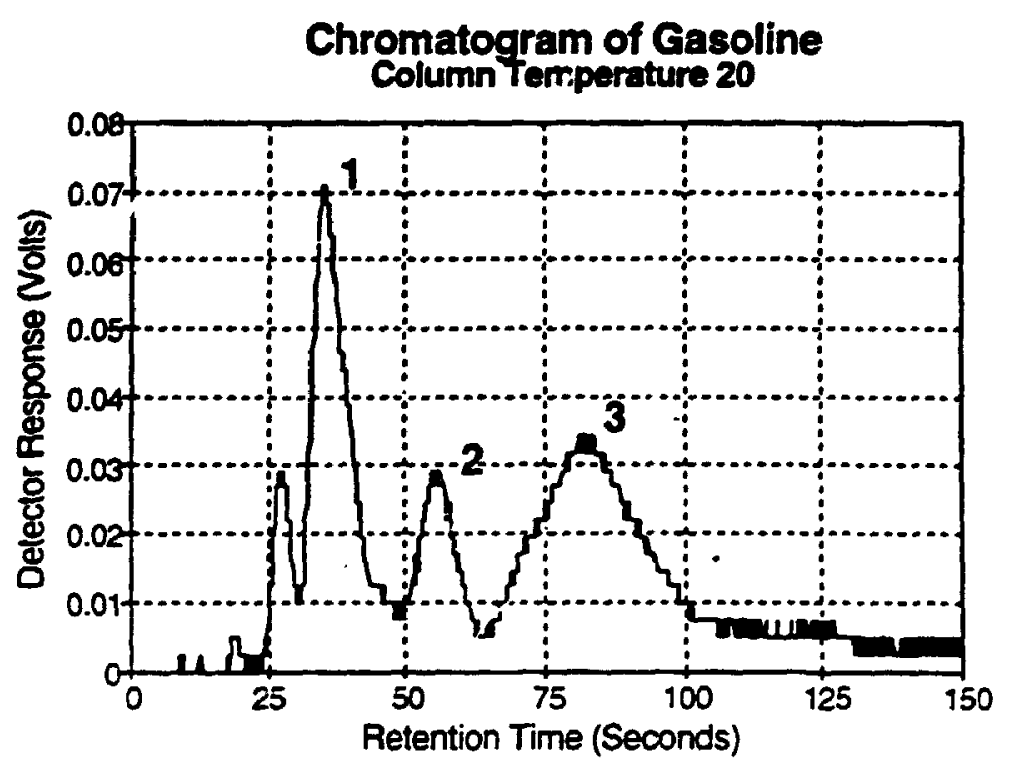

Graph 6.2

\section{Chromatogram of Gasoline Column Temperature 25}

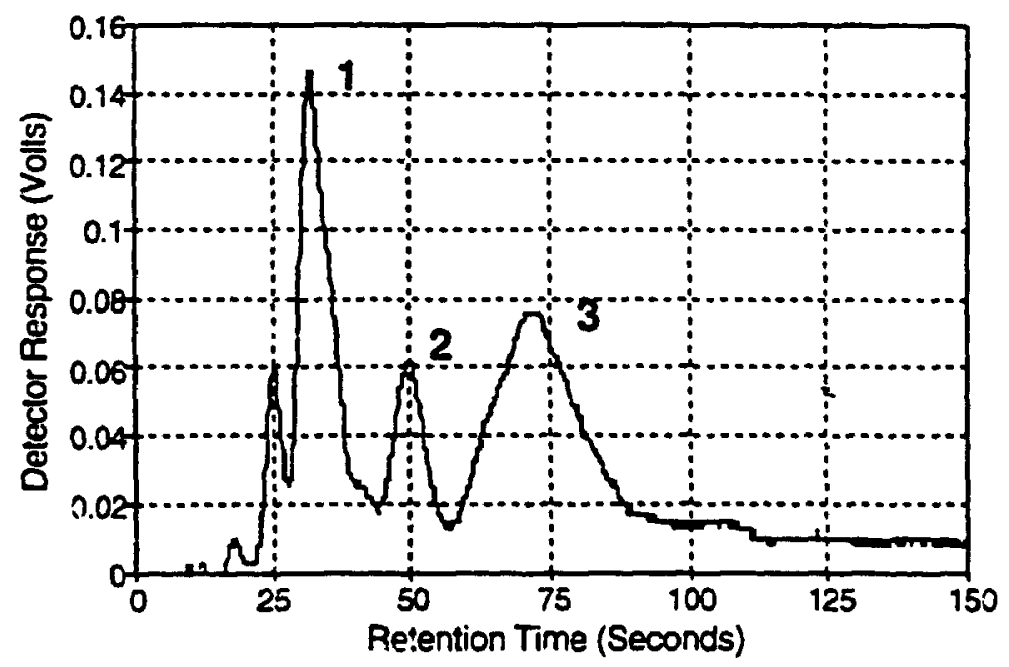

Graph 6.3 


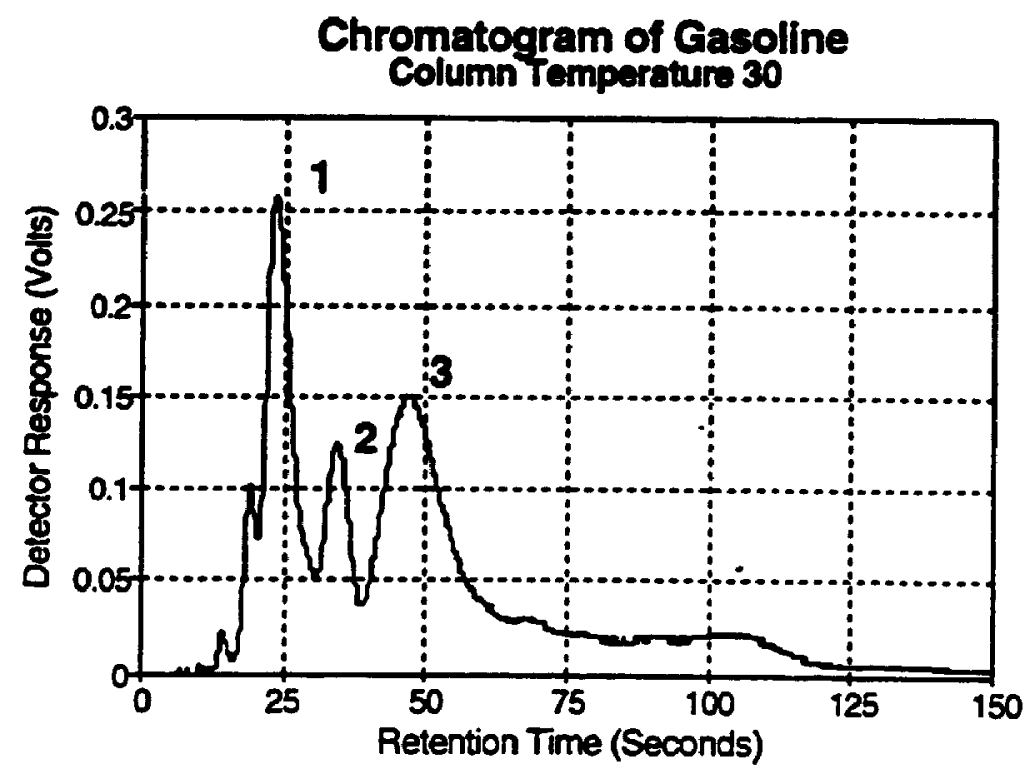

Graph 6.4

Chromatogram of Gasoline Column Temperature 40

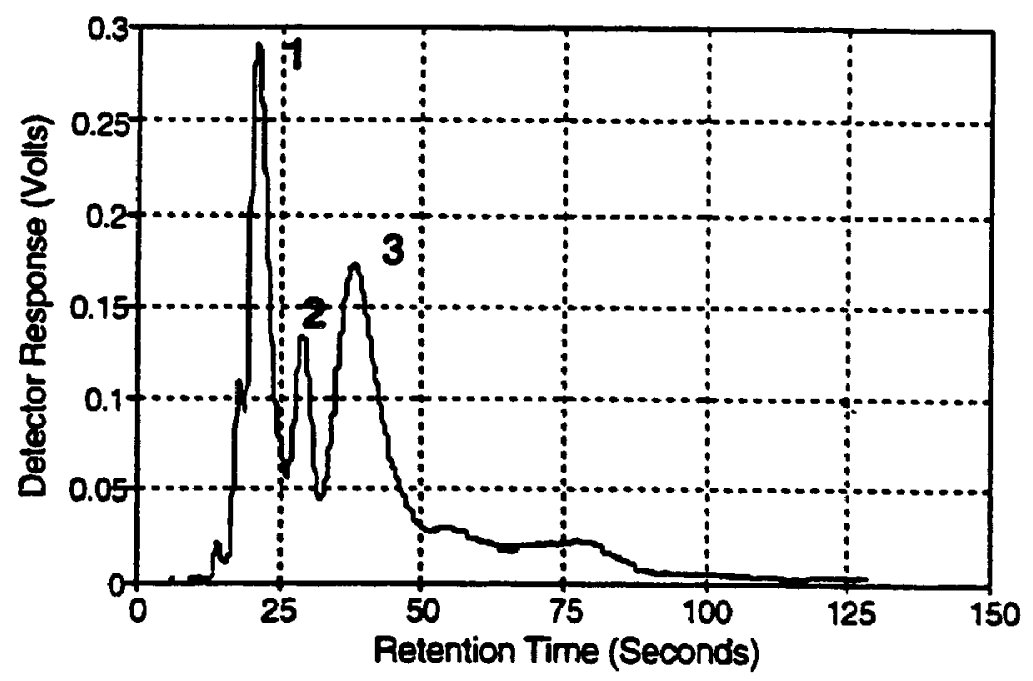

Graph 6.5 

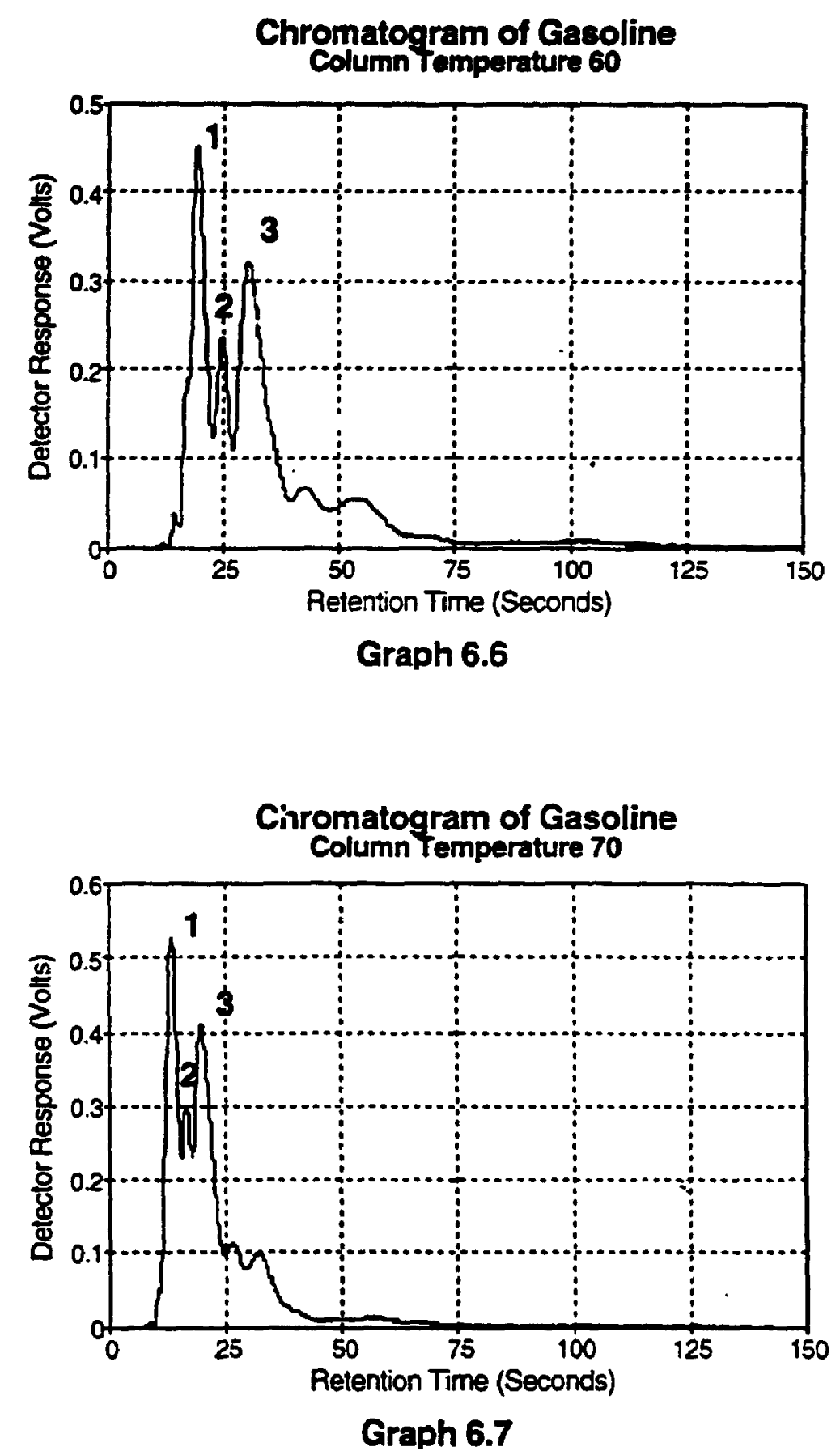

Experiment 


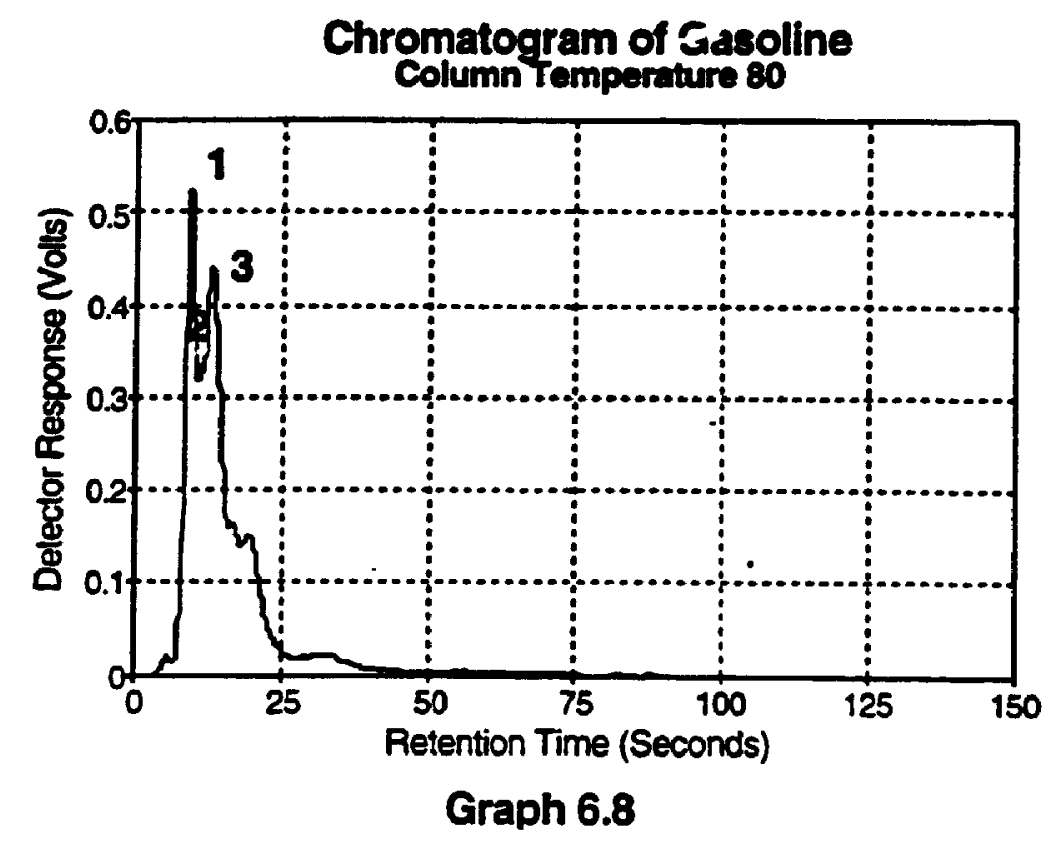

$\div$ 
Retention Time at Various Temperatures

\begin{tabular}{cccc}
\hline $\begin{array}{c}\text { Temperature } \\
\left({ }^{\circ} \mathrm{C}\right)\end{array}$ & Peak 1 & Peak 2 & Peak 3 \\
\hline 20 & 35.10 & 55.64 & 82.39 \\
25 & 32.01 & 49.60 & 71.90 \\
30 & 23.52 & 34.28 & 47.29 \\
40 & 21.20 & 29.06 & 37.96 \\
60 & 19.34 & 24.77 & 30.27 \\
70 & 13.35 & 16.54 & 19.67 \\
80 & 9.23 & 11.10 & 12.91 \\
\hline
\end{tabular}

Table 6.3

Peak Heights at Various Temperatures

\begin{tabular}{cccc}
$\begin{array}{c}\text { Temperature } \\
\left({ }^{\circ} \mathrm{C}\right)\end{array}$ & Peak 1 & Peak Heights (Volts) & Peak 2 \\
\hline 20 & 0.07 & 0.03 & 0.03 \\
25 & 0.15 & 0.06 & 0.08 \\
30 & 0.26 & 0.12 & 0.15 \\
40 & 0.29 & 0.13 & 0.17 \\
60 & 0.45 & 0.24 & 0.32 \\
70 & 0.5298 & 0.30 & 0.41 \\
80 & 0.5225 & 0.33 & 0.44
\end{tabular}

Table 6.4 


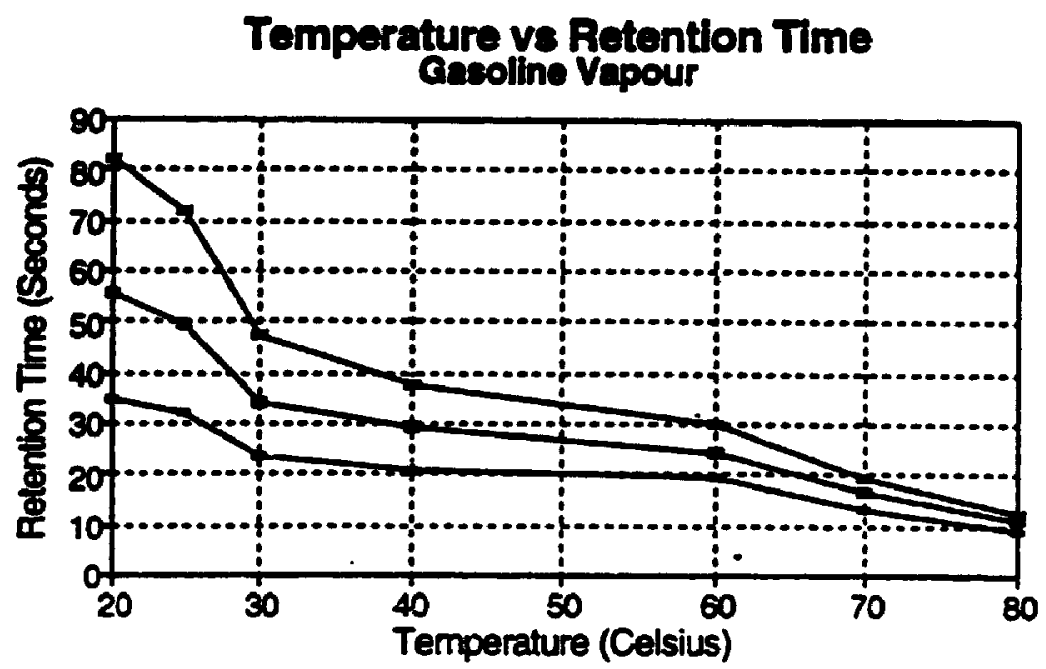

ancoline Vapour

$$
\text { Peak } 1-\text { Peak } 2-\text { Peak } 3
$$

Graph 6.9

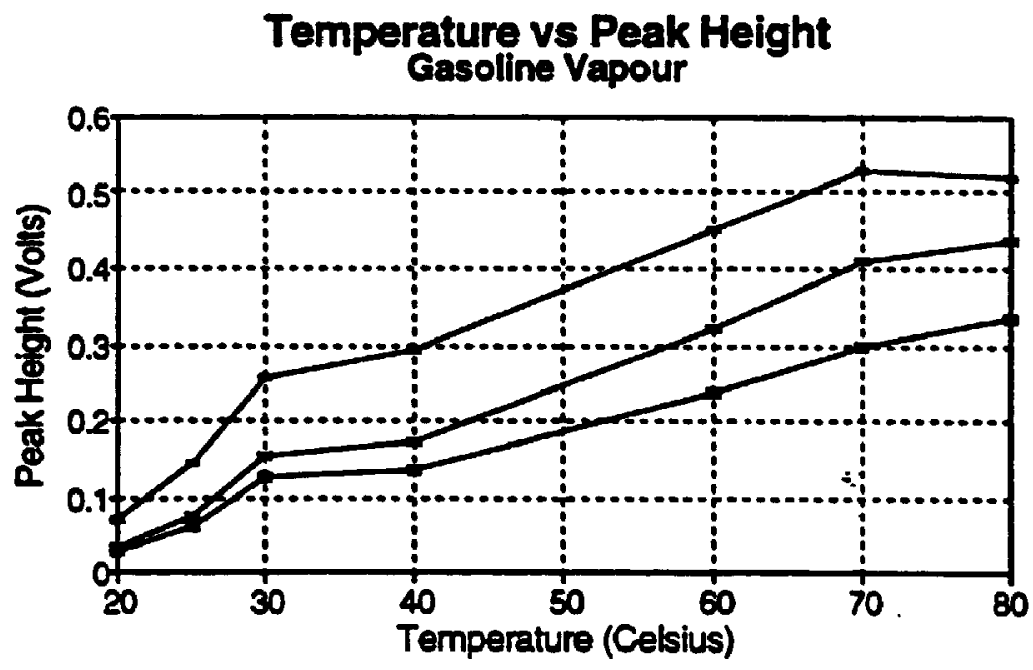

Peak $1-$ Peak $2-$ Peak 3

Graph 6.10 


\subsubsection{Discussion}

For qualitative analysis better resolution is desirable to observe retention times of the peaks. From Graph 6.9 it could be noticed when the temperature increases, the resolution decreases as the difference in retention time between peaks decreases. Therefore if better resolution alone is considered for qualitative analysis, the temperature range of 20 to $40^{\circ} \mathrm{C}$ is desirable. However from Graph 6.10 the sensitivity (peak height/amount of the constituent) is low in this region and the sensitivity increases with temperature. Therefore a temperature range of 40 to $60^{\circ} \mathrm{C}$ is desirable for both qualitative and quantitative analysis. Giving priority to attain a higher sensitivity a temperature of $60^{\circ} \mathrm{C}$ is selected for the rest of the analysis.

\subsection{The validity of the Quantitative Relation for Unresolved Peaks}

Existence of a linear relationship between the quantity of the constituents present in the injected sample to the size of the separated constituent-peaks of the chromatograms is reported in literature. However the analysis method used in this study is based the overall patterns of chromatograms made of unresolved peaks. This section is assigned to test the validity of this relationship for unresolved peaks.

\subsubsection{Procedure}

Different volumes of gasoline vapour were injected and the peaks heights were observed

\section{Experiment}


against the quantity injected. The gasoline vapour analyzed was withdrawn from the "sampling vial A" (Figure 6.1) The experimental conditions were the same as in Section 6.2.2.1 and the temperature of the column was kept at $50^{\circ} \mathrm{C}$.

\subsubsection{Observation}

Retention Times at Various Sample Sizes

\begin{tabular}{cccc}
\hline $\begin{array}{c}\text { Amount of Sample } \\
\text { Injected }(\mathrm{ml})\end{array}$ & \multicolumn{3}{c}{ Retention Time (Seconds) } \\
\cline { 2 - 4 } & Peak 1 & Peak 2 & Peak 3 \\
\hline 0.10 & 20.26 & 26.92 & 33.68 \\
0.20 & 20.48 & 26.97 & 33.72 \\
0.30 & 20.49 & 27.02 & 33.79 \\
0.40 & 17.02 & 22.40 & 28.01 \\
\hline
\end{tabular}

Table 6.5

Peak Heights at Various Sample Sizes

\begin{tabular}{cccc}
\hline $\begin{array}{c}\text { Amount of Sample } \\
\text { Injected (ml) }\end{array}$ & Peak 1 & Peak Heights (Volts) & Peak 2 \\
\hline 0.10 & 0.12 & 0.05 & Peak 3 \\
0.20 & 0.37 & 0.18 & 0.07 \\
0.30 & 0.45 & 0.24 & 0.24 \\
0.40 & 0.44 & 0.25 & 0.31 \\
\hline
\end{tabular}

Table 6.6 
Peak Height vs Amount of Sample

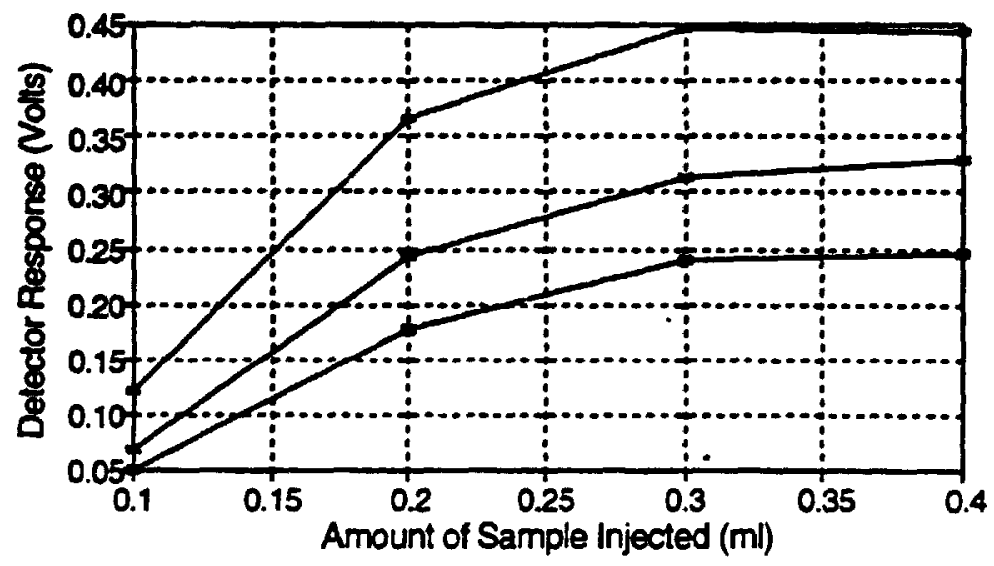

- Peak $1-$ Peak $2-$ Peak 3

Graph 6.11 


\subsubsection{Discussion}

A slight deviation from linearity was noticed in Graph 6.11. Therefore, linear interpolation or extrapo'ation may not be used to find the unknown quantity of the samples and calibration techniques should be used.

\subsection{Soil Vapour Analysis of the Laboratory Prepared Petroleum Contaminated Soil Samples}

\subsubsection{Sample Preparation}

One gram of the experimental soil (clean sand) was taken in the $1.5 \mathrm{ml}$ glass vial and closed with Teflon-lined septum cap. The weight of the vial with clean sand was measured to a milligram accuracy by the Mettler AT201 weighing machine of precision $0.01 \mathrm{mg}$. After labelling the glass vial with the experimental soil, a known volume of liquid-gasoline was added. The gasoline added was withdrawn in the Hamilton-syringe (precision 0.2 micro litre) by puncturing the Teflon-lined-septum-cap of the glass vial containing liquid gasoline and injected into the vial containing soil such to avoid any escape of volatile substances. The glass vial containing the gasoline contaminated soil sample was turned up side down 20 times to let the sample mix thoroughly. The total weight after the addition of gasoline was measured and the concentration of the gasoline in the soil was recorded in ppm by weight. 
A similar procedure was adopted to prepare various concentration of gasoline contaminated soil samples. In preparing all such concentration-samples the weight of the clean sand was kept constant at 1 gram and the quantity of liquid gasoline added was varied. This procedure was adopted to keep the headspace volume equal in all the samples at different concentration. Table 6.7 shows the concentration of the samples prepared. In all the samples at different concentrations, the volume of the soil to the headspace volume was kept constant as shown in Figure 6.2.

The concentration of the samples prepared

\begin{tabular}{cccc}
$\begin{array}{c}\text { Sampling Vial } \\
\text { Number }\end{array}$ & $\begin{array}{c}\text { Concentration } \\
(\mathbf{p p m})\end{array}$ & $\begin{array}{c}\text { Sampling Vial } \\
\text { Number }\end{array}$ & $\begin{array}{c}\text { Concentration } \\
(\mathbf{p p m})\end{array}$ \\
\hline 1 & 700 & 6 & 5400 \\
2 & 1500 & 7 & 5650 \\
3 & 2400 & 8 & 6600 \\
4 & 3100 & 9 & 7600 \\
5 & 4400 & - & - \\
\hline
\end{tabular}

Table 6.7 
Chapter 6

117

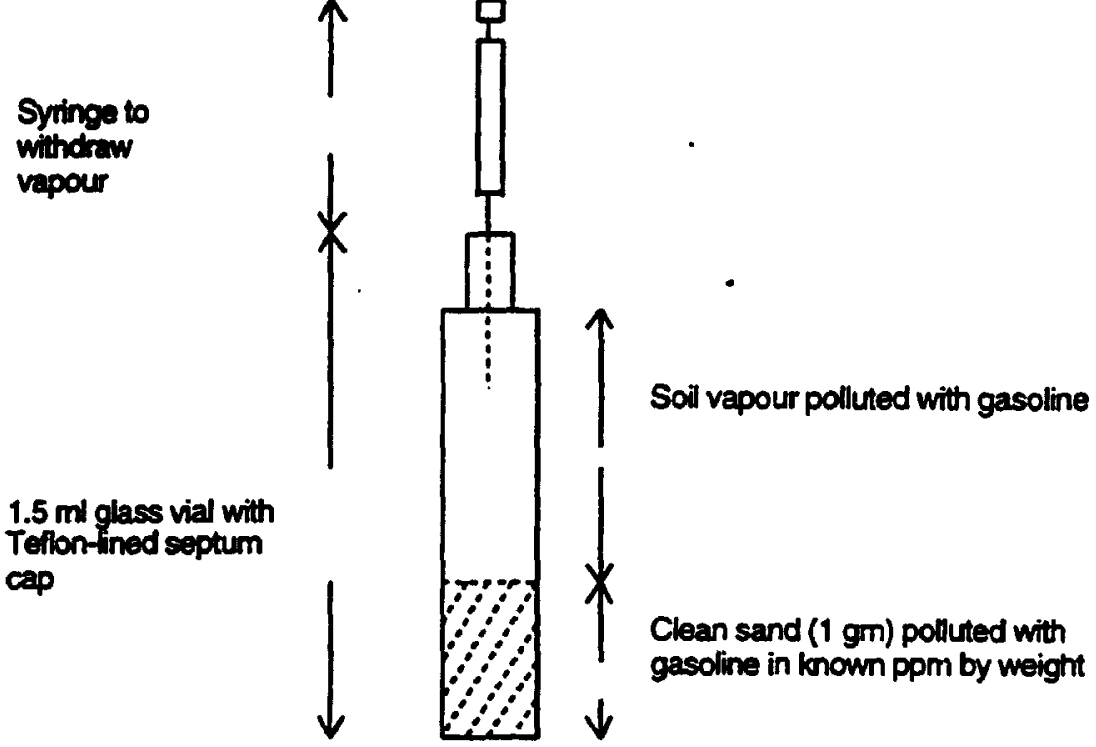

Figure 6.2

"Sampling Vial B" for Gasoline Contaminated Soil Samples

Experiment 


\subsubsection{GC analysis of gasoline contaminated soil vapour sample}

\subsubsection{Experimental Conditions}

Unless otherwise stated the experimental conditions were kept as below

\section{Conditions of the Gas Supply}

\begin{tabular}{lcc}
\hline Type of Gas & $\begin{array}{c}\text { Flow Rate } \\
(\mathbf{m} 1 \mathbf{m i n})\end{array}$ & $\begin{array}{c}\text { Outlet Pressure } \\
\mathbf{( k P a )}\end{array}$ \\
\hline Nitrogen & 50 & 35 \\
Hydrogen & 30 & 165 \\
Air & 300 & 160 \\
\hline
\end{tabular}

Table 6.8

Room temperature:

The temperature of the injection port:

The temperature of the detector:

The sensitivity of the GC set:

The attenuation of the GC set:

Sample size: $21.3^{\circ} \mathrm{C}$

$205^{\circ} \mathrm{C}$

$290^{\circ} \mathrm{C}$

$1 \mathrm{E}-10$

1

$0.25 \mathrm{ml}$

\subsubsection{Procedure}

After allowing the samples to stabilize at room temperature $\left(21.3^{\circ} \mathrm{C}\right)$ for a day, a $0.25 \mathrm{ml}$ volume of vapour in the headspace of samples at different concentration (samples 1 to 9 , Table 6.7) was taken in the insulin syringe and analyzed by the GC individually. A similar test was carried out after two days by analyzing another $0.25 \mathrm{ml}$ vapour samples withdrawn from each of those sampling vials. The chromatograms for each run were 
obtained. The peaks of the chromatograms were noted and the retention times and the peak heights were recorded.

In addition to the soil vapour samples tested, un-contaminated soil vapour of the experimental soil and pure gasoline vapour were tested for comparison purposes. Moreover, some other samples were tested to explain the variation of patterns for qualitative identification. 


\subsubsection{Observation}

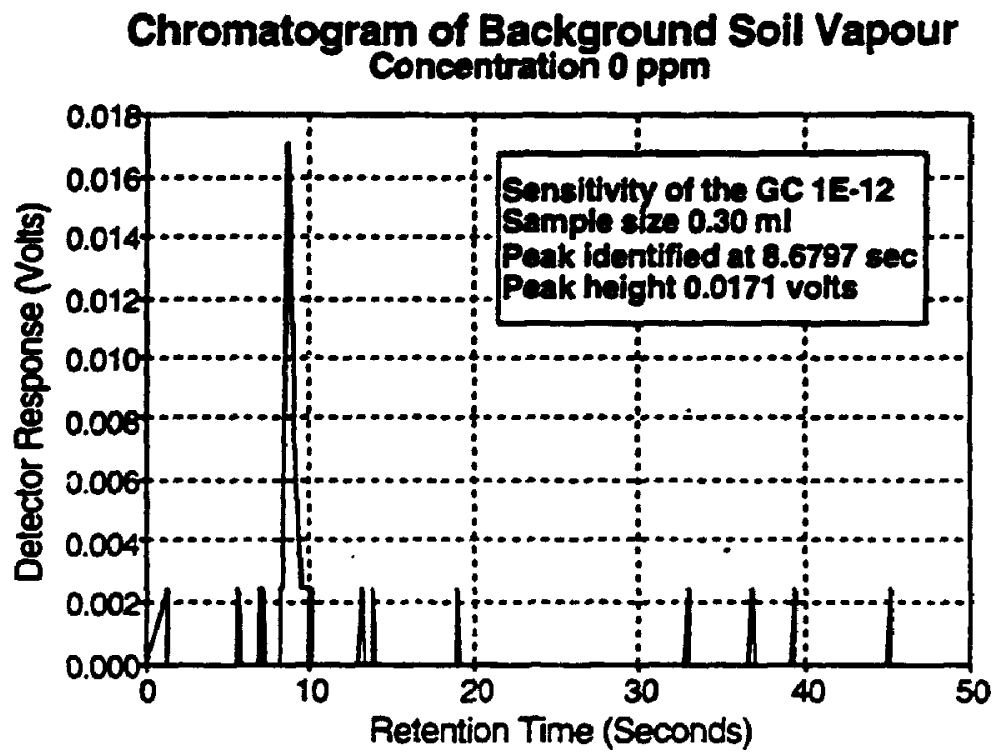

Graph 6.12

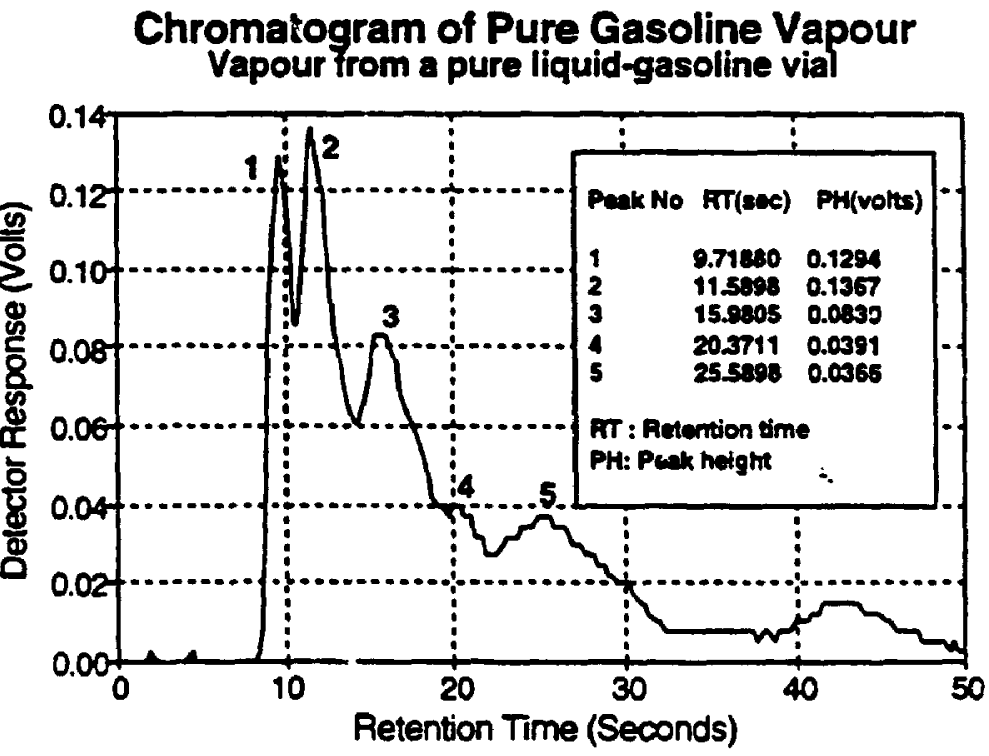

Graph 6.13 

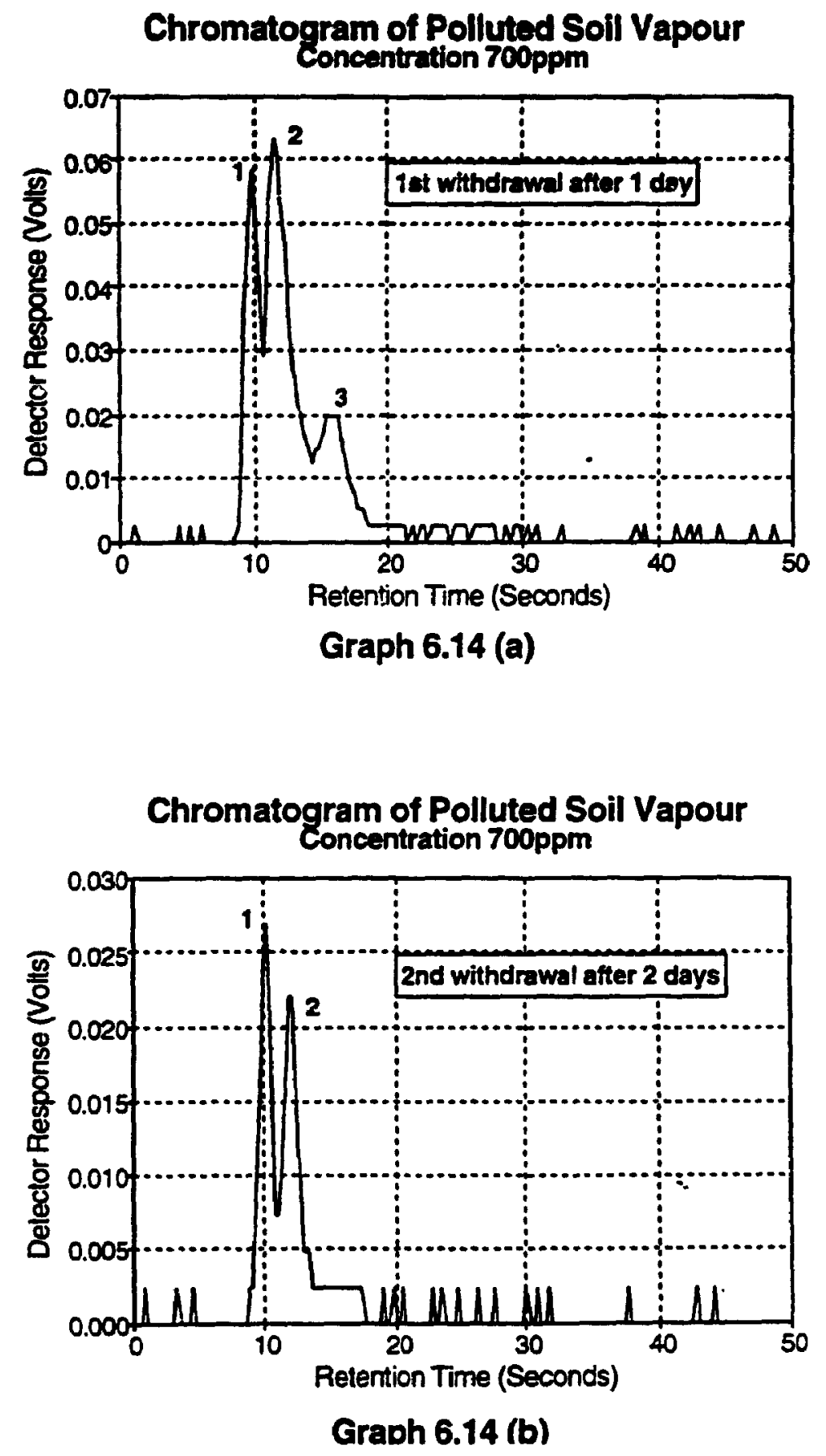

Experiment 

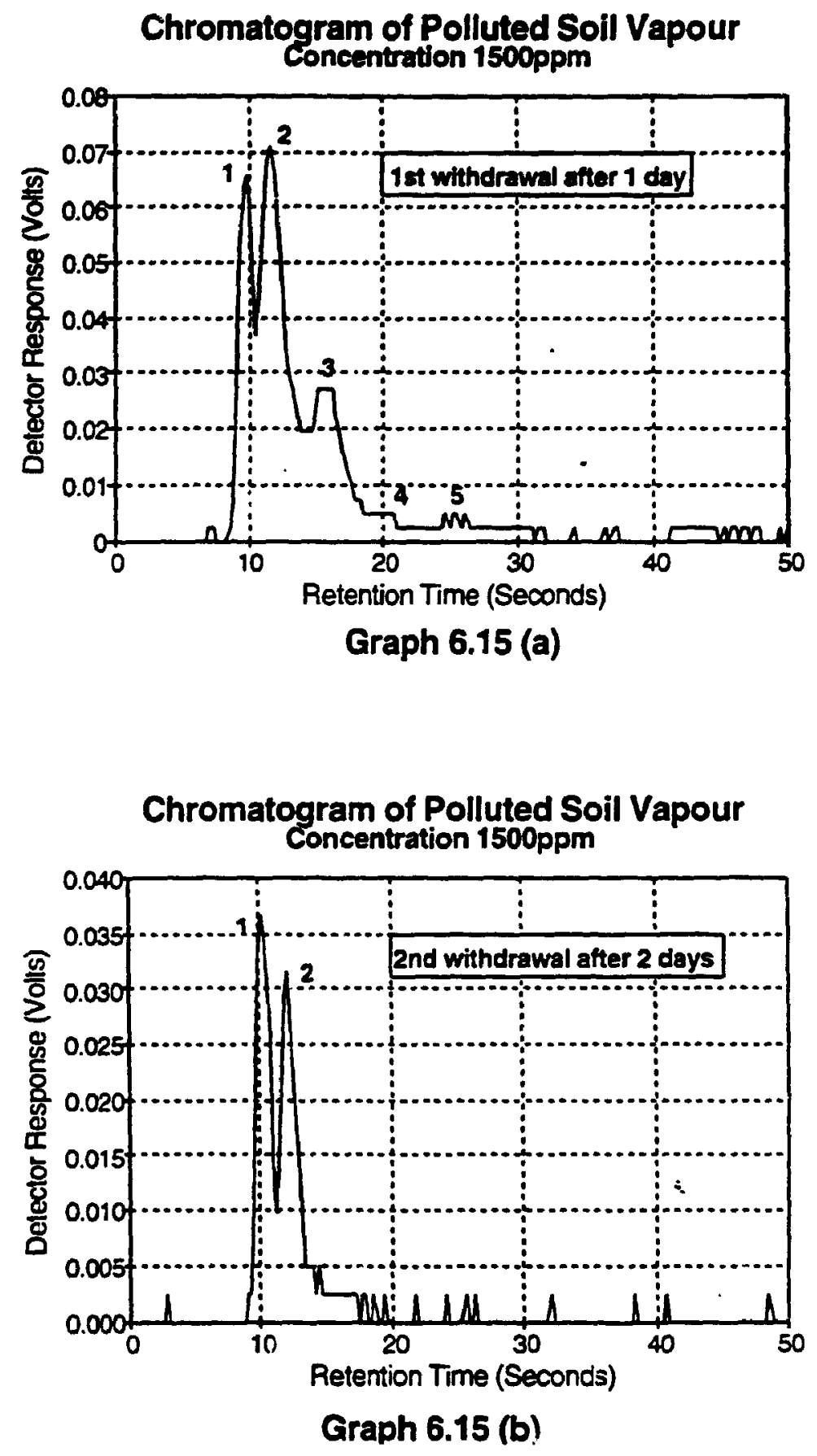

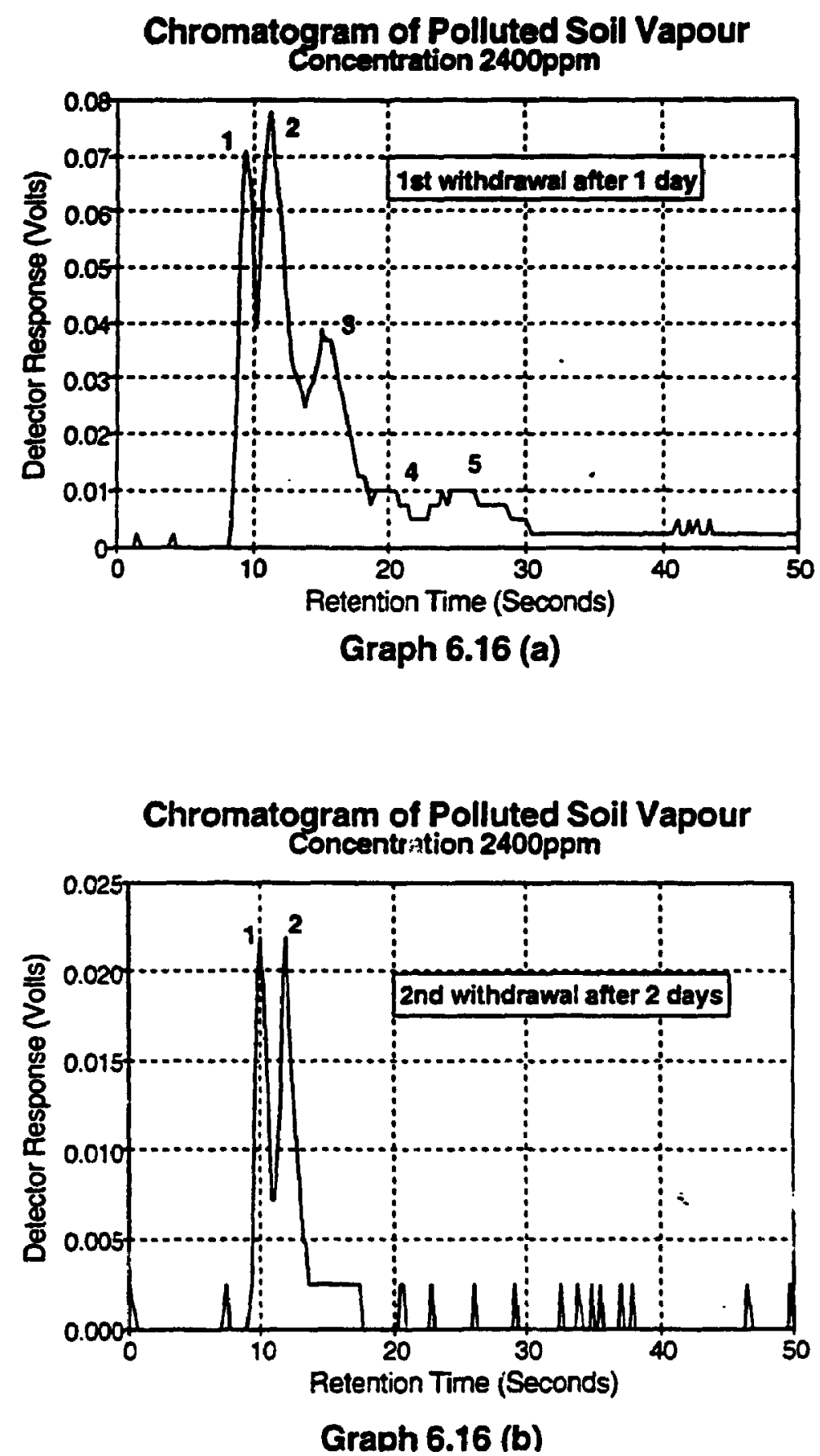


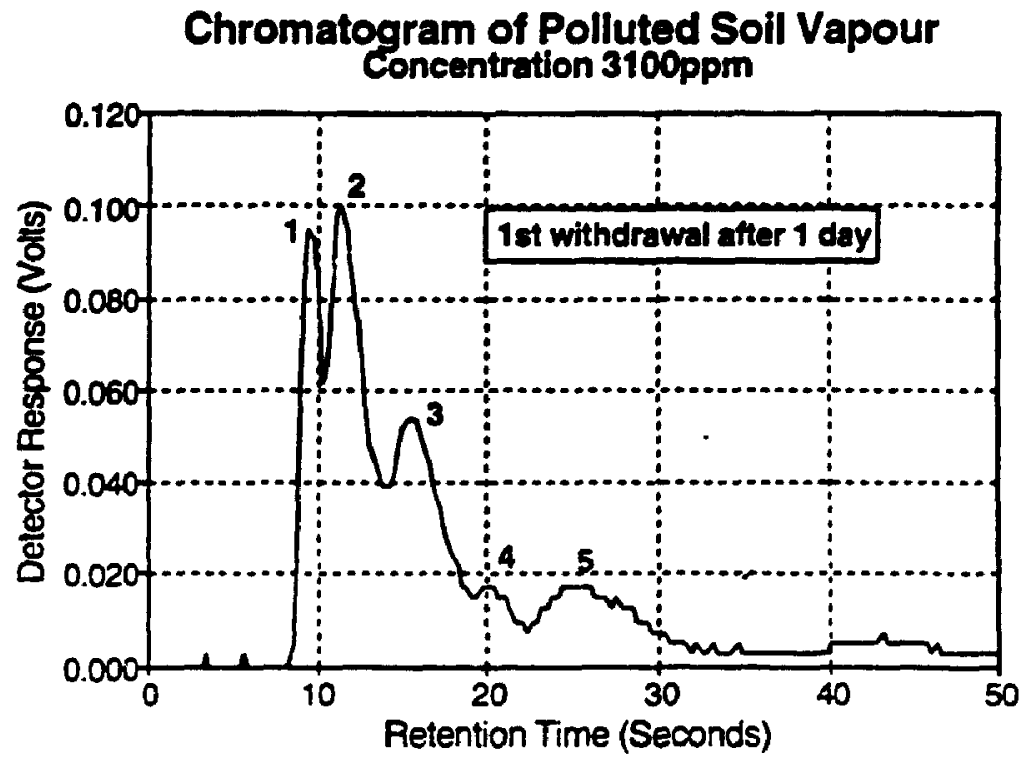

Graph 6.17 (a)

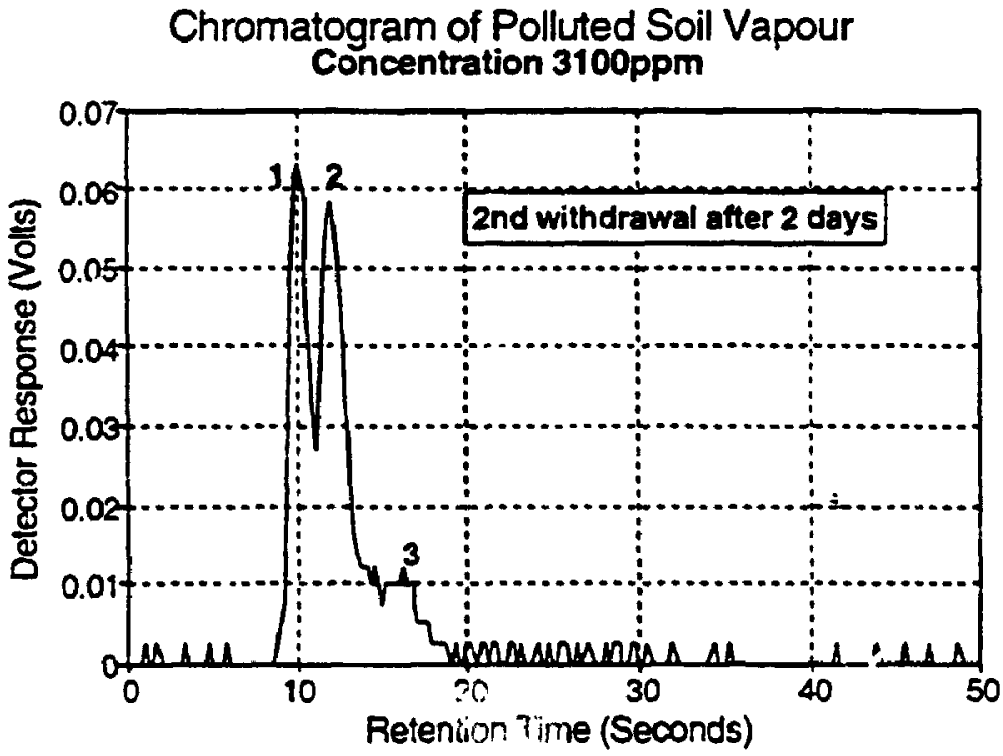

Graph 6.17 (b) 


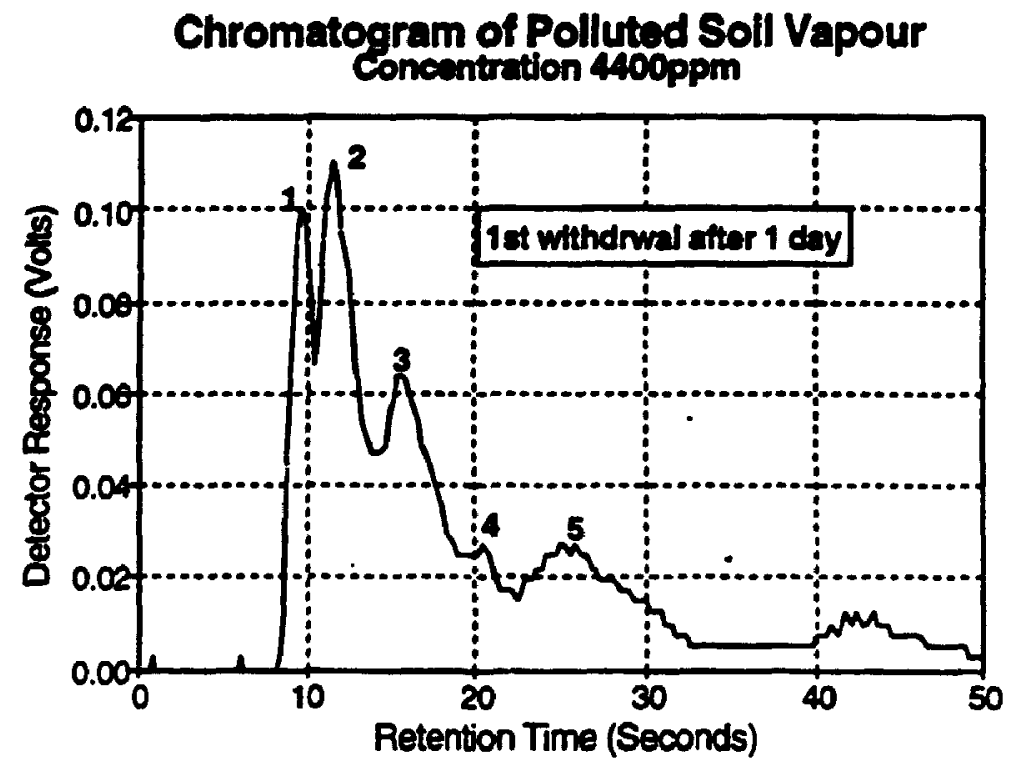

Graph 6.18 (a)

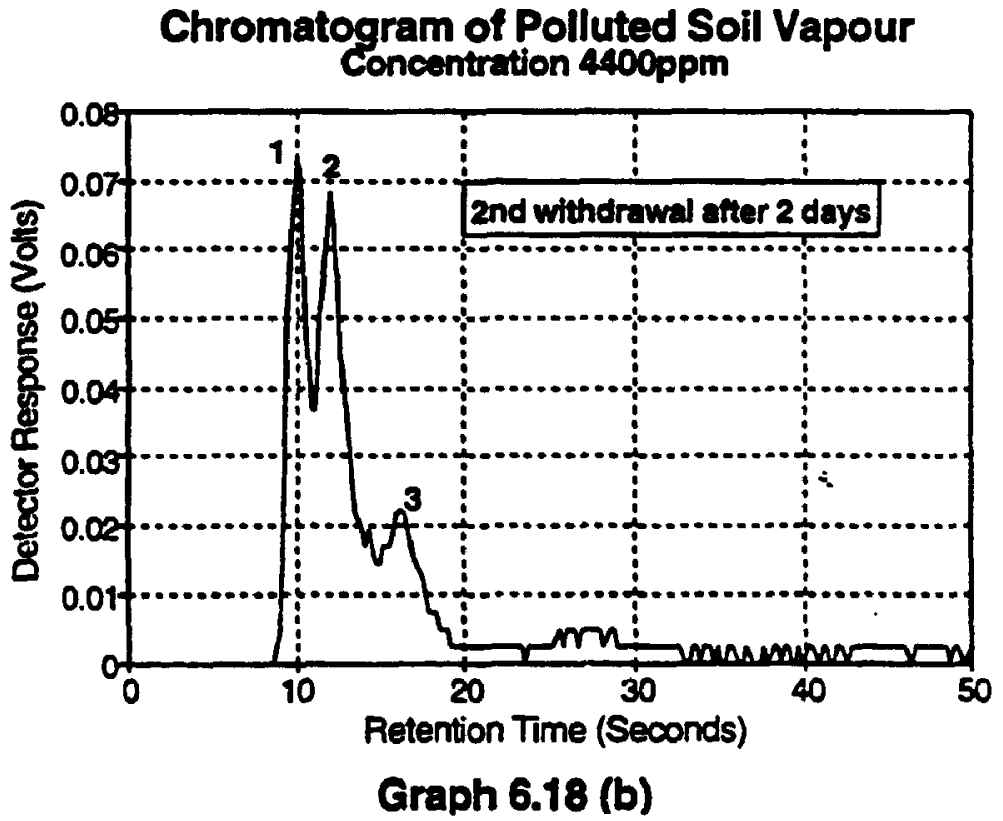




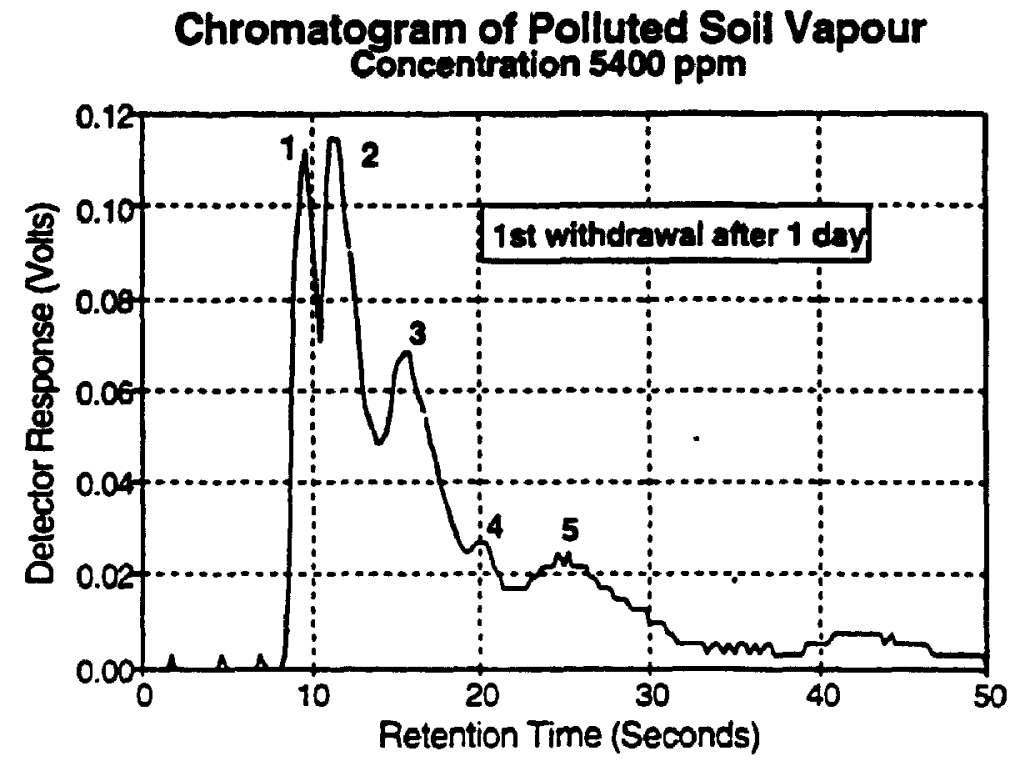

Graph 6.19 (a)

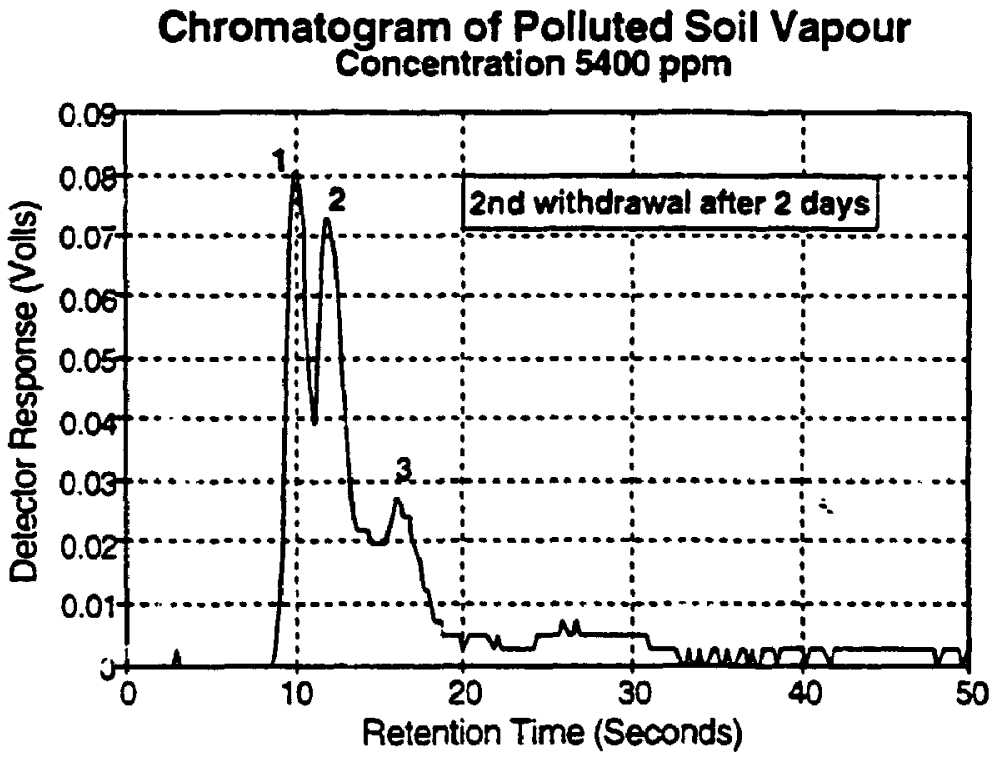

Graph 6.19 (b) 

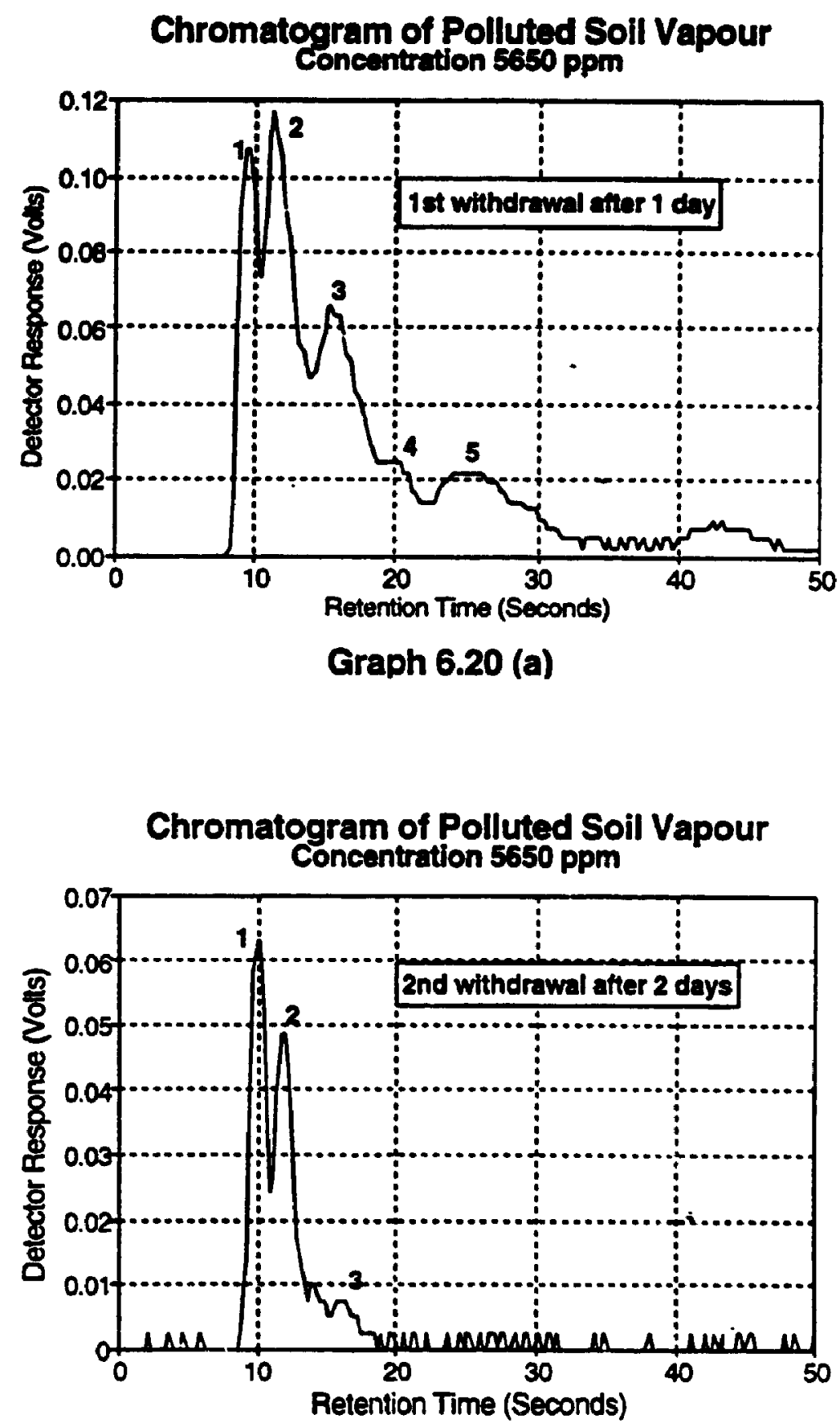

Graph 6.20 (b) 


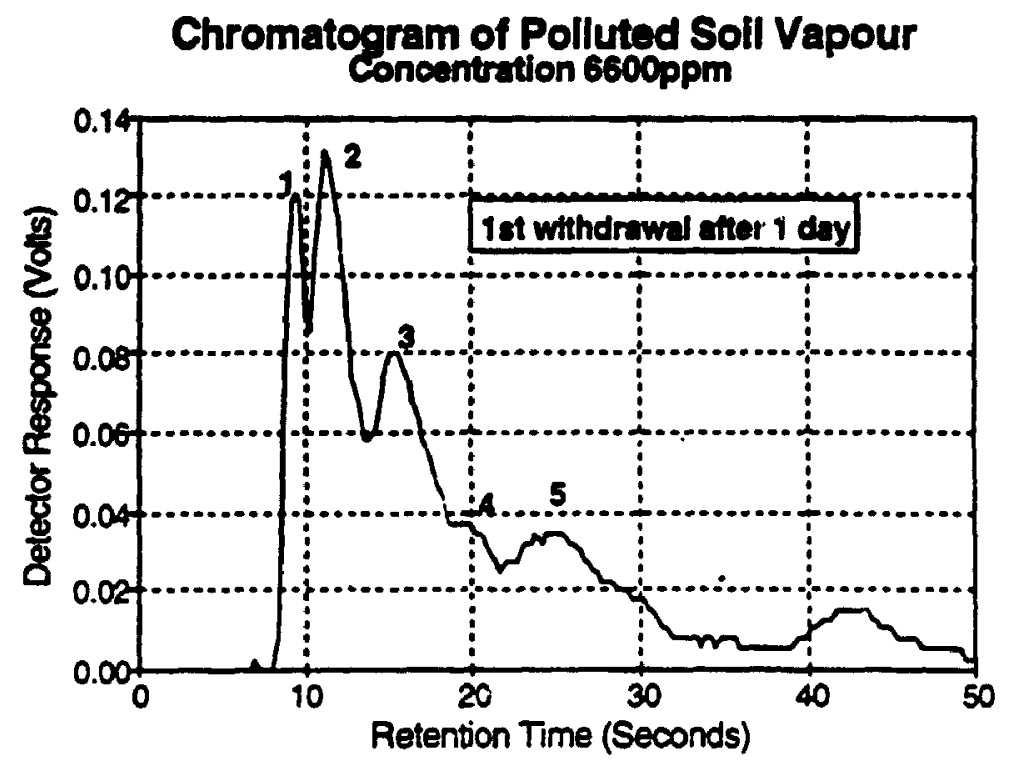

Graph 6.21 (a)

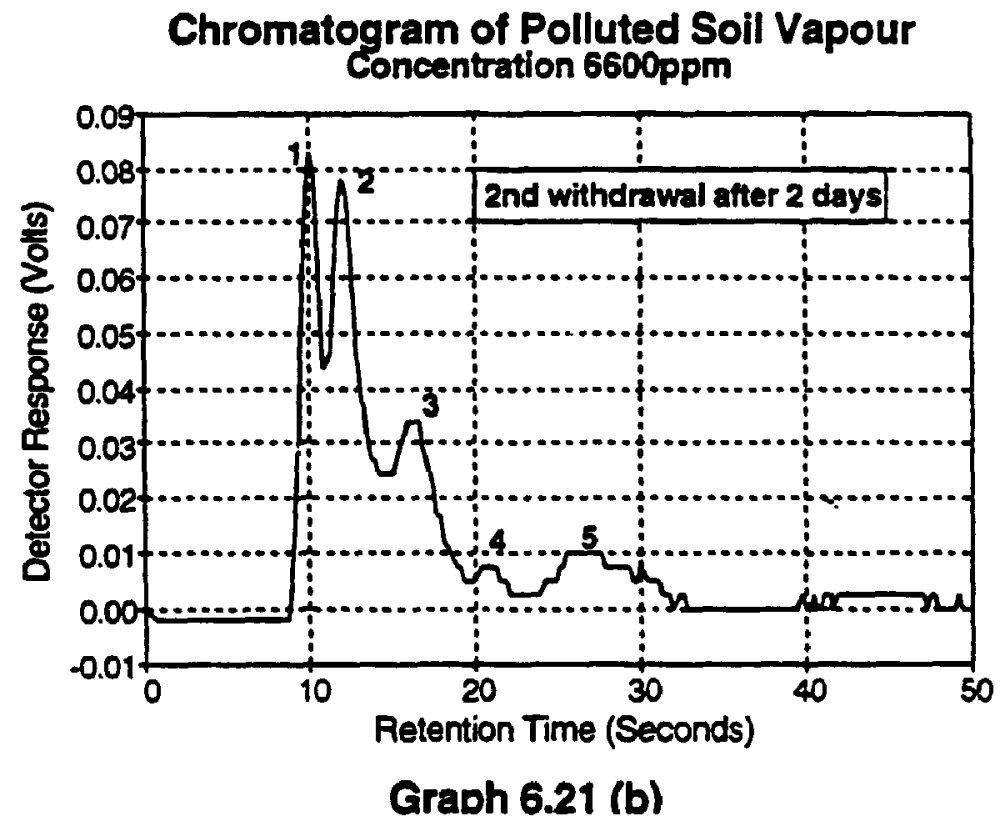



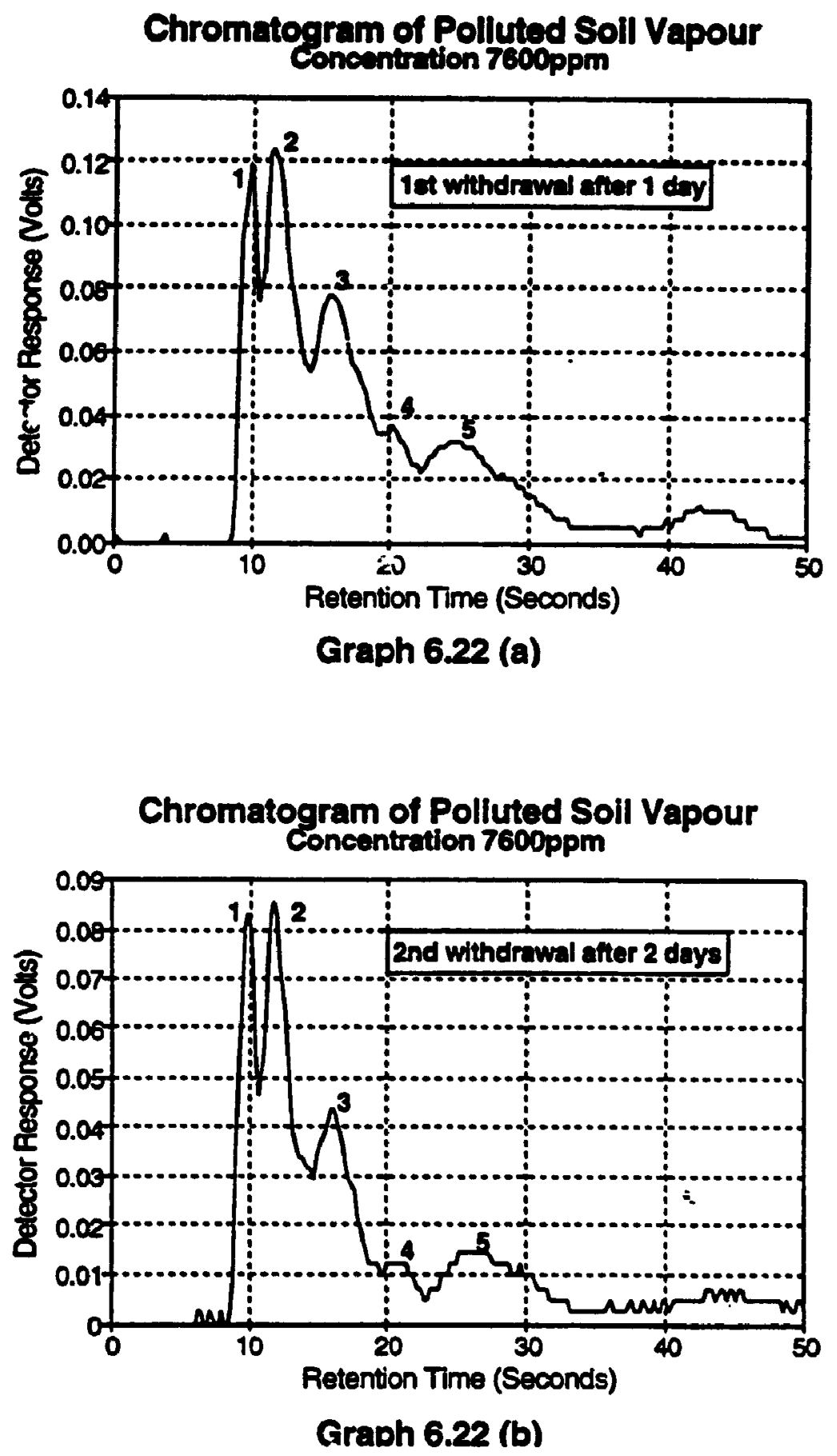


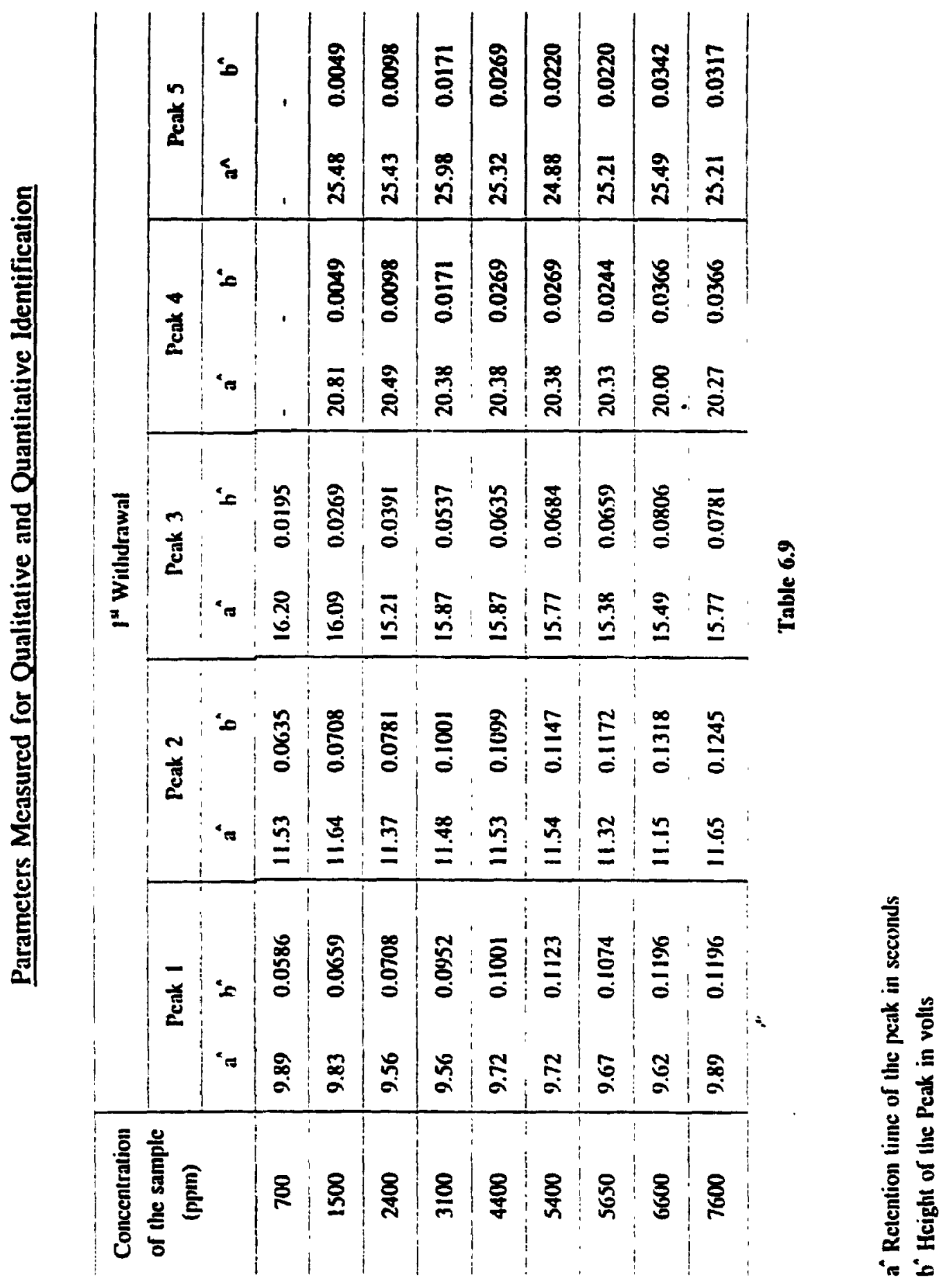




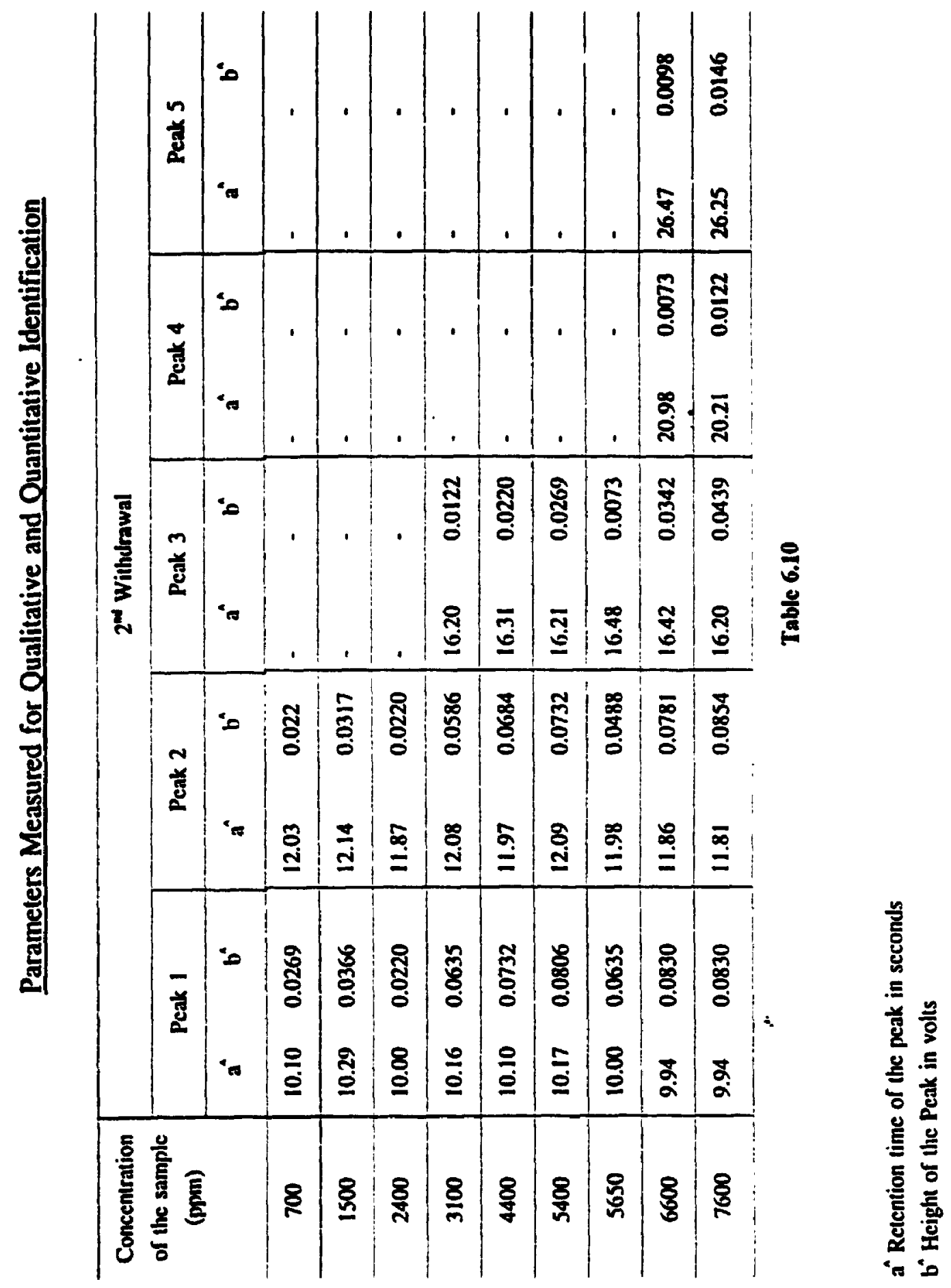




\subsubsection{Data Interpretation for Qualitative Analysis}

The data interpretation for qualitative identification is based on the retention time of the unresolved peaks of the chromatograms. Table 6.9 lists the retention time data of the peaks identified on the chromatograms at different concentration under the same set of experimental conditions. This set of chromatograms were obtained for the first set of $0.25 \mathrm{ml}$ soil vapour extracted from the headspace of the sampling vials 1 to 9 (Table 6.7).

The peaks identified at each of the chromatograms (Table 6.9) were almost at the same retention times. However the peaks eluting later were less visible on the chromatograms of less contaminated samples. This is because in the pure gasoline vapour itself the concentration of the constituents of peaks eluting later is less compared to the constituents of peaks eluting earlier.

Table 6.10 lists the retention time data of the peaks identified on the second set of chromatograms obtained for the set of $0.25 \mathrm{ml}$ soil vapour extracted from the headspace of the sampling vials 1 to 9 (Table 6.7) a second time. From Table 6.10 it could be seen in many of the chromatograms of less contaminated samples, the later peaks were not identified. This shows not only due to low contamination but also due to loss of volatile substances, the less concentration-constituent peaks may not be identified. 
The retention times of the peaks of the second set of chromatograms (Table 6.10) were slightly deviated from the retention times of the corresponding peaks of the first set of chromatograms (Table 6.9). Though all the experimental conditions during the second set of analysis were kept the same as during the first set of analysis, the carrier gas flow rate was reset during the second set of analysis. The small deviation in retention time is probably due to the slight variation in carrier gas flow rate resulted from the error involved in flow measuring techniques of the instrument.

\subsubsection{Pattern variation due to loss of volatile constituents}

Graphs 6.23 (a) to 6.23 (c) show the chromatograms obtained for the pure gasoline vapour from the "Sampling vial A" (Figure 6.1) after different amounts of headspace vapour being removed. The amount of headspace vapour removed prior to analysis is less in Graph 6.23 (a) and increases in Graphs 6.23 (b) and 6.23 (c).

In the chromatographical analysis of hydrocarbons, the elusion of constituents from the GC column is in the order of the volatility of the constituents. The higher the volatility of the constituent the earlier it will be eluted from the GC column. Therefore the retention time of the constituents will be inversely proportional to the volatility of the constituents. Therefore the chromatograms shown in Graphs $\$ .23$ (a), (b) and (c), the peaks eluting earlier correspond to the more volatile constituents. 
When each time a certain amount of vapour is removed from the "Sampling Vial A" (Figure 6.1), the amount of the constituents in the headspace-vapour is altered. Initially in the sample in the headspace volume, the more volatile constituents will be dominant. Therefore the initial withdrawals tend to contain a higher proportion of these volatile constituents. As the withdrawals continued, it can be expected that the less volatile ccristituents become dominant once most of the more volatile constituents have been removed.

The above discussic explains the variation in the overall pattern of the chromatograms shown in Graphs 6.23 (a) to (c). However with careful observation on the retention times of the individual peaks of the three chromatograms, it could be recognized the composition of the vapour being the same. A slight deviation was observed in the retention times of the peaks of the chromatogram shown in Graph 6.23 (c), and the reason is the pressure of the gas supply was slightly different. The pressure of the carrier gas was $37 \mathrm{kPa}$ in Graph 6.23 (c) where as in Graphs 6.23 (a) and (b) was $34 \mathrm{kPa}$. A similar variation for the vapour of the soil contaminated with gasoline is shown in Graphs 6.24 (a), (b) and (c). It could be seen from the graphs the concentration of the constituent corresponding to peak-1 is being reduced.

\section{Experiment}


Chromatogram of Pure Gasoline Vapour Sample Size $0.25 \mathrm{ml}$, Sensitutity $1 E-10$

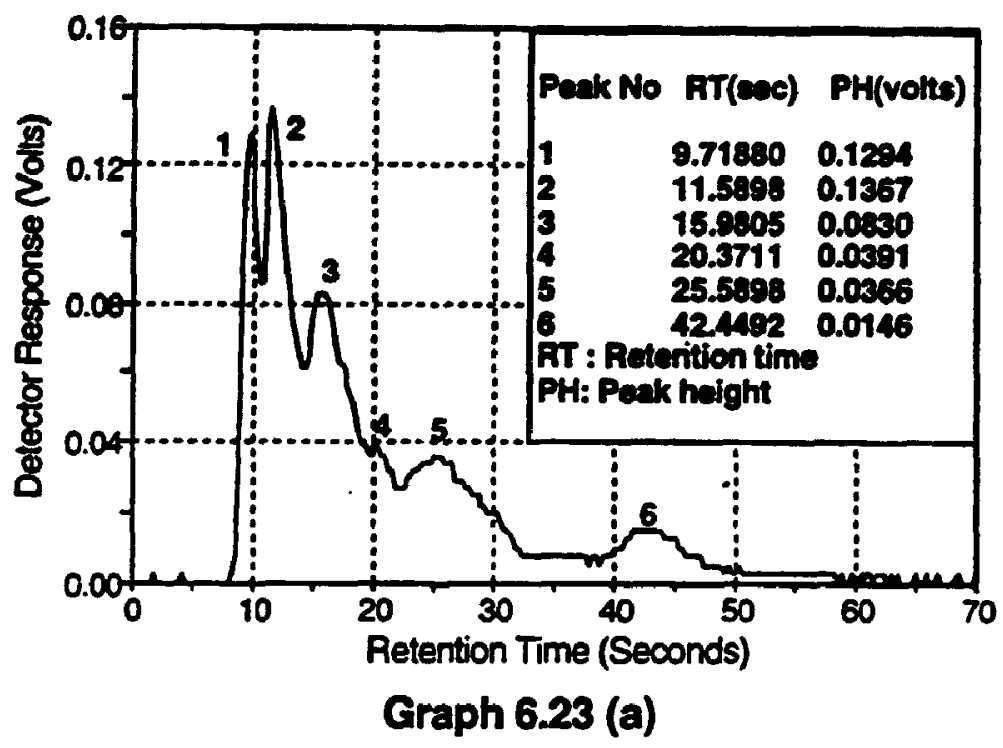

Chromatogram of Pure Gasoline Vapour Sample Size 0.05ml, Sensitivity 1E-11

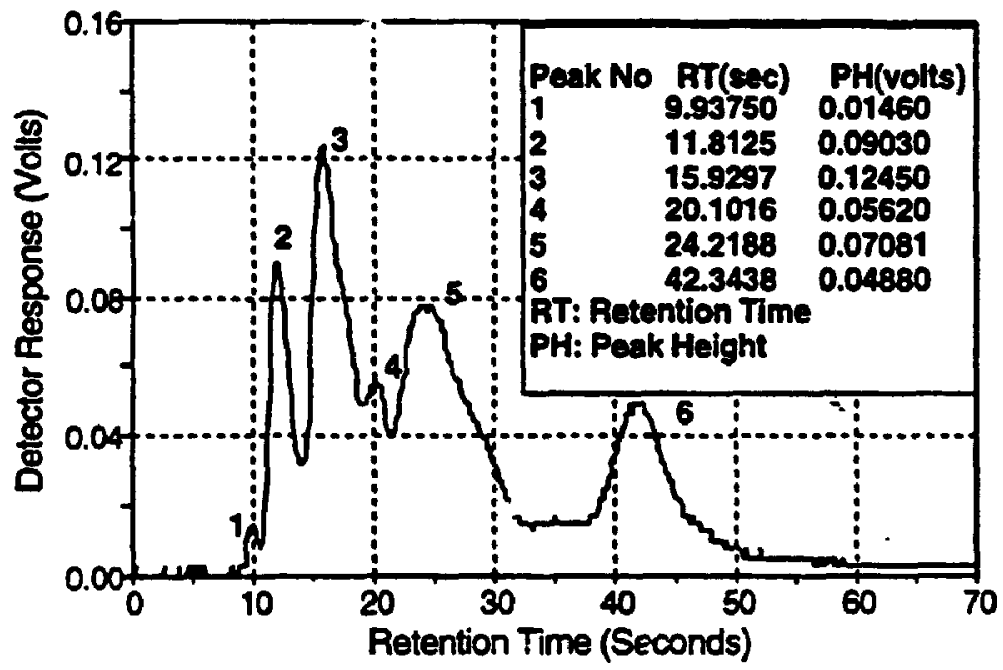

Graph 6.23 (b) 


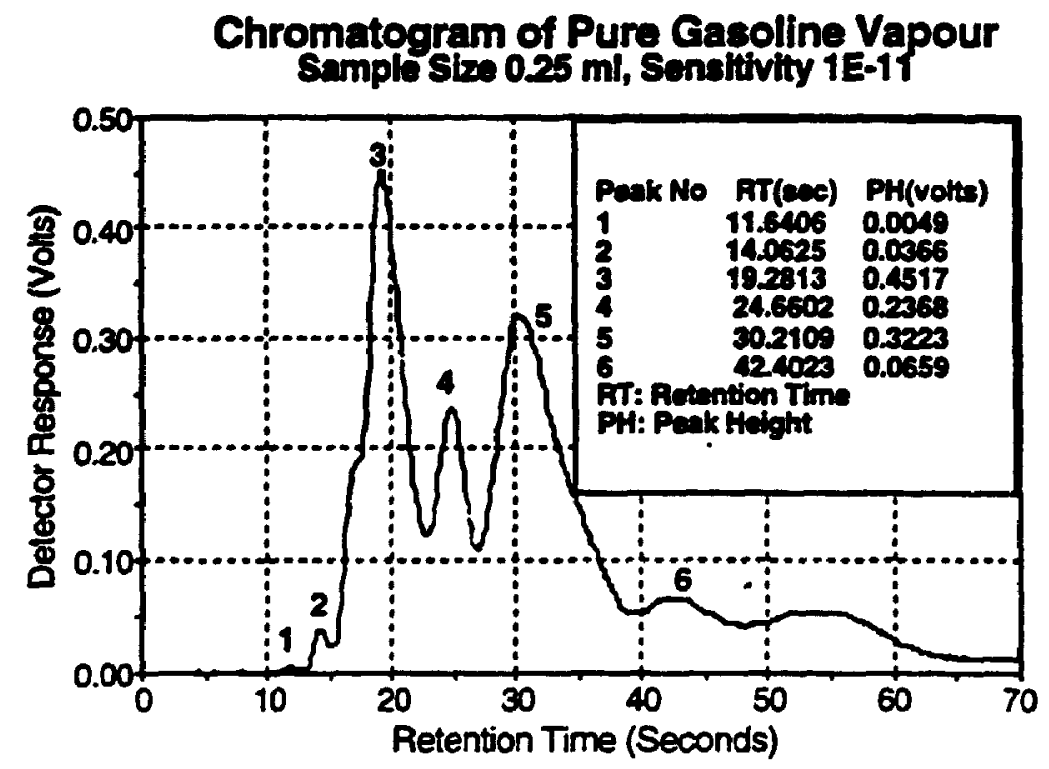

Graph 6.23 (c)

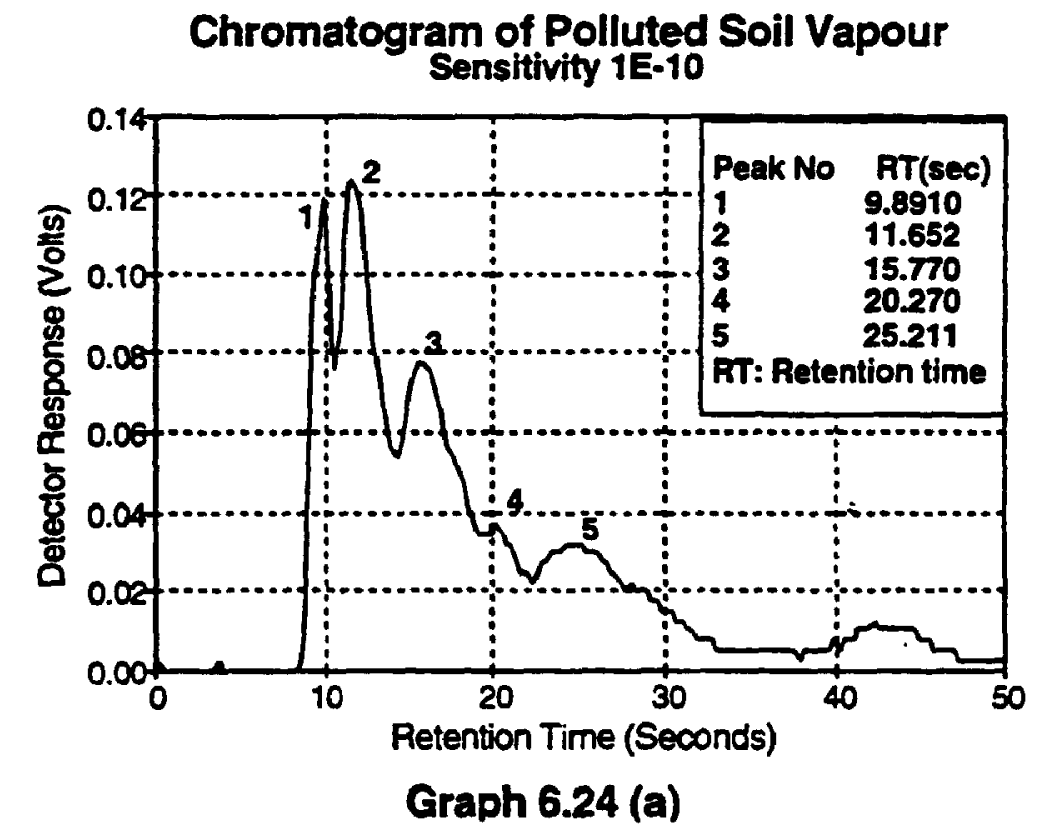


Chromatogram of Polluted Soll Vapour

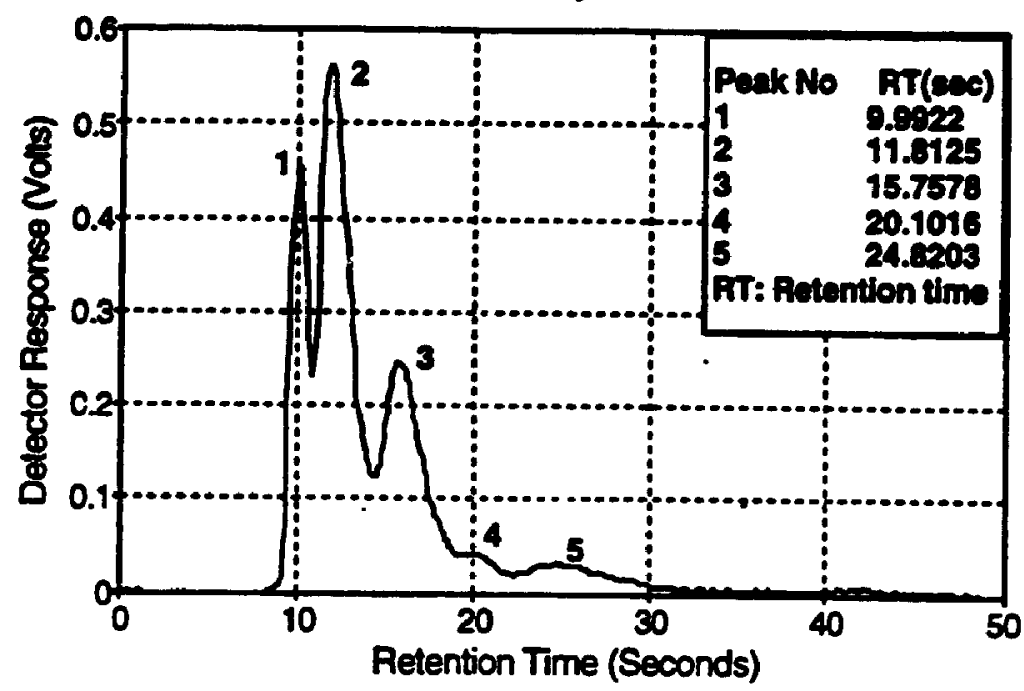

Graph 6.24 (b)

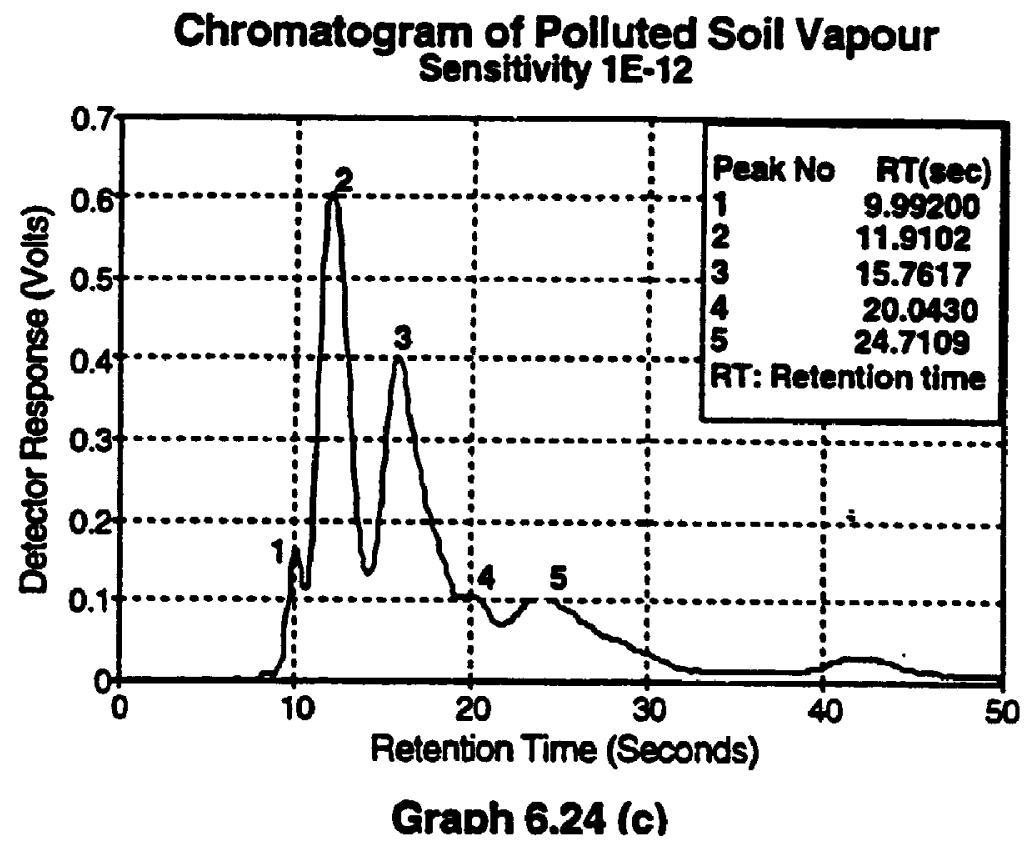




\subsubsection{Pattern Variation due to Sensitivity of the GC}

Depending on the sensitivity set, some of the peaks may or may not be identified and this will change the overall pattern of the chromatogram. When analyzing the samples by the GC, there will 'e situations in which the sensitivity of the GC has to be adjusted to different levels. When the analysis is carried out at low sensitivity (eg.. 10 $10^{-9}, 10^{-10}$ amps $/ \mathrm{mv}$ ), the constituents of low concentration may not be identified. Analyses at higher sensitivity will proportionally increase all the peak-heights (volts produced by the detector). When the GC response (peak-height or volts produced to the constituent) for any of a constituent increases beyond 1.2 volts, the amplifier of the electrometer becomes saturated and the particular component-peak will be appeared as a blunt peak. An example is shown in Graph 6.25. This chromatogram was obtained for the same gasoline vapour as the one in Graph 6.13 but at different sensitivity which is $1 \mathrm{E}-11 \mathrm{amps} / \mathrm{mv}$. The peaks 1 and 2 become blunt as the GC response to those peaks exceeded 1.2 volts. In such cases the retention times of these peaks cannot be identified for qualitative identification. However these peaks could made visible by analyzing the sample at low sensitivity. However under such settings, ail the peaks will be proportionally decreased in height. Consequently, the less concentration constituent peaks may not be visible. Therefore depending on the sensitivity of the GC set. some of the peaks may or may not be identified. Therefore analyses at different sensitivities will give more reliable information.

Experiment 


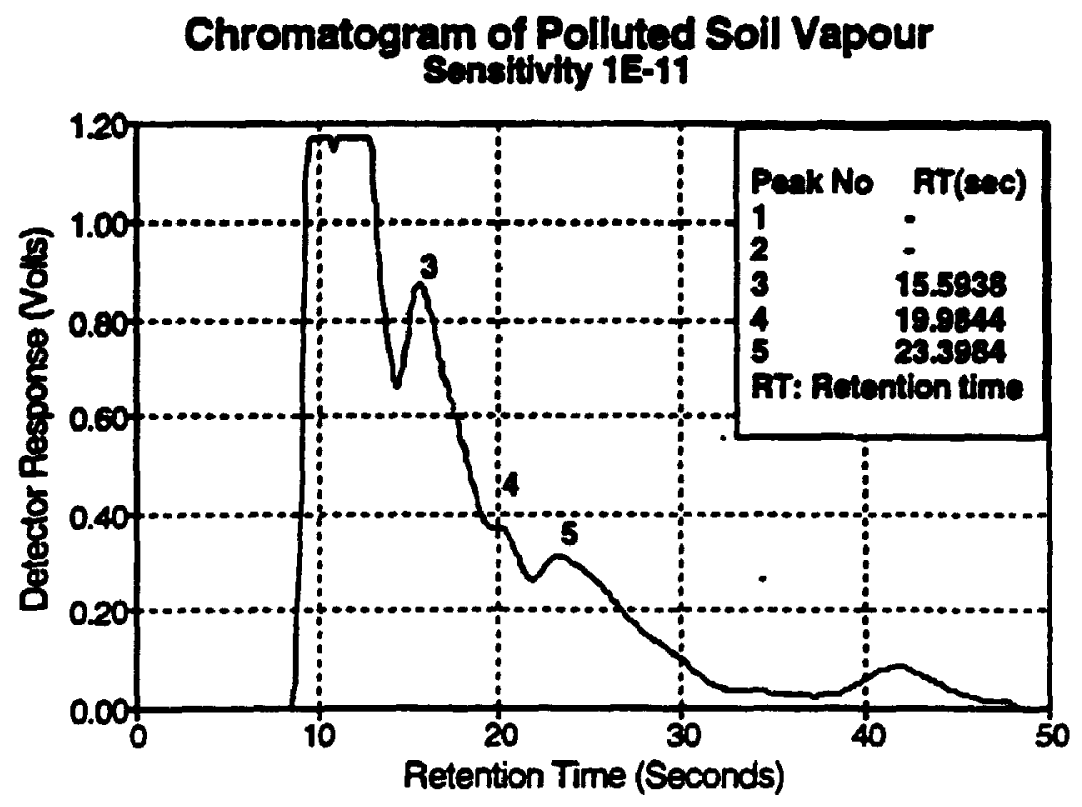

Graph 6.25 


\subsubsection{Pattern Variation due to Adsorption of the Constituents on to the Soil Matrix}

Graphs 6.26 (a) and (b) are the chromatograms obtained for the pure degraded gasoline vapour and the vapour of soil polluted with degraded gasoline. The term degraded refers the state of the gasoline after a higher amount of volatile substances being lost. The experimental conditions were the same as those in Section 6.4.2.1, exceft the sensitivity of the GC was set at $1 E-12$. In both of the chromatograms all the peaks were identified almost at the same retention times and this shows the composition being the same in both. However the overall patterns look different because the relative proportionality of the peak-heights were not the same in both of the chromatograms. The possible reason is that some of the constituents become absorbed on to the soil matrix and their concentration become less in the headspace vapour. Consequently the height of the peak decreases. For instance in Graph 6.26 (a), the height of the peak 1 is shorter than the height of the peak 5, whereas in Graph 6.26 (b) the height of the peak 1 is taller than the height of the peak 5. The constituent identified by peak 5 may have more affinity to soil matrix and may become adsorbed on to the soil when mixed with soil. 


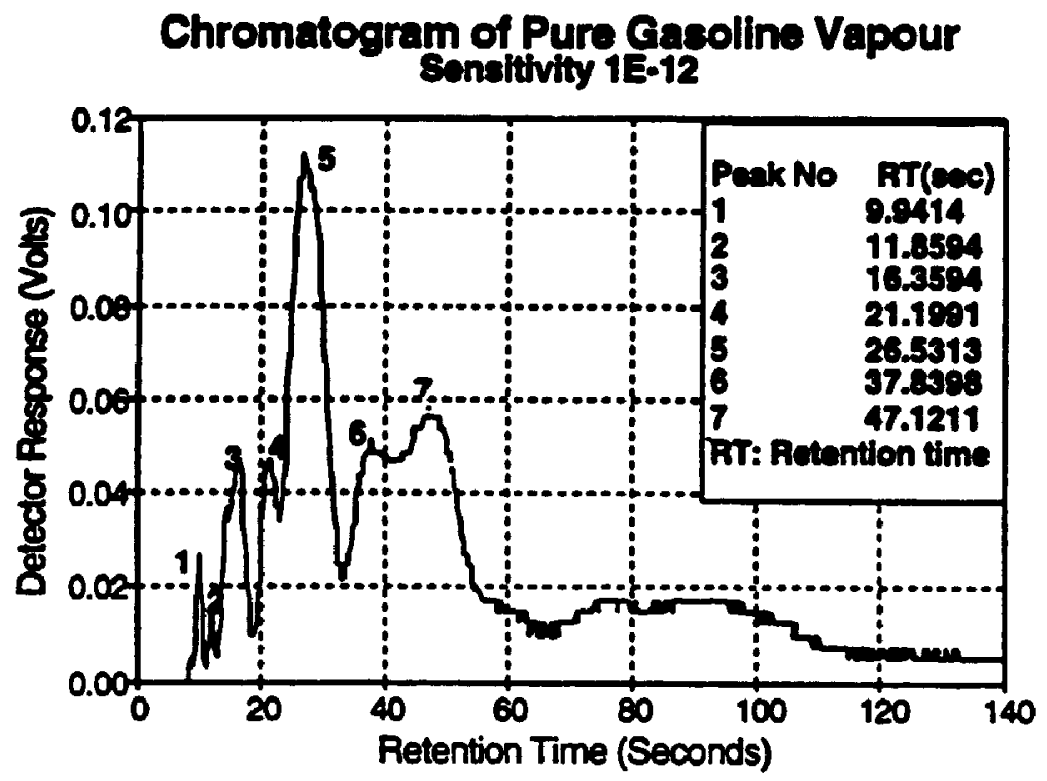

Graph 6.26 (a)

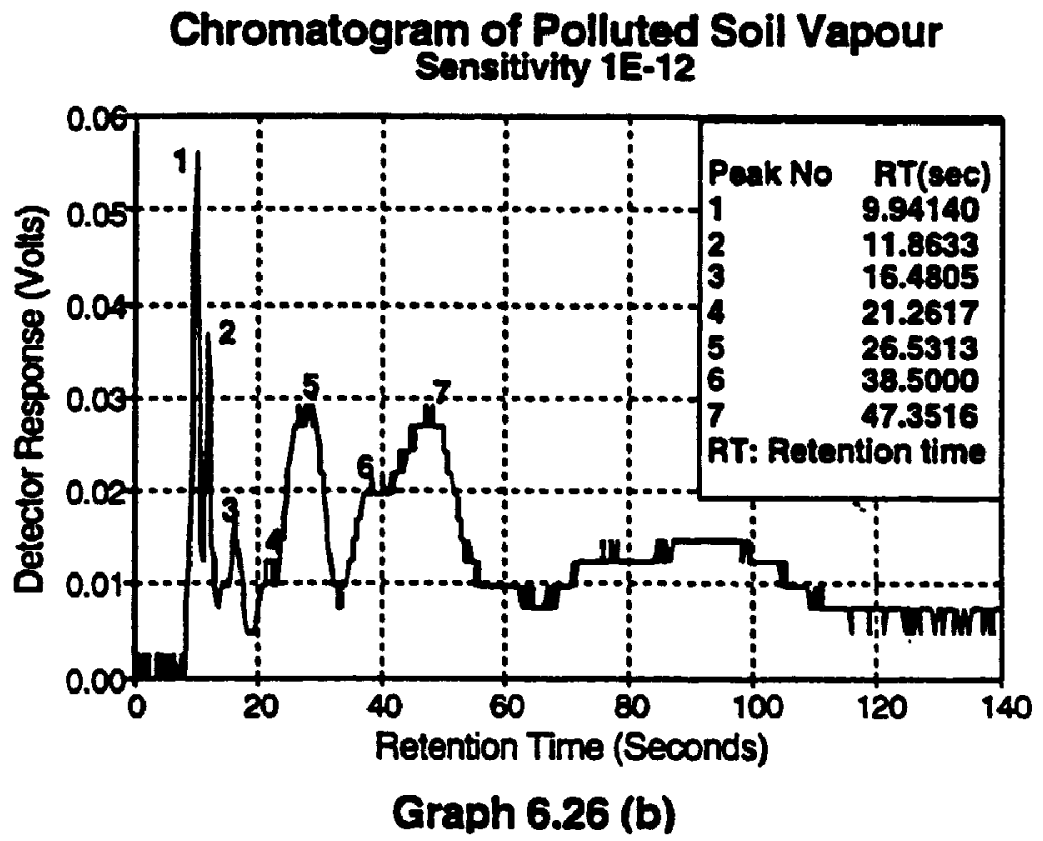

Experiment 


\subsubsection{Data interpretation for quantitative analysis}

The quantitative identification of the substances is based on the heights of the peaks of the chromatogram. The height of the peak is only proportional to the quantity present in the injected sample and not to the quantity of the gasoline in the contaminated sample. However, since it was proposed to detect the gasoline contamination by analyzing the soil vapour, a calibration curve was obtained by relating the GC response of the vapour sample to the mass content of the gasoline in the soil. Graph 6.27 shows the individual peak height vs the concentration of gasoline in soil in ppm by weight for the first set of $0.25 \mathrm{ml}$ vapour analyzed (Table 6.9). For samples of unknown concentration. if the peak height is found under exactly the same experimental conditions, the concentration could be found from the calibration curve corresponding to the peaks. However, prior to the use of this calibration curve for real samples it is essential to determine the factors that may influence the validity of this curve. One of such potential factors is loss of volatile substances prior to analysis.

Gasoline consists of a number of constituents with the boiling point varying over a wide range. Depending on the temperature of the sample, only certain constituents will escape to the vapour state from the liquid gasoline. Therefore when the soil vapour is analyzed, only the volatile constituents of the gasoline will be identified. However since it was attempted to detect the mass content of the gasoline contamination in the soil by

\section{Experiment}




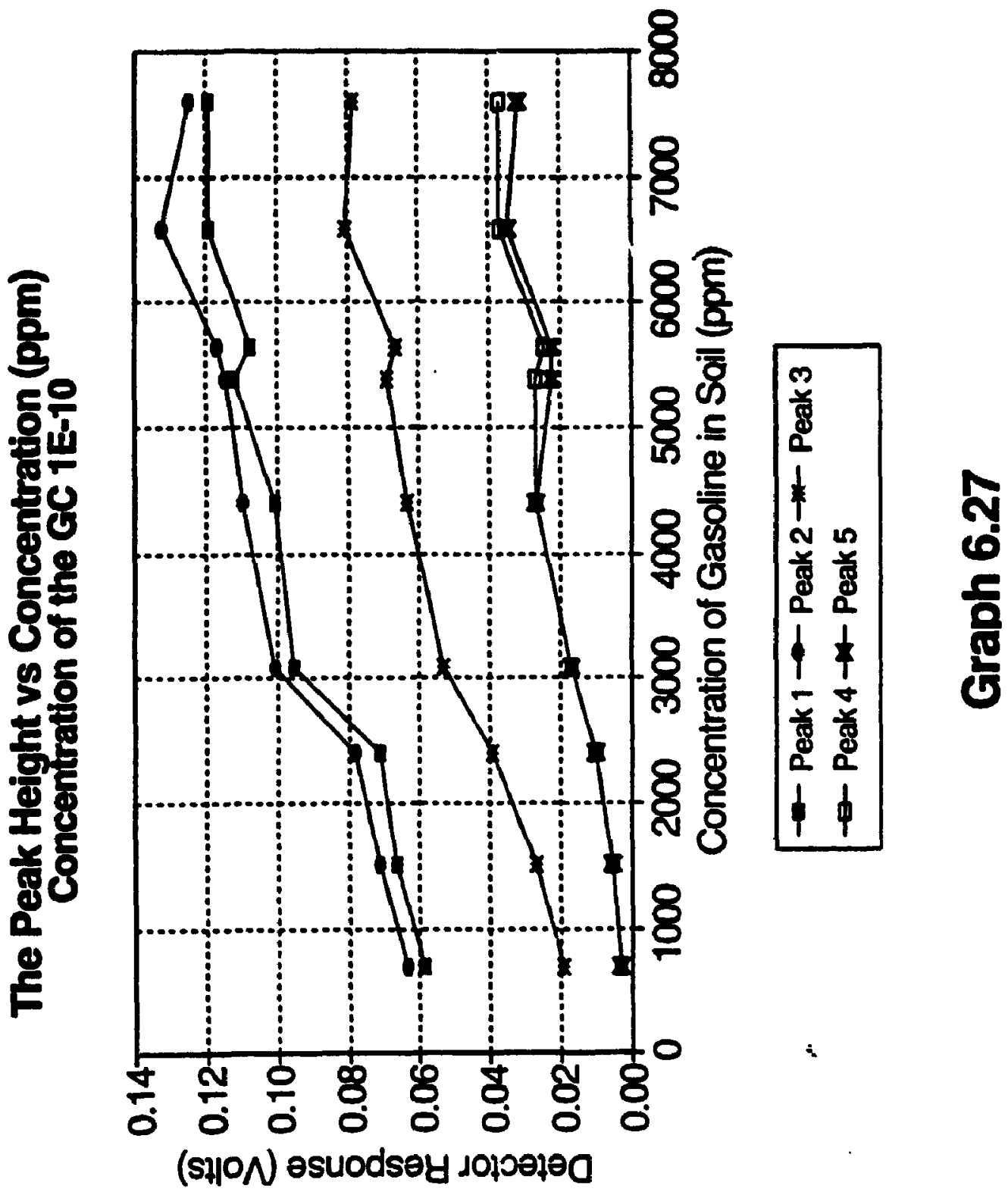

\section{Experiment}


analyzing the soil vapour, the calibration curve was obtained between the GC response of the constituents of the vapour sample to the mass content of the gasoline in soil. Therefore if the loss of volatile substances occurs, the vapour become diluted as far as the volume available for the vapour to occupy remains the same. Therefore if the analysis is carried out after some of the volatile substances are lost, the GC analysis may give a different response for the same mass content of the gasoline in soil. To test this potential variation in results, the calibration curve was obtained for the second set of soil vapour extracted from the sampling vials 1 to 9 (Table 6.7). Graph 6.28 shows the calibration curve obtained for the first two peaks of the first and the seccind set of chromatograms. The purpose of this graph is to compare the calibration curves obtained before and after loss of volatile constituents from the sampling vial.

A depiession on the calibration curves was observed for both the first and second set of analysis in the 2000 to $3000 \mathrm{ppm}$ region and the 5600 to $6000 \mathrm{ppm}$ region. The degree of this depression is less in the first set of samples withdrawn and is more to the second set of samples withdrawn. This abnormal phenomenon may be due to the natural physical processes related to constituent migration to vapour state and adsorption onto the soil matrix. 


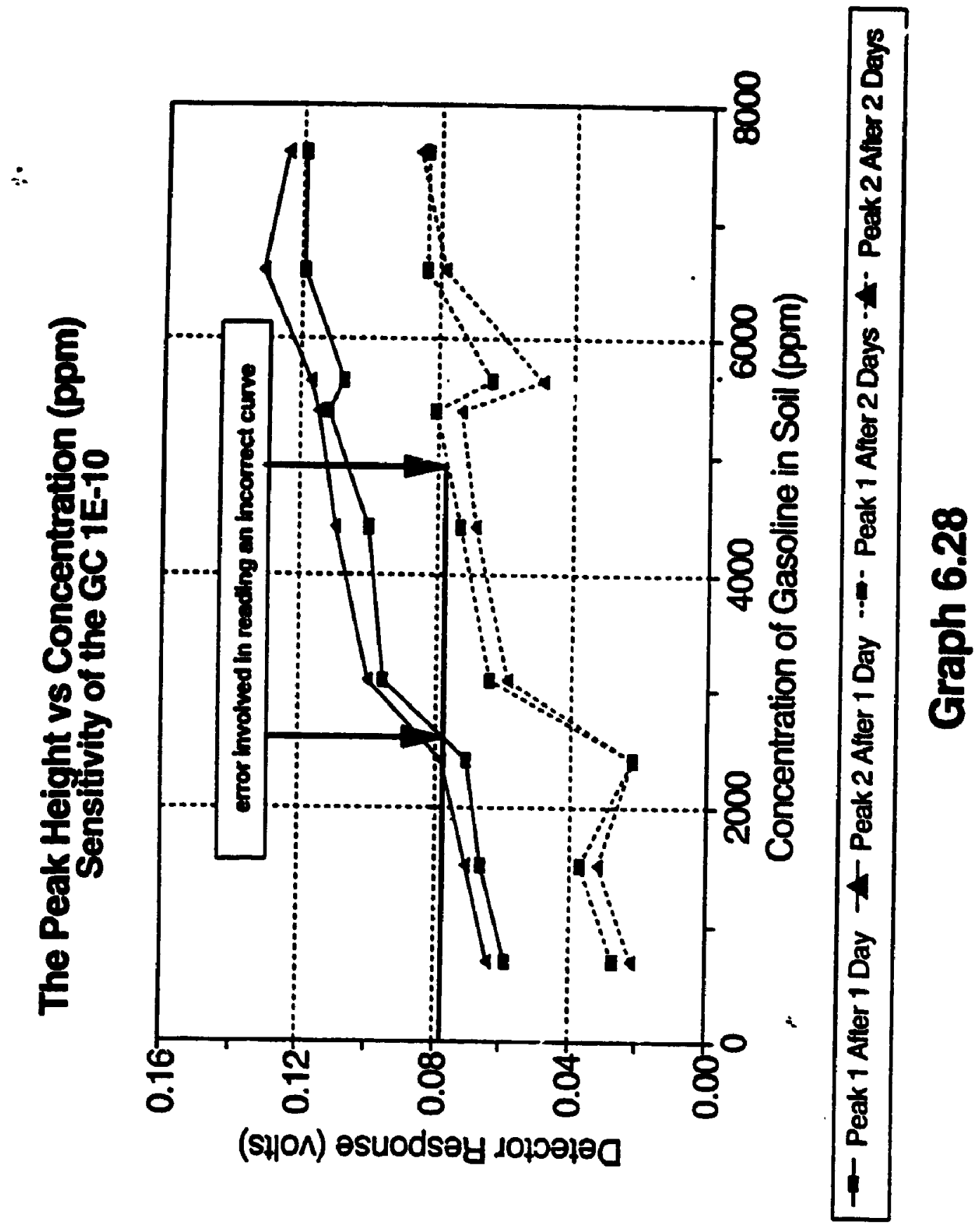


Moreover from the Graph 6.28 , it could be seen that the calibration curves will be different if volatile substances escape prior to analysis. Therefore to find the mass content of the gasoline in soil of unknown samples, it is important that the mass conterit value corresponding to the GC response should be read from the correct curve. For real samples it is impossible to know if the vapour is in the fresh state or with loss of volatile substances. From Graph 6.28 it could le seen the potential error involved in reading an incorrect curve is huge. As discussed in Section 6.4.4.1, when each time withdrawals take place, dilution of vapour in the headspace occurs. The degree of dilution will be less if the amount of vapour withdrawn each time is less. Under such conditions the deviation between the two curves shown in Graph 6.28 will be less and consequently the error involved in measuring an incorrect curve will be less.

The experimental evidence shown by B. Kolb supports this argument. The author mentioned, when each time the volatile substarices extracted from a solid and analyzed by the GC, the amount of constituents identified in the GC analysis will gradually decrease and the variation between the GC response of the vap'sur withdrawn each time to the number of withdrawals varies exponentially. This relation is graphically shown in Figure 6.3. From the figure it could be seen if the dilution of the vapour in the headspace is less, the reduction in GC response for the subsequent withdrawal analysis will be less. Consequently if the volume of vapour withdrawn each time is close to zero, the variation 
Chapter 6

147

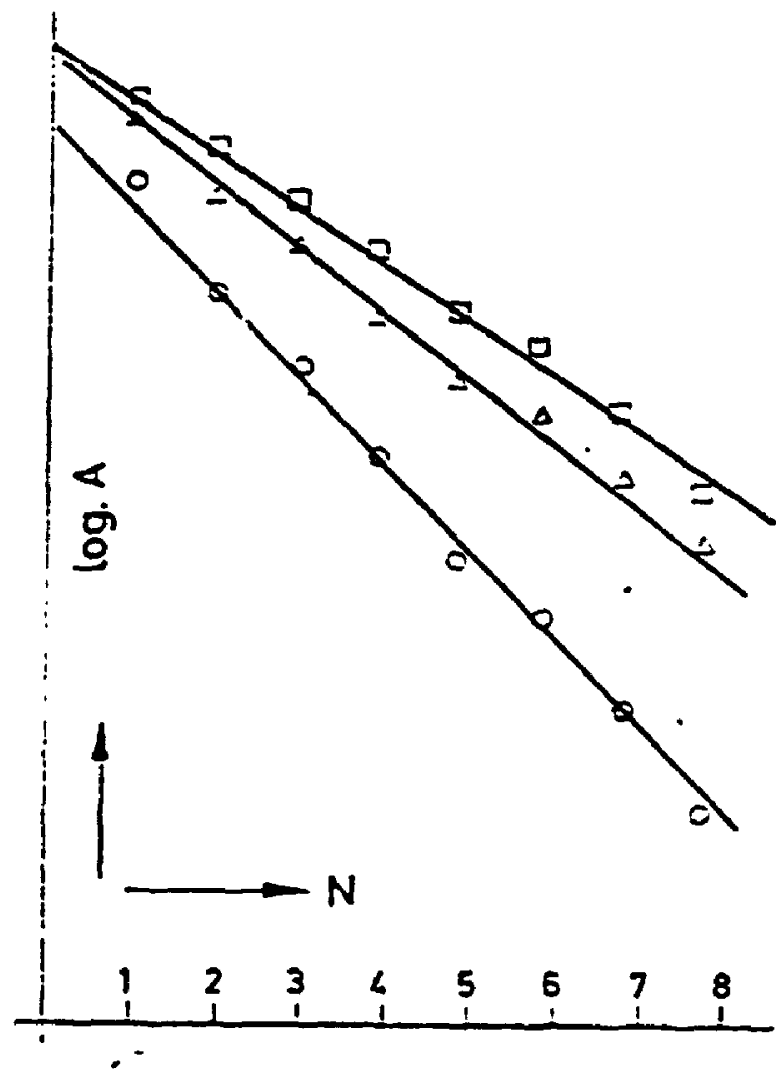

Figure 6.3

The Variation of $\log (\mathrm{GC}$ response) vs Number of withdrawals, Kolb, 1976

Experiment 
to the GC response to the number of withdrawals will be horizontal. In other words, if the loss of volatile substances prior to analy_is is extremely small, the first withdrawal curve could be used to find the concentration of unknown samples.

The situation in the experiment carried out is exaggerated to simulate the potential field condition. The volume of loss of vapour prior to second analysis is $0.25 \mathrm{ml}$ and this volume is comparable to the volume of contaminated soil sample which is 1 gram (Figure 6.2). In the real cases the loss of vapour may be less compared to the volume of contaminated soil. Therefore it could be concluded that the calibration techniques could be used to find the unknown concentration if the amount of loss of volatile constituents is extremely small.

\subsection{Practical difficulties encountered during the experiment}

\subsubsection{Adsorption of the Constituents onto the Interior Wall of the Syringes}

Plastic syringes used to transfer the soil vapour from the sampling vials to the GC column seemed to absorb some of the c.unstituents onto its interior wall. Therefore there will be a small error due to this absorption problem on the calibration curve obtained. In the next phase of this experiment it is proposed to use the glass syringes and it will improve the results. 


\subsubsection{Sensitivity}

Theoretically when a constant volume of the same sample is tested under different sensitivities, the peak heights produced for the corresponding constituents on the chromatograms at different sensitivities should be the products of the values shown in Table 6.11. However, practically it was seen the error involved in doing such calculation to find the response at different sensitivities is more than $20 \%$. As a result the samples at different concentrations (samples 1 to 9 , Table 6.7) could not be tested at the appropriate sensitivities related to the concentration. Saturation of peaks was observed for the highest concentration tested $(7600 \mathrm{ppm})$ at sensitivities of $10^{-12}$ and $10^{-11}$, therefore this sample was tested at a sensitivity of $10^{-10}$. Consequently all other samples were tested at this concentration for the comparison purposes.

From the results obtained in Table 6.9 and 6.10 , the later peaks were not identified in the less contaminated soils. From this it should not be assumed that the sensitivity of this method is low. If the samples were tested at a sensitivity of $10^{-12}$ the peak-heights would be 100 times the values shown in the Tables 6.9 and 6.10 . In that case all later peaks would be identified. 
Multiplying Value for Different Sensitivities of the GC

\begin{tabular}{lllll}
\hline Sensitivity of the GC & $10^{-9}$ & $10^{-10}$ & $10^{-11}$ & $10^{-12}$ \\
\hline $\begin{array}{l}\text { GC response for same sample } \\
\text { size at same concentration }\end{array}$ & $h$ & $10 \times h$ & $100 \times h$ & $1000 \times h$ \\
\hline
\end{tabular}

Table 6.11

\subsubsection{Background Noise}

The background noise of $3 \mathrm{mv}$ in a full scale (lv) was observed throughout the experiment regardless of the sensitivity of the GC. Therefore there will be an error as a result of this background noise on the quantitative results. Moreover this error may or may not change the position of the peaks. Therefore there may be a small error due to the background noise on the qualitative results as well.

\subsection{Discussion}

In addition to the factors discussed from Section 6.4.4 to Section 6.4.5. other factors which are discussed in Chapter 5 will also affect the qualitative and the quantitative results obtained for the experimental soil. In addition presence of any foreign substances will change the results over a wide range. Removing unwanted constituents or extracting hydrocarbon constituents selectively prior to analysis will reduce the complexity of this problem. For instance, addition of silica gel prior to analysis will remove the polar compcund: such as water, soaps, alcohols, pesticides and fertilizers. In addition specific 
or selective detectors (Section 3.1.2) could be employed to reduce the problem due to presence of foreign substances.

The quantitative results obtained in this studies depends on the ratio between the volume of the soil to the volume of the headspace-vapour as well.

\subsection{Conclusion}

The retention times of the unresolved peaks of the chromatograms of gasoline contaminated samples prepared separatively were consistent as far as the experimental conditions remain the same. Therefore qualitative identification of gasoline contaminated soil is possible by analyzing the soil vapour for the experimental soil. Various factors such as sensitivity of the GC, loss of volatile substances, adsorption of the volatile constituents on to the soil matrix may change the overall pattern of the chromatogram over a wide range. Importance should be given to see the existence of the peaks at specific retention times where the peaks were identified for the known samples. If the analysis is carried out at lower sensitivity due to saturation of the peaks of higher concentration, the analysis should also be carried out at higher sensitivity to identify the peaks of minor concentration constituents. If relative concentration of any of a constituent peak is very high compared to other constituents, analysis at different sensitivities alone may not help and sample size should be reduced.

\section{Experiment}


Only the constituents which have boiling point less than the sample temperature will escape to vapour phase and therefore the analytical results obtained for qualitative identification depends on the temperature of the sample. At a higher sample temperature, additional type of constituents of which the boiling point is less than the new-highertemperature may be identified and it will make the pattern different.

There exists an acceptable relation between the mass content of the gasoline in soil to the peak heights of the chromatograms obtained for the soil vapour samples. The factors which influence this relation include the loss of volatile constituents prior to analysis. size of the vapour sample analyzed, and the temperature. If loss of volatile constituents occurs prior to analysis, the error involved in finding the mass content value from the calibration curve may be huge. 


\section{Chapter 7}

\section{Summary and Conclusions}

\subsection{Overview}

Chromatographical, spectrographical and geophysical methods have been practised to identify petroleum contaminated soils. In all these methods the identification is based on comparing the response of known substances to the unknown substances. Based on the theoretical techniques involved in these methods. the.e methods are reliable and convenient when used to identify pure substances. However the problem arises when these methods are applied to identify substances with impurities. This will be the case when these methods are applied to identify petroleum products in soil. The presence of impurities will vary the results over a wide range and this causes lot of uncertainties in these methods. Moreover when the sample subject to natural processes (see Chapter 5) the composition of the sample changes with time. This causes additional uncertainties.

In chromatographical methods the substances can be selectively identified from a sample by choosing proper experimental conditions. the type of column and detector and by suitable sample preparation. In spectrographical methods the substances can be selectively identified from a sample by choosing proper range of wave-length radiation and by suitable sample preparation. In geophysical methods the substances can be 
selectively identified from a sample only by choosing proper sample preparation. In all these methods in sample preparation the impurities are removed as much as possible prior analysis to improve the reliability of the test results. As a result of these problems further research is needed to improve the reliability of these methods. Further there is a lack for a fast and reliable field apparatus to identify petroleum contaminated soils.

This project is carried out to provide the necessary information to improve the reliability of thesi .ethods and to be a supportive document for the development of a fast and reliable method and a field apparatus to identify petroleum contaminated soils.

In the proposed plan. the field apparatus will be a combination of a modified cone penetrometer and a portable gas chromatometer to analyze the soil vapour. The cone penetrometer will be used to determine the soil type and the engineering properties of the soil. The modifications to the cone penetrometer will be made to sample soil vapour in the ground at various depths. The gas chromatometer was selected for the analysis of soil vapour because in chromatographical methods sample constituents can be selectively identified to a greater extend compared to the other methods. In order to interpret the test results in the field, calibration data must be obtaintd in the laboratory. This project is aimed at investigating the potential of this procedure. 


\subsection{Conclusions}

\subsubsection{Qualitative Identification}

- Qualitative identification is possible by identifying soil vapour samples by gas chromatometer

- Interpretation of test results can be based on the overall patterns of the chromatograms

- Factors cause the variation of pattern include

- Loss of volatile constituents prior to analysis

- Sensitivity of the GC

- Adsorption of the constituents onto the soil matrix

- Temperature of the soil sample

- Presence of impurities

- Sample size

- Relative concentration of different constituents

\subsubsection{Quantitative Identification}

- There exists a relationship between the mass content of the gasoline in soil to the GC response

- This relationship is affected by the loss of volatile constituents

- Therefore quantitative identification is possible if loss of volatile substances is extremely small 


\subsection{Future experiments that may be conducted}

- A similar experiment could be carried out for real soils by adding known amount of gasoline. Analysis of soil vapour after addition of water will give information on the effect of solubility of the volatile constituents in water

Since the temperature of the real soils will vary to a wide range from season to season, a similar experiment at different temperatures will give information on the effect of the sample-temperature on the qualitative and quantitative results

- Small scale model tests for different soils could be carried out to see the effect of vapour migration on the analytical test results

- Improved accuracy can be obtained by testing larger samples

- With Improved techniques other members in the hydrocarbon family can be tested 


\section{References}

Amaral, O.C., Olivella, L., Grimalt, J.O. and Albaiges, J. 1984. Combined Solvent Extraction-Purge and Trap Method for the Determination of Volatile Organic Compounds in Sediments. Journal of Chromatography A, Volume 675, pp. 177-187.

Christian, D.G. 1986. Analytical Chemistry, fourth edition, Wiley: New York.

DeAngelis, D., Quantitative Determination of Hydrocarbons in Soil (Extraction-Infrared Adsorption Method). Mobil oil corporation, Technical Services Laboratories, New Jersey.

Debbrecht, F.J. 1985. Qualitative and Quantitative Analysis by Gas Chromatography. Modern Practice of Gas Chromatography, 2nd edition. pp. 359-421.

Donnelly, J.R., Abdel Hamid, M.S., and Jeter, J.L., Gurka, D.F. 1993. Application of Gas Chromatographic Retention Properties to the Identification of Environmental Contaminants. Journal of chromatography, Volume 642, pp. 409-415.

Dragun, J., Mason, S.A. and Berkach, J.H. 1991. What Do We Really Know About the Fate of Diesel Fuel in Soil Systems. Hydrocarbon Contaminated Soils, Volume 1, edited by Calabrese, E.J., and Kostecki, P.T. pp. 149-165. 
Drozd, J., and Novak, J. 1979. Headspace Gas Analysis by Gas Chromatography. Journal of Chromatography, Volume 165, pp. 141-165.

Fitzgerald, J. 1990. On Site Analytical Screening of Gasoline Contaminated Medial Using

a Jar Headspace Procedure. Petroleum Contaminated Soils, edited by Calabrese, E.J., Kostecki, P.T., Volume 2.

Hope P. 1983. An Introduction to Multivariate Analysis of Environmental Data. Analytical Aspects of Environmental Chemistry, edited by Natush, B.. and Hopke. P. pp. 219-162.

I.T. Corporation. Manual of Sampling and Analytical Methods for Petroleum Hydrocarbons in Ground Water and Soil. Knoxville, Tennessee, edited by Kame. M.. API Publication Number 4449, Health and Environmental Sciences Department.

Jones, V.T. 1987. Overview of Hydrocarbon Extractions in Soils and Waters: Research Needs and Problems. in Proceeding: Sampling and Analytical Methods for Determining Petroleum Hydrocarbons in Groundwater and Soil, American Petroleum Institute.

Karasek, F.W., and Clement. R.E. 1988. Basic Gas Chromatography - Mass Spectrometry. Principles and Techniques. 
Kolb, B. 1976. Application of an Automated Headspace Procedure for Trace Analysis by Gas Chromatography. Journal of Chromatography, Number 122. pp. 553-568.

Kolb, B. 1980. Applied Headspace Gas Chromatography.

Kolla, P. 1994. Gas Chromatography, Liquid Chromatography, and Ion Chromatography Adapted to the Trace Analysis of Explosives. Joum al of Chromatography A, Volume 674. pp. 309-318.

Law, RJ. and Portmann, J.R. 1982. Report on the First ICES Inter comparison Exercise on Petroleum Hydrocarbon Analysis in Marine Samples. International Council for the Exploration of the Sea, Copenhagen, Denmark, Report DE 8475001 í.

Litzwnberg, R.A., Oliver, R.H., and Severns, J.J. 1992. The Use of a Portable Infrared Analyzer to Perform Onsite Total Petroleum Hydrocarbon Analysis. Hydrocarbon contaminated soils and groundwater, Volume 2, edited Kostecki, P.T., and Calabrese, E.J. pp. $169-180$.

Lynch, T.P. 1995. Supercritical Fluid Extraction. Chromatography in The Petroleum Industry. Journal of chromatography library, Volume 56.

Mapes, J.P., Mckenzie, K.D., Arrowood, S.P., Studabakar, W.B., Allen, R.L., Manning, 
W.B., and Friedman, S.B. 1993. PETRO RISc ${ }^{\mathrm{TM}}$ soil: A Monoclonal Antibody Immuno Assay for the Rapid, Onsite Screening of Gasoline and Diesel Fuel Contaminated soil. Hydrocarbon contaminated soils and groundwater, volume 3, edited by Paul $\mathbf{I}$. Kostecki and Edward J. Calabrese. pp. 47-56.

Mckown, M.M., Warner, J.S., Riggins, R.M., Miller, M.P.. Heffelfiger, R.E., Garrett, B.C., Jungelaus, G.A., and Bishop, T.A. 1981. Devclopment of Methodology for the Evaluation of Solid Wastes. Report prepared for I.S Environmental Protection Agency Effluent Guidelines Division, Washington, D.C. By Battelle Columbas Laboratories. Columbus, under contract No. 68-03-2552.

McMinn, D.G., and Hill. H.H. 1992. The Flame Ionisation Detector. in Detectors for Capillary Chromatography, edited by Hill, H.H.. and McMinn, D.G. pp. 7-21.

Navak, J. 1988. Qualitative Analysis by Gas Chr.Jmatography. Second Edition, Volume 41.

Nadeau, R.J., and Lafornara, J.P. 1985. Measuring Soil Vapours For Defiring Subsurface Contaminant Plumes. Contaminated Soil, First International TNO Conference on Contaminated Soil, Utrecht, The Netherlands, 11-15 November. pp. 411-413.

O’Brien, M.J. 1985. Detectors. Modem Practice of Gas Chromatugraphy, 2nd editic n. pp. 
211-1?:.

Parr, J.L., Walters. G., and Hoffman, M. 1991. Sanıpling and Analysis of Soils for Gasoline Range Organics. Hydrocarbon contaminated soils and groundwater, Volume 1, edited By Kostecki, P.T.. and Calabrese, E.J. pp. 105-132.

Poole, C.F., and Poole, S.K. 1991. Instrumental Aspects of Gas Chromatography. Chromatography Today. pp. 231-309.

Potter, L. 1990. Fingerprinting Petroleum Products: Unleaded Gasolines. Fetroleum Contaminated soils, Volume 3.

Puttmann, W. 1988. Microbial Degradation of Petroleum in Contaminated Soil Analytical Aspects. Contaminated Soil 88, Second International TNO/BMFT Conference on Contaminated Soil, Hamburg. Federal Republic of Germany. 11-15 April. pp. 188-199.

Reisinger, H.J., Keri, J.M., Hinchee, R.E., Burris, D.R., Dykes. R.S., and Simpson. G.L. 1990. Petroleum Contaminated Soils, edited by Calabrese. E.J., and Kostecki. P.T, Volume 2, Lewis publishers.

Rosemblem, J., and Carlson, F. 1988. Alternative Investigation Techniques for Ground Water Contamination Sites: Soil Gas Testir: 3 and Spinner-Logging? Depth Sampling - A 
Case Study. Contaminated Soil 88, Second International TNO/BMFT Conference on Contaminated Soil, Hamburg, Federal Republic of Germany. 11-15 April. pp. 179-185.

Schantz, M.M., and Chesler, S.N. 1986. Supercritical Fluid Extraction Procedure for the Removal of Trace Urganic Species from Solid Samples. Joumal of chromatography, Volume 363. pp. 397-401.

Schwendeman, T.B. 1987. Eternal Tank Release Detection and Monitoring. Underground Storage Systems, edited by Schwendeman. T.G.. and Kendall Wilcox. H. pp. 53-111.

Selby, D.A. 1991. A Critical Review of Site Assessment Methodologies. Hydrocarbon contamiılated soils and groundwater, Volume 1. edited By Paul T.K and Edward J.Calabrese. pp. 149-160.

Seto, Y. 1994. Determination of Volatile Subrtances in Biological Samples bv Headspace Gas Chromatography. Journal of Chromatography A, Volume 674. pp. 25-62.

Skoog, D.A., and West. D.M. 1982. Fundamentals of Analytical Chemistry. Fourth edition. Saunders College Publishers, Philadelphia.

.ilofstra. J.G. 1985. Rapid On-site Analysis of Soil Contamination. Contaminated Soil. First International TNO Conference on Contaminated Soil. Utrecht. The Netherlands. 11- 
15 November. pp. $415-417$.

Stewart. J.E. 1970. Infrared Spectroscopy, Experimental Methods and Techniques. Marcel Dekier, INC., New York. pp. 13-26.

Suatoni, J.C. 1979. Hydrocarbon Group-type Analysis by High Performance Liquid Chromatography. In Chromatography in Petroleum Analysis, edited by Altglt, K.H., and Gouw, T.H., Volume 2.

Supina, W.R. 1985. Packed Columns/Column Selection in Gas Chromatography. Modern Practice of Gas Chromatography, second edition. pp. 117-156.

Sutton, D.L. 1985. Com zonent analysis by high resolution gas chromatography. Appendix b-7, In Manual of Sampling and Analytical Petroleum Hydrocarbon in Groundwater and Soil Prepared by I.T. Corporation, Knoxville, Tennessee, edited by Meryl Kane.

SWRCB (State Water Resources Control Board). 1989. Leaking Underground Fuel Tank Manual:Guidelines for Site Assessment. Cleanup. and Underground Storage Tank Closure State of Caiifornia Leaking Underground Fuel Tank Force. Sacramento, California. revised 5 th April. p. 121.

Chang, T.C.L. 1968. Gas Chromatographic Methods for Mixtures of Inorganic Gases and 
$\underline{C}_{1}-C_{2}$ Hydrocarbons. Journal of Chromatography, Volume 137. pp. 14-26.

U.S. Environmenta! protection Agency. 1982. Test Methods for Evaluating Solid Waste

Physical/Chemical Methods Office of Solid Waste. Washington, DC publication SW-846. 


\section{Appendix}

This section provides a set of columns and the experimental conditions that has been used fur hydrocarbon analysis in literature. The information is retrieved from ref 62 , manual for sampling and analytical methods for petroleum hydrocartons in groundwater and soil.

A column of $12 \mathrm{ft} \times 0.25$ stainless steel tubing packed with $25 \%$ SE-30 gum rubber on 30-60 mesh firebrick was used to test the solubility of hydrocarbons in water. The use of a FID permits the measurement of relatively low concentrations of hydrocarbons in water.

Reference: McAullife, C., Solubii.y in water of Paraffins. Cycloparaffin. Olefin, Acetylene, Cycloolefin, and Aromatic Hydrocarbons, J.Physical Chem. 70:1267, 1966.

Thirteen $C_{5}-C_{8}$ hydrocarbons were separated on a $300 \mathrm{ft} \times 0.02$ inches internal diameter soft glass capillary column coated with a $5 \%$ suspension of CD-100, a colloidal hydrophobic silica in heptane. Good separation was achieved under isothermal conditions $32^{\circ} \mathrm{F}$.

A second column with same dimensions as first but coated with Syloid 244 and lgepal CO430 mixture, afforded a superior separation of the 13-component hydrocarbon mixture and a petroleum distillate fraction under isothermal 
conditions $\left(79^{\circ} \mathrm{F}\right)$. In both cases a FID was used.

Reference: Mathews, R.G., Torres, J., and Schwartz, R.D.. Glass Capillary Adsorption Columns for Gas Chromatography, J.Chromatography. 186:183. 1979.

Light boiling $\mathrm{C}_{3}-\mathrm{C}_{14}$ hydrocarbons were separated on a $60 \mathrm{~m}$ narrow bore $(0.264$ $\mathrm{mm}$ ) fused silica capillary column in a GC with temperature programming. Very good separation was achieved. A FID was used.

Reference: Lubeck, A.. Analysis of Light Boiling Hydrocarbons in Water. Marathon oil company. Colorado, Manual of Sampling and Analytical Methods for Petroleum Hydrocarbons in Groundwater and Soil, 1987.

Lubeck, A., Free Product Analysis. Proceedings: Sampling and Analytical Methods for Determining Petroleum Hydrocarbons in Groundwater and Soil. American Petroleum Institute, 1987.

A column of $50 \mathrm{~m} \times 0.21 \mathrm{~mm}$ internal diameter, $0.5 \mu \mathrm{L}$ film thickness PNA/PONA fused silica capillary was used to analyze hydrocarbons with final bciling point less than $700^{\circ} \mathrm{F}\left(\mathrm{n}-\mathrm{c}_{22}\right)$. It was stated that targeted compounds such benzene, toluene, ethylbenzene. and xylene were separated, identified. and accurately quantified along with most other major compounds. For better separation 
temperature program techniques were used. The oven was held at $35^{\circ} \mathrm{C}$ for 30 minute. It is then linearly programmed at $2^{\circ} \mathrm{C} /$ minute to $70^{\circ} \mathrm{C}$ and from there are $3^{\circ} \mathrm{c} /$ minute to a final temperature of $250^{\circ} \mathrm{C}$. The individual components were detected and measured by a FID.

Reference: Sutton, D.L., Component Analysis By High Resolution Gas Chromatography, Marathon Oil Company, Colorado, Private contribution to API for inclusion in this publication, Manual of Sampling and Analytical Methods for Petroleum Hydrocarbons in Groundwater and Soil, 1987.

A column of $400 \mathrm{ft} \times 0.02 \mathrm{in}$ internal diameter soda lime glass coated with a $7.5 \%$ suspension of PZ 240 (prepared from syloid 244 and lgepal RC-520) in n-, entane was used to separate $C_{5}$ to $C_{12}$ hydrocarbons. The column temperature was kept at $25^{\circ} \mathrm{C}$ for 10 minutes and then it was increased at a rate of $1^{\circ} \mathrm{C} /$ minute until the temperature reaches $110^{\circ} \mathrm{C}$. Also the possibility of separation of aromatic hydrocarbons in gasolines on a glass colvimn coated with "polar" liquid phases (Syloid 244, Carbowax 350 and cyanoethylformamide) under isothermal conditions $\left(90^{\circ} \mathrm{C}\right)$ was mentioned. In both columns, FID was used.

Reference: Mathews, R.G., Torres, J., and Schwartz. R.D.. Applications of SurfaceModified Porous Silicas to Glass Capillary Column Preparation, J. Chromatography 199:97, 1980. 
An open tubular column of $0.2 \mathrm{~mm}$ internal diameter sodalime glass coated with OV-101 methylsilicone fluid in two different film thicknesses, approximately 0.2 and $0.9 \mu \mathrm{ms}$, was used to analyses hydrocarbons with upper boiling range of 230 $250^{\circ} \mathrm{C}$ in gasolines. A FID was used.

Reference: Johansen, N.G., Ettre, L.S., and Miller, R.L., Quantitative Analysis of Hydrocarbons by Structural Group Type in Gasolines and Distillates. J. chromatography 286:393, 1983.

A cclumn of $12 \mathrm{ft} . \times 1 / 8 \mathrm{in} .10 \%$ OV-1 on $60 / 80$ mesh Chromosorb $\mathrm{W}$ was used to obtain boiling point fingerprint of gasoline. The column was temperature programmed from $70^{\circ} \mathrm{C}$ to $360{ }^{\circ} \mathrm{C}$ at a rate of $8^{\circ} \mathrm{C} /$ minute.

Reference: Rygle, K.J., Methods for 'Free" Product Analysis, Gulf Research Development Company, Pennsylvania, Proceedings: Sampling and Analytical Methods for Determining Petroleum Hydrocarbons in Groundwater and Soil, American Petroleum Institute, 1987.

A column of $10 \mathrm{ft} . \times 0.5 \mathrm{in}$. packed with $20 \% \mathrm{CEF}$ on chromosorb $\mathrm{R}$. was used to determine aromatic hydrocarbons, benzene, toluene, ethylbenzene, orthometa and paraxylene in gasoline. Detectors used with GC were FID and TCD.

Reference: Rygle, K.J., Methods for 'Free' Product Analysis, Gulf Research Development 
Company, Pennsylvania, Proceedings: Sampling and Analytical Methods for Determine Petroleum Hydrocarbons in Groundwater and Soil, American Petroleum Institute, 1987.

A column of 900 -ft glass open tubular coated with squalane was used to separate 122 peaks of $\mathrm{C}_{3}$ to $\mathrm{C}_{9}$ hydrocarbon components. The analysis time was 20 hours.

Reference: Desty D.H., Coldup, A., and Swanton, W.T., ISA Proceedings of International

Gas Chroniatography, Michigan State University, Easl Lansing, Michigan, June 1961.

A 200ft. squalane column was used to determine $C_{3}$ to $C_{12}$ hydrocarbons in gasoline. The analysis time was 2 hours.

Reference: Sanders, W.N., and Maynard, J.B., Analytical Chemistry, 40:527, 1968. 

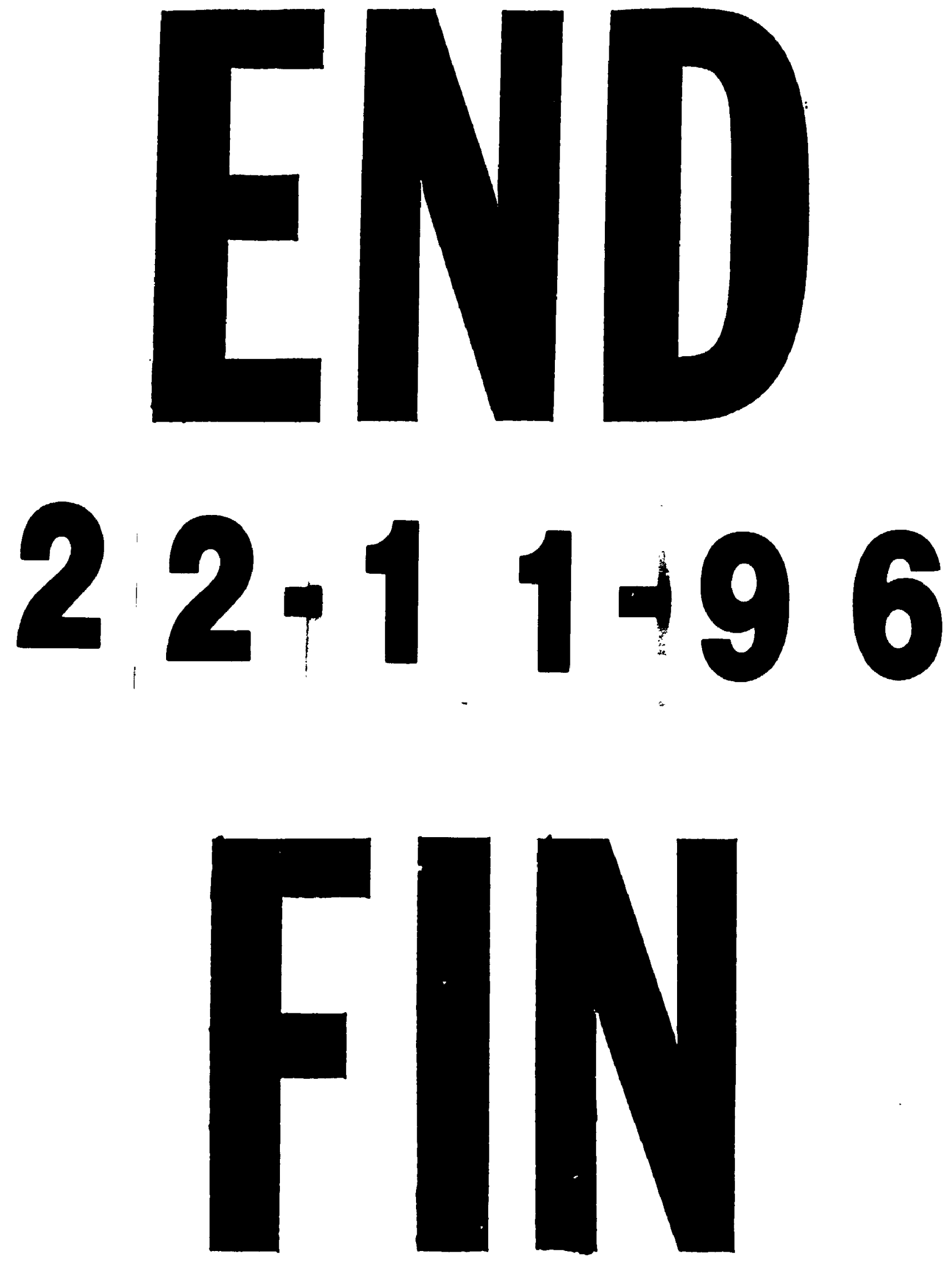